Arbeitspar

\title{
Franziska Smolnik
}

Zwischen Anspruch und Wirklichkeit:

Die EU-Konditionalität als

Demokratisierungsinstrument

Eine Studie zur externen Demokratieförderung an den Beispielen Georgien und Mazedonien

/2008 
Franziska Smolnik

Zwischen Anspruch und Wirklichkeit:

Die EU-Konditionalität als

Demokratisierungsinstrument

Eine Studie zur externen

Demokratieförderung

an den Beispielen Georgien und Mazedonien 


\section{ARBEITSPAPIERE DES OSTEUROPA-INSTITUTS DER FREIEN UNIVERSITÄT BERLIN}

\section{ARBEITSSCHWERPUNKT POLITIK}

Das Osteuropa-Institut der Freien Universität beschäftigt sich als multidisziplinäres regionalwissenschaftliches Zentralinstitut in Forschung und Lehre mit den Räumen Ost-, Ostmittelund Südosteuropas.

Mit der Reihe „Arbeitspapiere des Osteuropa-Instituts“ stellt der Arbeitsschwerpunkt Politik aktuelle Ergebnisse aus seiner Arbeit der Öffentlichkeit zur Verfügung.

Die Arbeitspapiere erscheinen in unregelmäßiger Folge. Einzelne Papiere können gegen eine Schutzgebühr bezogen werden bei:

Osteuropa-Institut der Freien Universität Berlin

Garystr. 55

14195 Berlin

http://www.oei.fu-berlin.de/

$$
\begin{array}{r}
\text { Tel.: ++493083854058 } \\
52075 \\
\text { Fax:++49 } 3083853616
\end{array}
$$


Arbeitspapiere des Osteuropa-Instituts

der Freien Universität Berlin

Arbeitsschwerpunkt Politik

Franziska Smolnik

\section{Zwischen Anspruch und Wirklich- \\ keit: Die EU-Konditionalität als \\ Demokratisierungsinstrument}

Eine Studie zur externen Demo-

kratieförderung an den Beispielen

Georgien und Mazedonien 
(C) 2008 by Franziska Smolnik

Osteuropa-Institut der Freien Universität Berlin Arbeitsbereich Politik und Gesellschaft

Herausgeber: Klaus Segbers

Redaktion: Julia Gerlach

ISSN $1434-419 X$ 
1. EINLEITUNG .............................................................................

2. DIE EU UND DIE EXTERNE DEMOKRATIEFÖRDERUNG......... 15

2.1 Die Entwicklung und Positionierung Der EU ALS EIN AKTEur DER EXTERNEN DEMOKRATIEFÖRDERUNG

2.2 HERANFÜHRUNGS- UND DEMOKRATIEFÖRDERUNGSSTRATEGIEN DER EU

UND DAS INSTRUMENT DER POLITISCHEN KONDITIONALITÄT..... .17

3. STAND DER FORSCHUNG UND THEORETISCHER

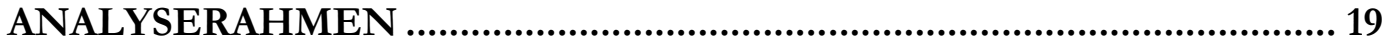

3.1 MÖGLICHE THEMATISCHE UND THEORETISCHE ANKNÜPFUNGSPUNKTE.....19

3.1.1 Transformations- und Demokratisierungsforschung ..............................................19

3.1.2 Compliance-Forschung und internationale Organisationen ...................................22

3.1.3 Forschungsfeld Europäische Integration..............................................................23

3.2 THEORETISCHER ANALYSERAHMEN ………….................................................26

4. INTERNATIONALE SOZIALISATION UND DER EINFLUSS DER

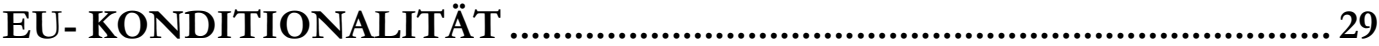

4.1 GRAD DER RECHTSSTAATLICHKEIT - DIE ABHÄNGIGE VARIABLE ...................29

4.2 DIE GRÖßE DES ANREIZES DER EU-KONDITIONALITÄT-_DIE

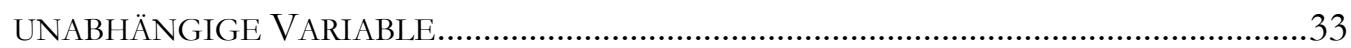

4.3 ADAPTIONSKOSTEN - BEDINGUNGSVARIABLE A ………........................................34

4.4 ASYMMETRISCHE INTERDEPENDENZ - BEDINGUNGSVARIABLE B ...................37

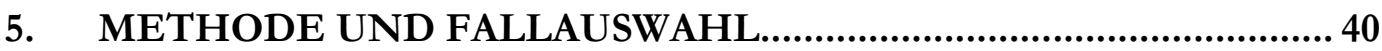

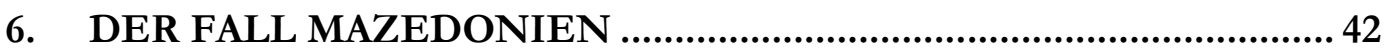

6.1 MAZEDONIEN UND DIE REFORMANREIZE DER EU ….......................................42

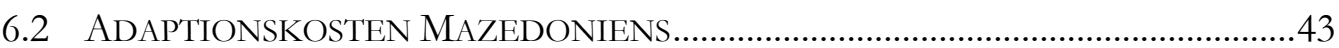

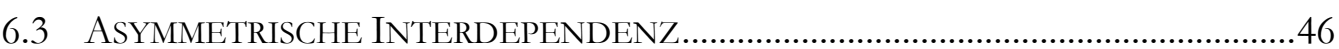

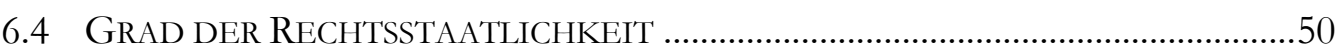

6.5 MAZEDONIEN - INTERAKTION DER VARIABLEN ……...........................................53

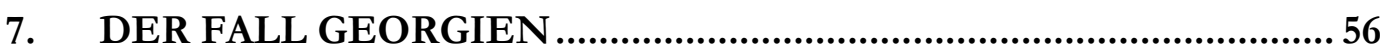

7.1 GEORGIEN UND DIE REFORMANREIZE DER EU ...................................................56

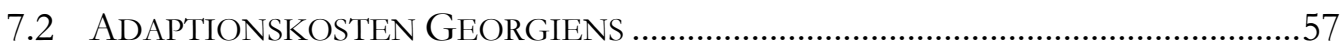

7.3 ASYMMETRISCHE INTERDEPENDENZ .................................................................6

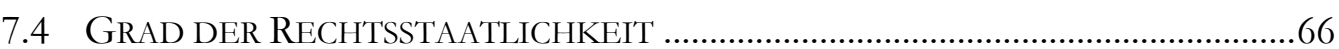

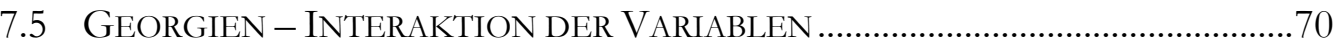


8. MAZEDONIEN UND GEORGIEN: EINE

GEGENÜBERSTELLUNG

74

8.1 DiE GRÖßE DES EU-ANREIZES ALS URSACHE FÜR DEN UNTERSCHIEDLICH

STARKEN EINFLUSS DER EU-KONDITIONALITÄT.

.75

8.2 DiE BEDINGUNGSVARIABLEN ALS EINFLUSSFAKTOREN AUF DIE

UNABHÄNGIGE VARIABLE .77

9. FAZIT: RÜCKBEZUG ZUR THEORIE UND AUSBLICK .................8 80

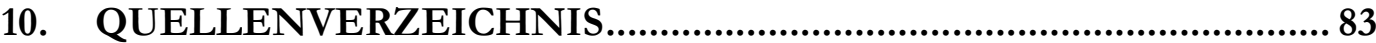

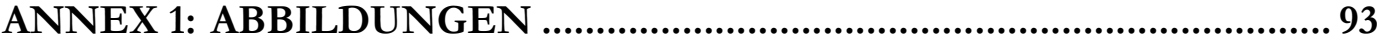




\section{Abkürzungsverzeichnis}

AV

BDI

BIP

BTI

ENP

EU

GTEP

IWF

KFOR

KKS

MCA

NATO

OJ

OME

PKA

RJC

SAA

SEK

Tab.

UV
Abhängige Variable

Democratic Union of Integration

Bruttoinlandsprodukt

Bertelsmann Transformation Index

Europäische Nachbarschaftspolitik

Europäische Union

Georgian Train and Equip Program

Internationaler Währungsfond

Kosovo Force

Kaufkraftstandards

Millenium Challenge Account

North Atlantic Treaty Organization

Oberster Justizrat

Ostmitteleuropäische Länder

Partnerschafts- und Kooperationsabkommen

Republican Judicial Council

Stabilisierungs- und Assoziierungsabkommen

Schimmelfennig, Engert und Knobel

Tabelle

Unabhängige Variable 


\section{Abbildungsverzeichnis}

Tab. 1: BIP-Vergleich: Mazedonien und die EU-15 bzw. EU-27

Tab. 2: Arbeitslosigkeitsstatistik: Mazedonien und die EU-15 bzw. EU-27

Tab. 3: Jährliche Militärausgaben Mazedoniens

Tab. 4: Außenhandel der EU bzw. der USA mit Mazedonien

Tab. 5: Grad der Rechtsstaatlichkeit für Mazedonien

Tab. 6: BIP-Vergleich: Georgien und die EU-15 bzw. EU-27

Tab. 7: Arbeitslosigkeitsstatistik: Georgien und die EU-15 bzw. EU-27

Tab. 8: Jährliche Militärausgaben Georgiens

Tab. 9: Außenhandel der EU, der USA bzw. Russlands mit Georgien

Tab.10: Öffentliche Entwicklungshilfe (Official Development Assistance, $O D A$ )an Georgien

Tab. 11: Grad der Rechtsstaatlichkeit für Georgien 
Franziska Smolnik: Zwischen Anspruch und Wirklichkeit: Die EU-Konditionalität als

Demokratisierungsinstrument. Eine Studie zur externen Demokratieförderung an den Beispielen

Georgien und Mazedonien

1.

Einleitung

Die externe Demokratisierungshilfe hat sich besonders seit den 1990er Jahren zu einer wahren „Wachstumsindustrie“ entwickelt. Während zur Zeit des Kalten Krieges weniger die liberal-demokratische Ausrichtung eines Staates zählte als seine Loyalität zum Anti-Kommunismus, versuchen heute nicht nur internationale Organisationen und einzelne Staaten, sondern auch private Stiftungen und andere Nichtregierungsorganisationen mit verschiedensten Programmen demokratische Entwicklungen in Drittländern zu fördern bzw. solche Entwicklungen zu initiieren. Sehr aktiv sind die Förderer der Demokratie in den ehemals sozialistischen Ländern. Nach dem Ende des Sozialismus sind dort neben US-amerikanischen Akteuren vor allem auch europäische Förderer im Dienst der Demokratisierung tätig.

Von direkten Formen der Einflussnahme auf die Transformationen dieser Länder durch beispielsweise finanzielle und technische Hilfe sowie durch Transfer von Know-How sind dabei indirekte Arten der Einflussnahme wie die Diffusion westlich-demokratischer Werte (contagion $\left.{ }^{1}\right)$ zu unterscheiden.

Die Einschätzungen über den Erfolg der Versuche, Demokratie von außen zu fördern, sind dabei genauso vielfältig wie die Zahl der Akteure und die Möglichkeiten der Einflussnahme. Während bei der indirekten Einflussnahme im Sinne von Wertediffusion eine messbare Überprüfung generell sehr schwierig ist, sind auch die Bewertungen der direkten Demokratieförderung äußerst heterogen. So werfen Kritiker den Akteuren der externen Demokratieförderung vor, es läge ihnen lediglich an der Aufoktroyierung eigener Demokratiekonzepte bzw. der Nutzung des Begriffs der Demokratieförderung als Deckmantel zur Durchsetzung egoistischer, nationaler Interessen und sie wirkten damit eher kontraproduktiv auf die Demokratisierung $e^{2}{ }^{2}$, andere wiederum sehen den positiven Einfluss externer Demokratisierungshilfe zu Unrecht unterschätzt. Besonders die Europäische Union (EU) wird oft als ein wichtiger Akteur der Demokratieförderung genannt und steht in der Literatur in der

\footnotetext{
1 Whitehead 1999: 5ff.

2 Schwanitz 1997: 26.

Die Diskrepanz zwischen Kritikern, die jegliche Form externer Demokratieförderung aufgrund der genannten und weiterer - zum Teil durchaus berechtigter - Einwände ablehnen und solchen, die die verschiedenen Formen der Demokratieförderung zwar differenziert bewerten, ihr aber nicht generell entgegenstehen, lässt sich wohl kaum überbrücken. Eine normative bzw. ethische Bewertung der Praxis der Demokratieförderung ist explizit nicht Ziel dieser Arbeit.
} 
Franziska Smolnik: Zwischen Anspruch und Wirklichkeit: Die EU-Konditionalität als Demokratisierungsinstrument. Eine Studie zur externen Demokratieförderung an den Beispielen Georgien und Mazedonien

„Hierarchie“ der Demokratisierungsförderer als besonders effektiv ganz oben ${ }^{3}$. Im Gegensatz zu Programmen mit rein technischer Hilfe, denen nur eine oberflächliche Wirkung zugesprochen wird ${ }^{4}$, würdigt man vor allem die politische Konditionalität der EU als ein vergleichsweise wirksames Demokratisierungsinstrument, welches durch starke Anreize nachhaltig Einfluss auf die demokratische Entwicklung von Staaten nehmen kann. Ob allerdings das Instrument der politischen Konditionalität der EU tatsächlich den mit ihm verknüpften Erwartungen gerecht werden kann, soll hier überprüft werden.

\section{Analysefeld und Erkenntnisinteresse}

Politische Konditionalität, speziell im Bereich der Demokratieförderung, bedeutet zunächst einmal, dass ein Staat oder eine internationale Organisation die Vergabe von Leistungen an bestimmte Bedingungen knüpft. Allgemein kann Konditionalität sowohl darin bestehen, die erwarteten Leistungen bei Nicht-Erfüllung der Bedingungen einzubehalten, als auch die Einhaltung der Bedingungen mit Hilfe von Sanktionen durchzusetzen. Die Bedingungen können sich dabei auf verschiedene Bereiche beziehen. Neben der allgemeinen Einhaltung demokratischer Prinzipien stellt speziell der Bereich der Rechtsstaatlichkeit einen Schwerpunkt dar, der, wie später noch näher dargestellt wird, Analysegegenstand der Arbeit ist.

Das Konzept der politischen Konditionalität wird nicht nur von der EU genutzt ${ }^{5}$, allerdings sieht man die EU aufgrund ihrer internationalen Reputation in der Lage, das Instrument der politischen Konditionalität besonders wirkungsvoll einsetzen zu können. Vor allem die Demokratisierungsprozesse der 2004 bzw. 2007 in die EU aufgenommenen ostmitteleuropäischen Länder $\left(\mathrm{OME}^{6}\right)$ sowie Bulgariens und Rumäniens werden zur Verdeutlichung der Effektivität der EU-Konditionalität herangezogen. Dabei wird oft übersehen, dass auch die Anwendung des Instruments

\footnotetext{
${ }^{3}$ Siehe hierzu auch Börzel/Risse 2004: 9; Cooley 2003: 26; Pravda 2001: 14f.; Vachudova 2001: 5.

${ }^{4}$ Cooley 2003: $28 f$.

${ }^{5}$ Bekannt wurde das Instrument der politischen Konditionalität vor allem auch durch seine Nutzung durch internationale Finanzinstitutionen (insbesondere der Weltbank und des IWF).

${ }^{6}$ Zwecks begrifflicher Transparenz werden die nachstehenden Begriffe folgendermaßen verwendet: mit ostmitteleuropäische Länder sind die sieben neuen postsozialistischen EU-Mitglieder gemeint; Südosteuropa umfasst die neuen EU-Mitglieder Slowenien, Rumänien und Bulgarien sowie die Länder des westlichen Balkans (Albanien und die Nachfolgestaaten Jugoslawiens); der Begriff Südkaukasus fasst Armenien, Aserbaidschan und Georgien zusammen, wohingegen unter dem Begriff Osteuropa Russland, die Ukraine, Belarus und Moldova subsumiert werden. Die zentralasiatischen Länder umfassen hier Kirgisien, Tadschikistan, Kasachstan, Usbekistan und Turkmenistan.
} 
Franziska Smolnik: Zwischen Anspruch und Wirklichkeit: Die EU-Konditionalität als Demokratisierungsinstrument. Eine Studie zur externen Demokratieförderung an den Beispielen Georgien und Mazedonien

der politischen Konditionalität durch die EU nicht überall gleichermaßen erfolgreich ist.

Die EU wendet politische Konditionalität nicht nur im Rahmen der Erweiterungsprozesse an, sondern diese ist vielmehr ein wichtiges Element in der Mehrzahl der EU-Vereinbarungen mit Drittländern, um Demokratie, den Schutz der Menschenrechte und eben Rechtsstaatlichkeit zu fördern. Demgemäß findet man politische Konditionalität insbesondere auch in den Partnerschafts- und Kooperationsabkommen zwischen der EU und den osteuropäischen, südkaukasischen und zentralasiatischen Staaten sowie in der Europäischen Nachbarschaftspolitik, die sich unter anderem an die osteuropäischen und südkaukasischen Staaten richtet, verankert. In diesen Ländern scheint der Einfluss der EU-Konditionalität allerdings weit entfernt von dem in den OME zu sein. So wurden im Freedombouse-Ranking Nations in Transit von $2007^{7}$ neun von zwölf der osteuropäischen, südkaukasischen und zentralasiatischen Staaten den Kategorien Semi-Consolidated-Authoritarian Regimes bzw. Consolidated Authoritarian Regimes zugeordnet. Auch innerhalb der ostmitteleuropäischen Staaten, die nun vollwertige Mitglieder der EU sind, gibt es allerdings Unterschiede bezüglich des Einflusses der EU-Konditionalität ${ }^{8}$; ebenso scheint es angesichts der wechselhaften Entwicklungen in den seit 2000 als potentielle Beitrittskandidaten feststehenden Ländern des westlichen Balkans fraglich, ob das EU-Instrument der politischen Konditionalität die gewünschte Wirkung auch erreichen kann. Die empirischen Befunde zeigen, dass der angenommene Einfluss des Instruments der Konditionalität überprüft und die oft attestierte Attraktivität der in Aussicht gestellten Anreize hinterfragt werden muss. Eine genauere Betrachtung der Wirkungsweise von politischer Konditionalität ist notwendig, um herauszufinden, welche Faktoren die Wirkkraft der EUKonditionalität tatsächlich beeinflussen. Die Arbeit leistet damit einen wichtigen

\footnotetext{
${ }^{7}$ Freedomhouse Nations in Transit 2007.

${ }^{8}$ Vgl. hierzu den Bertelsmann Transformation Index (BTI) und das Freedombouse-Ranking der Studie Nations in Transit. So verwundert es, dass Rumänien, welches 2000 Beitrittsgespräche mit der EU aufnahm beim Demokratie-Indikator von Freedomhouse für das Jahr 2006 in der Kategorie Semi-Consolidated Democracies aufgeführt ist, wohingegen die anderen neuen EU-Mitgliedstaaten in der Kategorie Consolidated Democracies gelistet sind. Kroatien, das erst seit 2004 als Beitrittskandidat der EU feststeht, wird beim BTI dagegen sowohl in den Rankings von 2003 als auch 2006 deutlich besser als Rumänien bewertet.
} 
Franziska Smolnik: Zwischen Anspruch und Wirklichkeit: Die EU-Konditionalität als

Demokratisierungsinstrument. Eine Studie zur externen Demokratieförderung an den Beispielen

Georgien und Mazedonien

Beitrag zur Forschung, da bislang nur wenige Theorie geleitete Arbeiten in diesem Bereich erstellt wurden.

\section{Fragestellung}

Um einen Beitrag zur oben angeführten Debatte zu leisten, lautet die Fragestellung der vorliegenden Arbeit:

Warum ist der Einfluss der EU-Konditionalität auf die Demokratisierung in den postsozialistischen Staaten unterschiedlich stark?

Während die genannte Fragestellung auf einen der Arbeit übergeordneten Problemzusammenhang verweist, nämlich die Wechselwirkung zwischen EUKonditionalität und der von der EU geforderten Etablierung und Einhaltung demokratischer Prinzipien und Verfahren, soll dieser Zusammenhang hier konkret am Beispiel der Rechtstaatlichkeit - als einer wichtigen Dimension von Demokratie und eines der Grundprinzipien der EU - überprüft werden. Die Fragestellung wird damit präzisiert als: W arum ist der Einfluss der EU-Konditionalität auf die Entwicklung der Rechtsstaatlichkeit in den post-sozialistischen Staaten unterschiedlich stark? Die abhängige Variable (AV) der Arbeit bildet dementsprechend der Grad an Rechtsstaatlichkeit ${ }^{9}$.

\section{Theorie}

Was die theoretischen Anknüpfungspunkte für die genannte Fragestellung betreffen, so bietet sich vor allem das Forschungsfeld der Europäischen Integration an, welches Forschungen zur EU-Erweiterung und Europäisierung (Europeanization) umfasst sowie das Forschungsfeld zu Compliance und internationalen Organisationen. Wie zu zeigen sein wird, gibt es bislang keine separate Theorie der externen Demokratisierung, die zur Beantwortung der Fragestellung zu Hilfe genommen werden könnte. Im Gegenteil sind Erkenntnisse im Bereich der Demokratisierungsforschung durch die Länder der dritten Demokratisierungswelle zum Teil wieder in Frage gestellt worden ${ }^{10}$.

Dagegen bietet der Bereich der Europäischen Integration, aber auch die ComplianceForschung aufschlussreiche Ansätze. Wie erläutert werden wird, spalten sich diese in einerseits konstruktivistische, andererseits rationalistische Ansätze auf. Es zeigt sich,

\footnotetext{
${ }^{9}$ Warum sich eine solche Vorgehensweise anbietet, wird in Kapitel 4.1 eingehender erläutert.

${ }^{10}$ Siehe hierzu Bunce 2006. Näheres auch in Kapitel 3.1.1.
} 
Franziska Smolnik: Zwischen Anspruch und Wirklichkeit: Die EU-Konditionalität als Demokratisierungsinstrument. Eine Studie zur externen Demokratieförderung an den Beispielen Georgien und Mazedonien

dass insbesondere in Hinblick auf die Handlungslogik der Adressaten der EUKonditionalität die dem rationalistischen Institutionalismus zugeordneten Theorieansätze passender sind. Im Rahmen der Arbeit wird daher auf die Theorie der internationalen Sozialisation ${ }^{11}$ zurückgegriffen. Diese kombiniert rationalistische und konstruktivistische Elemente. Während sie einerseits im Sinne des Konstruktivismus die Bedeutung internationaler Gemeinschaften und Organisationen betont, geht sie andererseits von rationalistischen Annahmen bezüglich der Handlungslogik aus und erweist sich somit als Erklärungsansatz für den unterschiedlich starken Einfluss der EU-Konditionalität als besonders vielversprechend. Angenommen werden rationale, Nutzen maximierende Akteure, die ihr Verhalten von Kosten-Nutzen-Rechnungen abhängig machen. Ob die Regeln der EU übernommen werden, ob also rechtsstaatliche Prinzipien und Verfahren etabliert und eingehalten werden, hängt dann davon ab, ob durch eine solche Anpassung ein Nutzen generiert werden kann, der die Kosten eben dieser Anpassung übersteigt.

\section{Hypothese(n), Variable(n) und Methode}

Überträgt man die theoretischen Überlegungen auf die der Arbeit zugrunde liegende Forschungsfrage, so lässt sich vermuten, dass der Einfluss der EU-Konditionalität deshalb so unterschiedlich stark ist, weil der erwartete Nutzen für die Zielländer ebenso unterschiedlich groß ist bzw. unterschiedlich bewertet wird.

Da als der wirkmächtigste, von der EU zu vergebene Anreiz die Beitrittsperspektive gilt, lautet die in der Arbeit zu überprüfende zentrale Hypothese:

Bietet die EU einem Drittland im Rahmen derpolitischen Konditionalität eine Beitrittsperspektive, so ist es wahrscheinlich, dass das Drittland die Regeln der EU übernimmt.

Abgeleitet aus der Theorie der internationalen Sozialisation wird in der empirischen Analyse die Größe des von der EU in Aussicht gestellten Anreizes als unabhängige Variable (UV) betrachtet. Wie in der folgenden, ausführlichen Auseinandersetzung mit den bisherigen Forschungsergebnissen deutlich werden wird, sollen hier allerdings noch zwei weitere Faktoren betrachtet werden, von denen angenommen wird, dass sie die Wirkung der UV vergrößern bzw. verringern und eventuell für die

${ }^{11}$ Schimmelpfennig/Engert/Knobel 2006. 
Franziska Smolnik: Zwischen Anspruch und Wirklichkeit: Die EU-Konditionalität als Demokratisierungsinstrument. Eine Studie zur externen Demokratieförderung an den Beispielen Georgien und Mazedonien

unterschiedlichen Ergebnisse der EU-Konditionalität mit verantwortlich zeichnen. Als Bedingungsvariablen (condition variables) werden der Grad der asymmetrischen Interdependen ₹- die ungleiche Abhängigkeit zwischen EU und Drittstaat - sowie die Adaptionskosten - verstanden als Machtverlust der Regierungspartei(en) betrachtet ${ }^{12}$. Die entsprechenden Hypothesen lauten, dass es zum einen wabrscheinlich ist, dass der Einfluss der UV positiv verstärkt wird, wenn diese neuen Regeln keinen bzw. nur einen geringen Machtverlust für die regierende(n) Partei(en) zur Folge haben und zum anderen, dass es wahrscheinlich ist, dass der Einfluss der UV geringer ist, wenn die asymmetrische Interdependenz zwischen sozialisierendem Akteur und Drittstaat ebenfalls gering ist. Im Sinne der zugrunde liegenden Theorie können die beiden hier zu betrachtenden Bedingungsvariablen die Kosten-Nutzen-Rechnung manipulieren. Zur empirischen Überprüfung der Hypothese(n) werden als Fallbeispiele Georgien und Mazedonien herangezogen. Wie gezeigt werden kann, eignen sich diese beiden Länder gemäß der Methode des most-similar-systems-design besonders gut für die Analyse.

\section{Struktur und Vorgehensweise}

Die Arbeit besteht aus einem konzeptionellen bzw. theoretischen Teil und einem empirischen Teil. Im ersten Teil der Arbeit wird zunächst die EU als Akteur der externen Demokratieförderung und das von ihr genutzte Instrument der politischen Konditionalität dargestellt (Kapitel 2), anschließend werden der Forschungsstand und der gewählte theoretische Analyserahmen erläutert (Kapitel 3). Nachdem die aus der Theorie gewonnenen, bereits kurz vorgestellten Variablen näher erklärt und operationalisiert werden (Kapitel 4), schließt die Darlegung der gewählten Methode sowie die Begründung der Fallauswahl (Kapitel 5) den ersten Teil der Arbeit ab. In Kapitel 6 und Kapitel 7 folgen im empirischen Teil die Analyseergebnisse für die betrachteten Fälle Mazedonien und Georgien. Neben der Darstellung der Ergebnisse für die gewählten Variablen wird jeweils in einem zusätzlichen Abschnitt die Interaktion der Variablen grob nachgezeichnet. In einem weiteren Kapitel werden die Ergebnisse für beide Fälle gegenübergestellt und bewertet. Die Arbeit endet mit einem Rückbezug auf die verwendete Theorie und einem Ausblick sowohl bezüglich

${ }^{12}$ Für eine detaillierte Darstellung der Variablen und Hypothesen siehe Kapitel 4. 
Franziska Smolnik: Zwischen Anspruch und Wirklichkeit: Die EU-Konditionalität als

Demokratisierungsinstrument. Eine Studie zur externen Demokratieförderung an den Beispielen

Georgien und Mazedonien

der Praxis der EU-Demokratieförderung als auch bezüglich weiterer Forschungen, die die Wirkungsweise der EU-Konditionalität weiter erhellen können.

\section{Die EU und die externe Demokratieförderung}

\subsection{Die Entwicklung und Positionierung der EU als ein Akteur der externen Demokratieförderung ${ }^{13}$}

Während bereits im Vertrag zur Gründung der Europäischen Wirtschaftsgemeinschaft ${ }^{14}$ von 1957 die Wahrung von Frieden und Freiheit als Ziel in der Präambel festgelegt ist, so setzte nicht nur der Ost-West-Konflikt, sondern auch das damalige Selbstverständnis der Gemeinschaft als vorrangig auf die wirtschaftliche Dimension gerichteter Zusammenschluss einer entsprechenden aktiven Politik enge Grenzen. Auch die konkretere Benennung der eigenen Werte und Identität erfolgte erst rund 15 Jahre später in der Deklaration zur Europäischen Identität ${ }^{15}$ der EG-Außenminister vom 14.12.1973. Als zu verteidigende Prinzipien geben die Außenminister die repräsentative Demokratie, Rechtsstaatlichkeit und soziale Gerechtigkeit sowie den Schutz der Menschenrechte an. Die Deklaration spielt eine wichtige Vorreiterrolle, wurde doch in der 1986 verabschiedeten Einheitlichen Europäischen Akte erstmals in der Präambel eines EU-Vertrages der Wille benannt, für die genannten Grundsätze Demokratie, Wahrung des Rechts und den Schutz der Menschenrechte einzutreten. Die Verabschiedung der Einheitlichen Europäischen Akte ist somit auf zweierlei Weise für die Entwicklung der EU zu einem eigenständigen Akteur der externen Demokratieförderung wichtig: Zum einen ist sie ein wichtiges Dokument in der Entwicklung der Europäischen Gemeinschaft zu einer politischen Union und Wertegemeinschaft, zum anderen ist sie ein wichtiger Schritt zur Etablierung einer institutionalisierten europäischen Außenpolitik ${ }^{17}$.

Obwohl auch schon 1973 eine weitere Integration der Außenpolitik der Mitgliedsländer angestrebt wurde, konnte dieses Ziel letztlich erst 1991 mit der

\footnotetext{
${ }^{13}$ In Abhängigkeit mit dem Forschungsgegenstand der Arbeit wird auf eine nähere Darstellung der EU-Demokratieförderung im Bereich der Entwicklungspolitik verzichtet.

14 Vertrag zur Gründung der Europäischen Wirtschaftsgemeinschaft 1957: 165.

${ }^{15}$ Europäische Gemeinschaften 1988: 49.

${ }^{16}$ Single European Act 1987: 2.

${ }_{17}$ Die Einheitliche Europäische Akte legte die Grundlage für die Europäische Politische

Zusammenarbeit, die spätere Gemeinsame Außen- und Sicherheitspolitik.
} 
Franziska Smolnik: Zwischen Anspruch und Wirklichkeit: Die EU-Konditionalität als Demokratisierungsinstrument. Eine Studie zur externen Demokratieförderung an den Beispielen Georgien und Mazedonien

Etablierung der Gemeinsamen Außen- und Sicherheitspolitik (Vertrag von Maastricht) realisiert werden. Durch den Zusammenbruch der Sowjetunion und das Ende des Sozialismus eröffneten sich der EU neue Handlungsmöglichkeiten, aber auch Herausforderungen. Der weltpolitische Wandel beschleunigte die Integration der Außenpolitik der Mitgliedsstaaten maßgeblich ${ }^{18}$. Das Jahr 1991 steht nicht nur für einen neuen Abschnitt in der europäischen Außenpolitik der nun Europäischen Union, sondern außerdem für den Beginn der aktiven EU-Demokratieförderung. So heißt es in Artikel J.1 (2) des Vertrags von Maastricht.

„Die Gemeinsame Außen- und Sicherbeitspolitik hat zum Ziel [...] die Entwicklung und Stärkung von Demokratie und Rechtsstaatlichkeit sowie die Achtung der Menschenrechte und Grundfreiheiten"."19

Die EU, die sich im Vertrag von Maastricht außerdem explizit als Wertegemeinschaft darstellt, verpflichtet sich damit, die bereits 1986 genannten Grundsätze nicht nur innerhalb der Union zu wahren, sondern auch mittels ihrer Außenpolitik in Drittländern zu fördern.

Die nun vertraglich festgeschriebene Direktive, nämlich die aktive Förderung von Demokratie und Rechtsstaatlichkeit, hat konkrete Auswirkungen. So ist seit 1995 eine Demokratie-Klause ${ }^{20}$ fester Bestandteil aller EU-Abkommen mit Drittstaaten. Mit dem Vertrag von Nizza, der 2000 verabschiedet wurde, wird die Rolle der EU als externer Demokratieförderer weiter gestärkt. In Artikel 181a wurde festgelegt: „Die Politik der Gemeinschaft in diesem Bereich [Anm.: der wirtschaftlichen, finanziellen und technischen
Zusammenarbeit] trägt dazu bei, das allgemeine Ziel der Fortentwicklung und Festigung der Demokratie
und des Rechtsstaats sowie das Ziel der Wabrung der Menschenrechte und Grundfreibeiten qu verfolgen".

Da mit diesem Artikel die Förderung von Demokratie und Rechtsstaatlichkeit übergreifend auch in der wirtschaftlichen, finanziellen und technischen Kooperation mit Drittstaaten verfolgt werden soll, spricht man hier auch von einem Prozess des Democracy Mainstreaming ${ }^{22}$.

Hat sich die EU, wie durch die vertraglichen Festschreibungen skizziert, als ein gewichtiger Akteur der Demokratieförderung aufgestellt, so ist diese Politik dennoch

\footnotetext{
${ }^{18}$ Knodt/Jünemann 2007: 13.

${ }^{19}$ Vertrag über die Europäische Union (Vertrag von Maastricht) 1992, Artikel J.1 (2).

${ }^{20}$ Die Klausel schreibt demokratische Grundsätze und den Schutz der Menschenrechte als ein essentielles Element der Abkommen fest. Sie erlaubt den Parteien im Falle schwerer Verstöße gegen diese Grundsätze restriktive Maßnahmen zu ergreifen (Europäische Kommission 1995).

21 Vertrag von Nizza 2001: 20.

22 Knodt/Jünemann 2007: 15.
} 
Franziska Smolnik: Zwischen Anspruch und Wirklichkeit: Die EU-Konditionalität als Demokratisierungsinstrument. Eine Studie zur externen Demokratieförderung an den Beispielen Georgien und Mazedonien

nicht frei von $\mathrm{Kritik}^{23}$. Jünemann und Knodt nennen die Strategie der EU dementsprechend eine Politik der double standards ${ }^{24}$, da sie nur unvollständig angewendet wird. Halm ${ }^{25}$ führt diese abweichenden Anwendungen der Instrumente und Richtlinien auf Fremdinteressen der EU in Bezug auf bestimmte Länder zurück. So würde die EU bei Ländern, mit denen sie enge wirtschaftliche oder politische Beziehungen unterhält, den Grundsatz der Förderung von Demokratie und Rechtsstaatlichkeit weniger streng befolgen. Die festgeschriebene Kohärenz der verschiedenen Politikbereiche würde hier umgangen. Ebenso wie der USamerikanischen Demokratieförderung wird also auch der EU vorgeworfen, dass sie lediglich die Durchsetzung nationaler Interessen unter einem anderen Etikett betreibe $^{26}$.

\subsection{Heranführungs- und Demokratieförderungsstrategien der EU und das Instrument der politischen Konditionalität}

Wie dargelegt, hat sich die EU auch offiziell immer deutlicher als ein Akteur der Demokratieförderung positioniert und schließlich die Förderung von Demokratie und Rechtsstaatlichkeit in den Beziehungen mit Drittstaaten in den EU-Verträgen fixiert. Die politische Konditionalität ist hier das wohl bedeutendste Instrument, um Demokratie und Rechtsstaatlichkeit in Drittländern zu fördern und letztlich zu verankern. Politische Konditionalität wird vor allem auch in Bezug auf die östlichen Nachbarländer der EU genutzt, um neben der Förderung der genannten Prinzipien auch eine Angleichung dieser Länder an den Besitzstand der Europäischen Union, den aquis communitaire, zu unterstützen. Auch wenn das Instrument der politischen Konditionalität besonders im Zusammenhang mit den Heranführungsprozessen der OME sowie Slowenien, Bulgarien und Rumänien, die 2004 bzw. 2007 EU-Mitglieder wurden, wahrgenommen wurde, so muss festgehalten werden, dass die EU seit Mitte der 1990er Jahre die hier angewandten Strategien und Instrumente auf die weiteren Außenbeziehungen, insbesondere aber auf die mit ihren Nachbarländern, ausgeweitet

\footnotetext{
${ }^{23}$ Wie schon an anderer Stelle erwähnt, wird die Arbeit auf diese Kontroverse nicht weiter eingehen. Vielmehr soll hier kurz angesprochen werden, welche spezielle Kritik es an der tatsächlichen Ausführung bzw. Nicht-Ausführung der Demokratieförderung der EU gibt.

${ }^{24}$ Knodt/Jünemann 2007: 19.

${ }^{25}$ Halm 1997: 169.

${ }^{26}$ Siehe hiezu auch 4.4 .
} 
Franziska Smolnik: Zwischen Anspruch und Wirklichkeit: Die EU-Konditionalität als

Demokratisierungsinstrument. Eine Studie zur externen Demokratieförderung an den Beispielen

Georgien und Mazedonien

hat. So stellen Börzel und Risse in ihrer Studie zur Strategie der EU-

Demokratieförderung fest:

"Thus, the strategies and policies to promote democracy are similar, and the mechanisms and incentives to
promote compliance vary only slightly with type of third country (accession, association, partner, ,circle of
friends', other third countries). In fact, the EU follows quite clearly a specific cultural script". ${ }^{27}$

Auch Morlino und Magen ${ }^{28}$ kommen zu einer solchen Einschätzung. Sie sehen die in Bezug auf Drittländer genutzten Strategien und Instrumente, darin inbegriffen die Nutzung politischer Konditionalität, als Variationen der OME-Erweiterungsstrategie, deren Unterschied in der Intensität zu suchen, aber nicht grundsätzlicher Natur ist.

Die Intensität sei abhängig davon, ob es sich um solche Strategien handelt, die letztlich zur Aufnahme in die EU führen sollen (enlargement-bound) und solchen, die zwar ähnliche Ziele verfolgen, allerdings ohne eine EU-Mitgliedschaft vorzusehen (enlargement-like). Die Ähnlichkeit der verschiedenen EU-Programme macht einen Vergleich der politischen Konditionalität möglich. Während vor allem Anfang der 1990er Jahre die Beitrittsprozesse der OME und der drei südosteuropäischen Länder einen Vergleich des Einflusses der politischen Konditionalität mit den anderen postsozialistischen Staaten nur bedingt zuließen, bietet sich ein Vergleich der unterschiedlich modulierten, in ihren Grundsätzen aber doch sehr ähnlichen Programme mittlerweile an.

\section{Positive politische Konditionalität (Reinforcement by reward)}

Wie im Einleitungskapitel erklärt, bedeutet Konditionalität, dass Leistungen an die Erfüllung bestimmter Bedingungen geknüpft sind. Die Umsetzung der Bedingungen können nun sowohl durch Sanktionen (negative Konditionalität) als auch durch positive Anreize herbeigeführt werden. Die EU bedient sich hauptsächlich einer Strategie der positiven Konditionalität (reinforcement by reward ${ }^{29}$ ). Hierbei wird die Umsetzung von EU-Auflagen belohnt, keine oder mangelnde Umsetzung allerdings wird nicht bestraft, sondern führt allein zur Einbehaltung der Belohnungen. Als zu erfüllende Bedingungen der EU gilt die Übernahme der Grundprinzipien Demokratie, Rechtsstaatlichkeit und Schutz der Menschenrechte wie auch der Gesetze des aquis communitaire. Die „Belohnungen“ können hier unterschiedliche

\footnotetext{
${ }^{27}$ Börzel/Risse 2004: 2.

${ }^{28}$ Morlino/Magen 2004: 4.

${ }^{29}$ Schimmelfennig/Engert/Knobel 2006: $31 \mathrm{f}$.
} 
Franziska Smolnik: Zwischen Anspruch und Wirklichkeit: Die EU-Konditionalität als Demokratisierungsinstrument. Eine Studie zur externen Demokratieförderung an den Beispielen Georgien und Mazedonien

Intensitätsstufen einnehmen. Während ganz oben die Mitgliedschaft steht, sind auch „Gegenleistungen“ in Form von politischer und wirtschaftlicher Zusammenarbeit oder finanzieller Hilfen vorgesehen ${ }^{30}$.

3. Stand der Forschung und theoretischer Analyserahmen

Im Folgenden soll der Stand der bisherigen Forschung dargestellt werden, um daran anknüpfend den theoretischen Rahmen der Arbeit vorzustellen.

\subsection{Mögliche thematische und theoretische Anknüpfungspunkte}

Potentielle Forschungsfelder, die ein theoretisches Fundament liefern könnten, sind neben dem Bereich der Demokratisierungs- und Transformationsforschung außerdem die Compliance-Forschung sowie die meist unter dem Überbegriff der Europäischen Integration zusammengefassten Forschungsfelder Europäisierung und EU Erweiterung. Diese werden im Folgenden vorgestellt.

\subsubsection{Transformations- und Demokratisierungsforschung}

Besonders durch das Ende des Ost-West-Konflikts traten Fragen der Systemtransformation und Demokratisierung erneut in den Vordergrund ${ }^{31}$. Aber obwohl die Transformationen der post-sozialistischen Länder eine wahre Flut an Literatur zu Systemtransformation und Demokratisierung nach sich zogen, gibt es kaum gesicherte Annahmen darüber, welche Faktoren und Voraussetzungen die Demokratisierung stützen und welche sie hemmen ${ }^{32}$. Im Gegenteil stellen die Transformationsverläufe der post-sozialistischen Länder die aus früheren Transformationen gewonnenen Erkenntnisse wieder in Frage. Früher angenommene

\footnotetext{
30 Positive Konditionalität wird besonders in der Zusammenarbeit mit potentiellen Beitrittskandidaten deutlich: Entspricht deren Verfasstheit nicht den von der EU festgelegten Kriterien, kommt es nicht zur Aufnahme von Beitrittsgesprächen; die EU versucht dagegen nicht, diese Länder per Zwangseinwirkung zur Erfüllung der Anforderungen zu bringen.

31 Zuvor gab es in diesem Bereich bereits Arbeiten zur Systemtransformation in Lateinamerika und in Südeuropa.

Transformation meint den „Übergang von einem nationalen politischen/ökonomischen System zu einem anderen System. In diesem neuen System werden grundlegend andere Kriterien zur Regelung politischer und ökonomischer Herrschaft institutionalisiert" (Varwick 1998: 369).

32 Kopecky und Mudde machen hierfür die nur geringe Anzahl an Theorie geleiteten Studien verantwortlich (Kopecky/Mudde 2000: 517).
} 
Franziska Smolnik: Zwischen Anspruch und Wirklichkeit: Die EU-Konditionalität als Demokratisierungsinstrument. Eine Studie zur externen Demokratieförderung an den Beispielen Georgien und Mazedonien

Einflussfaktoren wie eine demokratische Vergangenheit, hohe Einkommen bzw. eine große Mittelklasse sowie festgelegte Außengrenzen
„emerged as not very influential.[...] Little support can be found for earlier arguments that new democracies are unusually fragile and uncertain, that economic performance is critical to democratic survival or that democracy is harder to implement in diverse cultural contexts". ${ }^{33}$

Ähnliches gilt auch für die Rolle der nach dem Systemwechsel neu entstandenen staatlichen Institutionen.

Wenn Merkel in einer neueren Studie ${ }^{34}$ drei Faktoren anführt, von denen er im Gegensatz zu Bunce annimmt, dass diese erheblichen Einfluss auf die Demokratisierung haben, so handelt es sich zumindest nicht um überall gleichermaßen stichhaltige Erklärungen. Während Merkel den Faktor der Modernität (hier verweist er auf das Bildungs- und das sozioökonomische Niveau) vor allem im Vergleich der post-sozialistischen Staaten mit den Ländern Lateinamerikas für wichtig erachtet, sieht er den Faktor Staatlichkeit für den unterschiedlichen Demokratisierungsgrad innerhalb der post-sozialistischen Länder verantwortlich. Das zu Zeiten der Sowjetunion sozioökonomisch relativ entwickelte und nun autoritär regierte Belarus sowie das ehemals jugoslawische, jetzt EU-Mitgliedsland Slowenien sind aber nur zwei Beispiele dafür, dass auch Merkels Faktoren nicht ohne Einschränkungen zutreffen.

Der dritte von Merkel genannte Faktor dagegen - der Einfluss externer Akteure wurde lange in der Betrachtung gar nicht berücksichtigt bzw. ist bis heute ein zu wenig erforschtes, vor allem aber ein zu wenig theoretisch gefasstes Phänomen ${ }^{35}$. Während im Verlauf der 1990er Jahre internationalen Faktoren zwar eine zunehmend größere Rolle zugesprochen wurde, blieben systematische, Theorie generierende Studien aus ${ }^{36} . \mathrm{Zu}$ den frühesten Autoren, die versuchten den internationalen Einfluss auf Systemtransformationen zu analysieren und zumindest zu kategorisieren, gehört Laurence Whitehead ${ }^{37}$. Während er bereits Ende der 1980er Jahre auf internationale

\footnotetext{
${ }^{33}$ Bunce 2006: 606.

${ }^{34}$ Merkel 2007: 428ff.

35 Siehe hiezu auch Sandschneider 2003: 3ff.; Knodt/Jünemann 2007: 12ff.; Kopecky/ Mudde 2000: $525 \mathrm{ff}$.

${ }^{36}$ Schmitter sieht mögliche Gründe hierfür sowohl in der fest verankerten Kluft zwischen der Komparatistik und den Internationalen Beziehungen als auch im verengten Blick der Regionalwissenschaftler, welche die Generierung einer umfassenden Theorie der externen Demokratisierung verhindern (Schmitter 1999: 28f.).

37 Whitehead 1999.
} 
Franziska Smolnik: Zwischen Anspruch und Wirklichkeit: Die EU-Konditionalität als Demokratisierungsinstrument. Eine Studie zur externen Demokratieförderung an den Beispielen Georgien und Mazedonien

Faktoren bei der Demokratisierung von Staaten aufmerksam gemacht hat, unterscheidet er in dem 1999 von ihm herausgegebenen Sammelwerk drei verschiedene Arten der externen Einflussnahme auf Transformationsprozesse: Ansteckung (contagion), Kontrolle (control) und Konsens (consent) ${ }^{38}$. Diese dreiteilige Klassifikation von internationalen Faktoren wird von Philippe Schmitter noch um einen vierten ergänzt: die Konditionalität (conditionality) $)^{39}$. Obwohl sowohl Whitehead als auch Schmitter versuchen, den internationalen Einfluss auf Transformationsprozesse zu konzeptualisieren, gelingt auch ihnen die Entwicklung einer umfassenden Theorie der externen Demokratisierung nicht. Ähnliches gilt für die konzeptionellen Überlegungen Pridhams und Sandschneiders. Während Pridham ${ }^{40}$ versucht, den Einfluss internationaler Faktoren während der Transitionsphase in verschiedene Kategorien aufzuschlüsseln und dabei zu dem Ergebnis kommt, dass der Einfluss internationaler Faktoren immer abhängig vom innenpolitischen Kontext ist, versucht auch Sandschneider ${ }^{41}$ lediglich, das Feld der externen Demokratisierung zu strukturieren. Sandschneider selbst betont, dass er mit seiner Arbeit keine Theoriebildung anstrebe, sondern ein Raster erstellen will, das eine Einordnung der verschiedenen Prozesse im Bereich der externen

Demokratieförderung ermöglicht.

Obwohl also seit Mitte der 1990er Jahre Fragen der externen Demokratieförderung sehr wohl auch wissenschaftliche Aufmerksamkeit erfahren haben, gibt es bis heute lediglich rudimentäre Theorieansätze. Was die Demokratieförderung der Europäischen Union und das von ihr genutzte Instrument der politischen Konditionalität betrifft, so werden diese zwar im Rahmen der Klassifikationen und Kategorisierungen genannt, einen theoretischen Unterbau, der die Wirkungsweise der Konditionalität erklären und Hypothesen bezüglich ihrer Effektivität beinhalten würde, gibt es aber nicht.

\footnotetext{
38 Mit „Ansteckung“ meint Whitehead den positiven Einfluss eines bereits demokratischen Landes auf ein weniger demokratisches Land in Form eines Nachahmungseffekts. „Kontroll“ steht für die Aufzwingung eines demokratischen Systems auf einen Staat, der sich im Einflussbereich eines hegemonialen demokratischen Staates befindet. Die Kategorie „Konsens“ dagegen umfasst solche Arten des Einflusses, die auf die Bereitschaft von politischen Akteuren zielen, demokratische Regeln zu etablieren (Whitehead 1999: 5ff.).

${ }^{39}$ Die Kennzeichen von Konditionalität sieht Schmitter in der bewussten Nutzung von Zwang, indem die Gewährung von Leistungen und Unterstützung an bestimmte Bedingungen geknüpft werden (Schmitter 1999: 30).

40 Pridham 1997.

${ }^{41}$ Sandschneider 2003: 13.
} 
Franziska Smolnik: Zwischen Anspruch und Wirklichkeit: Die EU-Konditionalität als Demokratisierungsinstrument. Eine Studie zur externen Demokratieförderung an den Beispielen Georgien und Mazedonien

\subsubsection{Compliance-Forschung und internationale Organisationen}

Um mögliche theoretische Anknüpfungspunkte für den Forschungsgegenstand zu finden, bietet sich das Forschungsfeld der Compliance an, konkret die ComplianceForschung für den Bereich der internationalen Organisationen. Diese versucht zu erklären, wie internationale Regelsysteme auf das Verhalten von Akteuren einwirken. Allgemein wird Compliance als Normeinhaltung definiert, also als regelkonformes Verhalten. Im Zusammenhang mit internationalen Organisationen gilt dabei nicht nur, dass Staaten internationale Regeln in nationales Recht aufnehmen und widersprüchliche bestehende nationale Regeln ändern, sondern auch dass entsprechende Ressourcen für die tatsächliche Anwendung der Regeln zur Verfügung gestellt werden. Schließlich muss die Regeleinhaltung effektiv überwacht werden $^{42}$. Die Compliance-Forschung im Zusammenhang mit internationalen Organisationen findet vor allem auch in Bezug auf die Europäische Union Anwendung. Hier wird untersucht, wie es in den Mitgliedstaaten zu Compliance mit EU-Vorgaben kommt bzw. welche Probleme diesbezüglich auftreten können.

Die Compliance-Forschung geht davon aus, dass lediglich solche Regeln, die in einem gewissen Widerspruch zu den in einem Land bereits existierenden Regeln stehen, Probleme bei ihrer Einhaltung verursachen. Die Regelübernahme führt dann zu Anpassungskosten, da die Diskrepanz zwischen bestehenden und zu übernehmenden Regeln überwunden werden muss. Hier setzt die Compliance-Forschung an und untersucht, wann und warum es zur Einhaltung bzw. Anpassung an internationale Regeln und Normen kommt oder nicht. Die hierbei generierten Erklärungsansätze lassen sich in konstruktivistische, rationalistische sowie Management-Ansätze unterscheiden.

Konstruktivistische Ansätze sehen die Normeinhaltung als einen Prozess. Angenommen wird, dass es vor allem durch Bildung und Wissenstransfer bei den Adressaten zur Internalisierung der internationalen Regeln kommt und diese Internalisierung zu einer Präferenzänderung bei den Akteuren führt. Rationalistische Ansätze dagegen erklären die Normeinhaltung mit Hilfe von positiven und negativen Anreizen $^{43}$, die das Verhalten der Adressaten steuern. Angenommen werden Kosten-

\footnotetext{
${ }^{42}$ Börzel/ Risse 2001: $3 f$.

${ }^{43}$ Mögliche Anreize können sein: Prestige-, Reputationsgewinn, finanzielle/ materielle Hilfsleistungen, zwischenstaatliche Kooperation (z.B. im Bereich Sicherheit, Wirtschaft), Mitgliedschaft in
} 
Franziska Smolnik: Zwischen Anspruch und Wirklichkeit: Die EU-Konditionalität als Demokratisierungsinstrument. Eine Studie zur externen Demokratieförderung an den Beispielen Georgien und Mazedonien

Nutzen-Kalkulationen der Akteure - zu Compliance kommt es dann, wenn der erwartete Nutzen die erwarteten Kosten übersteigt. Die Kosten-Nutzen-Rechnung kann durch das Gewähren von Anreizen bzw. durch die Androhung von Sanktionen seitens der internationalen Organisation beeinflusst werden. Demgegenüber betonen Management-Ansätze die Wichtigkeit von Kapazitätsaufbau (capacity building). Diese Ansätze gehen davon aus, dass Staaten grundsätzlich bereit sind, internationale Regeln einzuhalten; wenn es dennoch nicht zur Regelbefolgung kommt, werden hierfür die fehlenden Handlungskapazitäten der betroffenen Staaten verantwortlich gemacht ${ }^{44}$.

Auch die EU möchte, dass die post-sozialistischen Staaten ihre Regeln - zumindest einen gewissen Teil - übernehmen. Obwohl diese Staaten keine Mitgliedsländer der EU sind, lassen sich Annahmen der Compliance-Forschung auf diesen Sachverhalt übertragen. Greift die Konditionalität der EU zwar teilweise auf Elemente zurück, die der konstruktivistischen Erklärungsvariante zugeschrieben werden, so ist zu beachten, dass es sich dennoch vorwiegend um ein Instrument handelt, welches mit Hilfe von Anreizen versucht, das Verhalten von Staaten zu beeinflussen. Es bieten sich daher besonders die rationalistischen Annahmen der Compliance-Forschung für die Analyse des Einflusses der EU-Konditionalität an ${ }^{45}$.

\subsubsection{Forschungsfeld Europäische Integration}

Auch das Feld der Europäischen Integration - mit der hierunter subsumierten Europäisierungsforschung und Forschung zur EU-Erweiterung - bietet sich an, einen theoretischen Rahmen für den hier zu behandelnden Forschungsgegenstand zu liefern

Die Forschung zur Europäisierung beschäftigt sich sowohl mit der Entwicklung spezifischer Institutionen auf EU-Ebene als auch mit dem Einfluss der EU auf die Politik der Mitgliedstaaten. Wie es auf der nationalstaatlichen Ebene der EUMitgliedstaaten zu Anpassungen an das Regelwerk der EU kommt, haben 
Franziska Smolnik: Zwischen Anspruch und Wirklichkeit: Die EU-Konditionalität als Demokratisierungsinstrument. Eine Studie zur externen Demokratieförderung an den Beispielen Georgien und Mazedonien

beispielsweise Börzel und Risse ${ }^{46}$ dargestellt. Sie betrachten dabei die bereits in Kapitel 3.1.2 genannten zwei Theoriepfade, den rationalistischen und den konstruktivistischen Institutionalismus ${ }^{47}$. Ähnliche Überlegungen finden sich auch bei Schimmelfennig und Sedelmeier ${ }^{48}$ wieder. Während aber Börzel und Risse in ihrer Studie untersuchen, wie es zu Anpassungen an EU-Regeln in den Mitgliedstaaten kommt, interessiert Schimmelfennig und Sedelmeier mehr der Anpassungsprozess innerhalb der Beitrittskandidatenländer. Dabei nehmen sie die EU-Konditionalität in ihre Betrachtung auf. Während sie zunächst von einem rationalen VerhandlungsModell ausgehen, in welchem gemäß einer Strategie der „Verstärkung durch Belohnung“ (reinforcement by reward) die Kosten-Nutzen-Kalkulation der Zielländer zugunsten der Nutzenseite modifiziert werden kann, haben sie dieses Modell später zum External incentives model erweitert. Auch dieses Modell geht von rationalistischen Grundannahmen aus wie sie auch für den rationalistischen Ansatz der ComplianceForschung gelten ${ }^{49}$. Die EU-Konditionalität wird hier gleichermaßen als ein Instrument angesehen, mit welchem die Kosten-Nutzen-Kalkulationen der Zielländer zugunsten der Nutzen-Seite geändert werden können und somit eine Anpassung an EU-Regeln die Folge ist. Dabei wird der Nutzen einer Regelübernahme mit den daraus entstehenden Kosten verrechnet ${ }^{50}$. Das Ergebnis der Studie deutet darauf hin, dass vor allem die Größe der Anreize, die Glaubwürdigkeit der Konditionalität ${ }^{51}$ sowie die Höhe der Adaptionskosten entscheidend sind. In ihrer 2005 publizierten Arbeit testen Schimmelfennig und Sedelmeier ${ }^{52}$ dieses rationale Modell, ähnlich wie auch Börzel und Risse, gegen einen im sozialen Konstruktivismus basierenden

\footnotetext{
${ }^{46}$ Börzel/Risse 2000.

${ }^{47}$ Diese beiden Theoriestränge werden im Folgenden näher dargestellt. In der Forschung zu Konditionalität spaltet sich die Debatte entlang dieser Theoriestränge.

${ }^{48}$ Schimmelfennig/Sedelmeier 2005.

${ }^{49}$ So bezieht sich das Modell auf strategische, Nutzen maximierende Akteure, die durch KostenNutzen-Kalkulationen ihr Verhalten bestimmen (Schimmelfennig/Sedelmeier 2005: 10ff.) ${ }^{50}$ Ebenso wie auch Börzel und Risse nutzen Schimmelfennig und Sedelmeier zur Operationalisierung der Kosten die Veto-Spieler-Theorie und sehen die Adaptionskosten in Abhängigkeit von der Anzahl der Veto-Spieler. Dies sind solche Akteure, deren Einwilligung nötig ist, um Veränderungen durchsetzen zu können. Gemäß der Veto-Spieler-Theorie ist die Regelübernahme umso unwahrscheinlicher, je mehr die Macht im politischen System verteilt ist, je mehr Akteure also im politischen System Einfluss besitzen und bei einer Regelübernahme möglicherweise Einbußen zu verzeichnen haben.

${ }^{51}$ Hier muss allerdings angemerkt werden, dass die Glaubwürdigkeit der Konditionalität nur sehr schwierig gemessen werden kann, da sich diese vor allem auf kommunikativer Ebene manifestiert. Um hier aussagekräftige Ergebnisse zu erzielen, müsste wohl auf eine Diskursanalyse zurückgegriffen werden.

${ }^{52}$ Schimmelfennig/Sedelmeier 2005: $18 \mathrm{ff}$.
} 
Franziska Smolnik: Zwischen Anspruch und Wirklichkeit: Die EU-Konditionalität als Demokratisierungsinstrument. Eine Studie zur externen Demokratieförderung an den Beispielen Georgien und Mazedonien

Erklärungsansatz, das Social Learning Model. Nicht mögliche Kosten und Nutzen einer Regelanpassung sind hier entscheidend, sondern inwiefern die Drittländer die zu übernehmenden Regeln und Normen als Teil ihrer eigenen kollektiven Identität wahrnehmen ${ }^{53}$.

Die Forschung zur EU-Erweiterung konzentriert sich dagegen vorrangig nicht, wie man meinen könnte, auf den Einfluss der EU in den Beitrittskandidaten, sondern befasst sich mehrheitlich mit den Entscheidungen der EU in Bezug auf die Erweiterung sowie mit den Interessen der Mitgliedstaaten in diesem Prozess. So konstatieren Schimmelpfennig und Sedelmeier eine eklatante Forschungslücke, bezüglich des Angleichungsprozesses der Beitrittskandidaten. Die Studien, die sich mit den Beitrittsländern beschäftigen, konzentrierten sich meist auf ein Land und sind deskriptiver Natur, besonders Theorie geleitete Arbeiten seien selten ${ }^{54}$. Als eine von wenigen Ausnahmen dieser Einschätzung soll hier Vachudovas ${ }^{55}$ Ansatz skizziert werden, der die Einwirkung der EU-Konditionalität auf die ostmitteleuropäischen Länder zur Grundlage hat. Auch ihre Ausgangshypothese ist, dass je größer die Gewinne sind, desto wahrscheinlicher die Erfüllung der EUBedingungen sein wird. Analog zu den Adaptionskosten von Schimmelfennig und Sedelmeier ist für Vachudova auch die nationalstaatliche Ebene der Zielländer wichtig. Hier ist für sie die An- bzw. Abwesenheit einer starken Opposition zum Kommunismus das entscheidende Kriterium. Im Gegensatz zu anderen Ansätzen auch dem bereits genannten von Schimmelfennig und Sedelmeier - unterscheidet Vachudova allerdings zwei Formen des Einflusses der EU auf die OME. Zum einen geht sie vom direkten Einfluss der EU durch die Nutzung der politischen Konditionalität aus, zum anderen bezieht Vachudova einen passiven Einfluss der EU (passive leverage) in ihre Betrachtung ein. Diesen Einfluss sieht sie als Anziehungskraft der EU, die auf der stark asymmetrischen Beziehung zwischen EU und Drittland

\footnotetext{
${ }^{53}$ Dabei kommen Schimmelfennig und Sedelmeier allerdings ähnlich wie Kubicek zu dem Ergebnis, dass insbesondere zur Erklärung des Verhaltens der Zielländer, ob diese also die Regeln der EU übernehmen, die rationalistischen Erklärungsansätze fruchtbarer sind.

${ }^{54}$ Schimmelfennig/Sedelmeier 2005: 2ff. Ähnliches stellen auch Knodt und Jünemann fest (Knodt/ Jünemann 2007: 10ff.).

55 Vachudova 2001.
} 
Franziska Smolnik: Zwischen Anspruch und Wirklichkeit: Die EU-Konditionalität als Demokratisierungsinstrument. Eine Studie zur externen Demokratieförderung an den Beispielen Georgien und Mazedonien

basiert. Vachudova macht hierfür vor allem Abhängigkeiten im Bereich Handel und Sicherheit verantwortlich ${ }^{56}$.

\subsection{Theoretischer Analyserahmen}

Wie gezeigt wurde, bieten die Forschungsfelder Compliance und Europäische Integration theoretische Anknüpfungspunkte für den Forschungsgegenstand, während die Transformationsforschung bisher kaum Theorie fundierte Annahmen zur externen Demokratisierung bereithält. Beide erst genannten Forschungsfelder gehen aber zunächst mehrheitlich nicht von einem Regeltransfer in Drittländer aus. Dagegen will die Theorie der internationalen Sozialisation, die viele Gemeinsamkeiten mit den Annahmen der Compliance-Forschung und einzelnen Ansätzen im Rahmen des Forschungsfelds Europäische Integration aufweist und auch in letzterem Bereich zu verorten ist, erklären, wie es zur Übernahme von Regeln internationaler Gemeinschaften und Organisationen in Drittstaaten kommt. Wie zu sehen sein wird, erweist sich die Theorie der internationalen Sozialisation für den Forschungsgegenstand als besonders fruchtbar und bildet daher den theoretischen Rahmen der vorliegenden Arbeit ${ }^{57}$. Da deutlich gemacht wurde, dass sich rationalistische Annahmen besser eignen, die Forschungsfrage zu beantworten, wird auf rationalistische Annahmen vor allem in Bezug auf die Handlungslogik der Akteure zurückgegriffen.

Wie auch die Theorieansätze der Compliance- und der Europäisierungsforschung entwickelt sich die Theorie der internationalen Sozialisation entlang der „Konstruktivismus-Rationalismus-Debatte“ in den Internationalen Beziehungen. Während man die Theorie zwar streng in zwei idealtypische konstruktivistische und rationalistische Ansätze trennen kann, soll hier im Einklang mit Schimmelfennig, Engert und Knobel (im folgenden SEK) ${ }^{58}$ ein aus beiden Theorierichtungen

\footnotetext{
${ }^{56}$ Ebd. 2001: 63ff.

${ }^{77}$ Die Theorie der internationalen Sozialisation ist ein neuerer Ansatz, dem erst seit Kurzem größere Aufmerksamkeit gewidmet wird und der bezüglich der rationalistischen Annahmen besonders mit Schimmelfennigs und Sedelmeiers External Incentives Model eine große Ähnlichkeit aufweist.

${ }^{58}$ Die Arbeit wird auch im Folgenden weitestgehend dem Ansatz zur internationalen Sozialisation von Schimmelfennig/Engert/Knobel 2006 folgen.
} 
Franziska Smolnik: Zwischen Anspruch und Wirklichkeit: Die EU-Konditionalität als Demokratisierungsinstrument. Eine Studie zur externen Demokratieförderung an den Beispielen Georgien und Mazedonien

kombinierter Ansatz verwendet werden ${ }^{59}$, wobei die rationalistischen Annahmen vor allem in Bezug auf die Handlungslogik (logic of action) der Akteure übernommen werden $^{60}$. Aus dem Konstruktivismus dagegen wird die Prämisse der Wichtigkeit internationaler Organisationen als sozialisierende Akteure übernommen und auch die Annahme eines institutionell-kulturellen Umfelds, in welchem die Staaten agieren.

Der Theorieansatz der internationalen Sozialisation sieht den Prozess der Europäisierung als eine Form der Sozialisation. SEK definieren internationale Sozialisation allgemein wie folgt:

"We define international socialization as a process in which states are induced to adopt the constitutive rules of an international community. [...] we analyze international socialization in a 'forward-looking' perspective, as a process directed at or potentially leading to rule adoption by the target states. The observation of international or non-international inducements to adopt the constitutive rules of an international community is thus sufficient to characterize a process as a socialization process". ${ }^{61}$

Internationale Sozialisation liegt also dann vor, wenn Staaten veranlasst werden, die Regeln einer internationalen Gemeinschaft oder Organisation zu übernehmen ${ }^{62}$. Von Sozialisation spricht man dementsprechend nicht erst dann, wenn die Übernahme der Regeln ${ }^{63}$ abgeschlossen ist. Vielmehr handelt es sich um einen Ergebnis offenen Verlauf. Kommt es trotz entsprechender Veranlassungen der internationalen Gemeinschaft bzw. einzelner internationaler Organisationen nicht zu einer Regelangleichung beim zu sozialisierenden Zielland, so handelt es sich gleichwohl um internationale Sozialisation, die in diesem Fall allerdings als gescheitert angesehen werden muss. Die Regelübernahme wiederum ist dann gegeben, wenn innerstaatliche Strukturen im Zielland - und nicht etwa die Anreize des sozialisierenden Akteurs -

\footnotetext{
${ }^{59}$ In der Kombination rationalistischer und konstruktivistischer Elemente kann denn auch der Hauptunterschied zu den bereits dargestellten Ansätzen gesehen werden, die in ihren Annahmen nach rationalistischen bzw. konstruktivistischen Prinzipien getrennt sind.

${ }^{60}$ Dies entspricht den Überlegungen der vorausgehend genannten Autoren, die rationalistische Ansätze eben hauptsächlich wegen ihrer Annahmen bezüglich der Handlungslogik als erklärungskräftiger einschätzen.

${ }^{61}$ Schimmelfennig/Engert/Knobel 2006: 2.

${ }^{62}$ Welche Formen diese „Veranlassung“ annehmen kann, hängt wiederum davon ab, ob man rationalistische oder konstruktivistische Annahmen einbezieht. Für einen Überblick im Konstruktivismus verankerter Mechanismen: Checkel 2005 (IO 59).

${ }^{63}$ SEK heben hervor, dass neben Regeln auch die Übernahme von Identitäten, Werten, Rollen und ähnlichem das Ziel von Sozialisation sein kann. Die Fokussierung auf Regeln erfolgt zum einen aus pragmatischen Gründen, da hier die internationale Sozialisation am ehesten empirisch nachzuweisen ist, zum anderen gehen die Autoren davon aus, dass Regeln als institutioneller Ausdruck der genannten anderen Elemente gesehen werden können.

Die konstitutiven Regeln können bezogen auf die EU sowohl explizit die im acquis communitaire festgehaltenen Regeln als auch die in den Verträgen fixierten Grundprinzipien der EU sein, wie sie bereits in Kapitel 2.1. ausführlich beschrieben wurden.
} 
Franziska Smolnik: Zwischen Anspruch und Wirklichkeit: Die EU-Konditionalität als Demokratisierungsinstrument. Eine Studie zur externen Demokratieförderung an den Beispielen Georgien und Mazedonien

die Regeleinhaltung garantieren ${ }^{64}$. Die zitierte Definition von Sozialisation verdeutlicht auch, dass es hier nicht um die Sozialisation einzelner Individuen geht. Vielmehr wird allein die Regelübernahme auf staatlicher Ebene betrachtet ${ }^{65}$. Auch wenn also Individuen die Regeln nicht internalisiert haben, so reicht für eine erfolgreiche Regelübernahme aus, dass auf staatlicher Ebene effektive Mechanismen bestehen, die Compliance sicherstellen und notfalls erzwingen können ${ }^{66}$.

Während dem sozialisierenden Akteur ein Interesse an internationaler Sozialisation unterstellt werden kann, da er so in der Lage ist, seine politischen Prinzipien auch auf andere Länder auszuweiten, darf für das Zielland ein solches Interesse nicht generell angenommen werden. Würden die grundlegenden Prinzipien und Regeln des Ziellandes mit denen des zu sozialisierenden Akteurs einhergehen, so wäre Sozialisation weitgehend überflüssig ${ }^{67}$. Warum es aber auch trotz (zum Teil) unterschiedlicher Prinzipien und Regeln zur Regelübernahme kommt, kann zum einen durch konstruktivistische, zum anderen durch rationalistische Theorieannahmen erklärt werden. Diese Annahmen betreffen die bereits erwähnte Handlungslogik der Akteure. Während die konstruktivistische Theorievariante der internationalen Sozialisation davon ausgeht, dass die Regelübernahme einhergeht mit einem Wandel von Identität und Präferenzen, der durch Nachahmen oder auch aus Überzeugung generiert wird, geht die rationalistische Variante von strategischen Akteuren aus, die ihr Verhalten auf der Grundlage von Kosten-NutzenKalkulationen anpassen (rationalistische Handlungslogik) ${ }^{68}$. Die Übernahme von demokratischen und rechtsstaatlichen Regeln und Prinzipien erfolgt daher zumindest anfänglich - aus Kalkül, um eher materielle Interessen wie Wohlfahrts-, Sicherheits- Macht- aber auch Prestigesteigerung befriedigen zu können. Generell

\footnotetext{
${ }^{64}$ Neben den beiden Polen „Regelübernahme“ und „keine Regelübernahme“ sind allerdings, das machen SEK deutlich, verschiedene weitere Abstufungen möglich.

${ }^{65}$ Bereits in einer früheren Studie macht Schimmelfennig (Schimmelfennig 2005: 833f.) deutlich, dass der Sozialisationsprozess zwischen der EU und den postsozialistischen Ländern auf intergouvernementaler Ebene verläuft, da die jeweiligen Gesellschaften bzw. zivilgesellschaftlichen Akteure dieser Länder zu wenig einflussreich sind.

${ }^{66}$ Auch diese Annahme wird von den Konstruktivisten nicht geteilt. Vielmehr handelt es sich ihrem Ansatz gemäß erst dann um Sozialisation, wenn es abschließend auch zur Internalisierung kommt (Checkel 2005).

${ }^{67}$ Wie in Kapitel 3.1.2 dargelegt wurde, ist dies auch eine Prämisse der Compliance-Forschung.

${ }^{68}$ Die rationalistische Variante der Theorie der internationalen Sozialisation schließt eine Internalisierung der Regeln in der Folge nicht aus. Sie besagt aber, dass der Internalisierung die Verhaltensangleichung vorausgeht und die Internalisierung sich nicht zwingend anschließt (Schimmelfennig 2005: 829).
} 
Franziska Smolnik: Zwischen Anspruch und Wirklichkeit: Die EU-Konditionalität als Demokratisierungsinstrument. Eine Studie zur externen Demokratieförderung an den Beispielen Georgien und Mazedonien

gilt, dass die Regelübernahme umso wahrscheinlicher ist, je höher die Anreize sind. Um die Kosten-Nutzen-Kalkulationen auf Seiten der Regierungen des Ziellandes zugunsten der Nutzen-Seite und somit zugunsten der Regelübernahme zu beeinflussen ${ }^{69}$, stehen dem sozialisierenden Akteur verschiedene Anreiz- aber auch Sanktionsmechanismen zur Verfügung ${ }^{70}$.

Damit die internationale Sozialisation aus Sicht der sozialisierenden Akteure erfolgreich ist, benötigt es darüber hinaus einer asymmetrischen Abhängigkeit zwischen den beteiligten Akteuren, das heißt, der sozialisierende Akteur muss eine vergleichsweise günstigere Verhandlungsposition einnehmen als der Adressat, um seine Strategie der Sozialisation durch Anreize auch umsetzen zu können.

4.

Internationale Sozialisation und der Einfluss der EUKonditionalität

Die Theorie der internationalen Sozialisation bietet also eine geeignete Grundlage, um den unterschiedlich starken Einfluss der EU-Konditionalität in den postsozialistischen Ländern zu verstehen. Dabei wird auf rationalistische Annahmen bezüglich der Handlungslogik der Akteure zurückgegriffen, um den Einfluss der vor allem auf Anreizen basierenden Konditionalität der EU analysieren zu können. Im Folgenden werden die zu untersuchenden Variablen und ihre jeweiligen Indikatoren vorgestellt. Deutlich gemacht wird außerdem, wo die Theorie der internationalen Sozialisation von SEK erweitert bzw. modifiziert werden soll.

\subsection{Grad der Rechtsstaatlichkeit - die abhängige Variable}

Die übergeordnete Fragestellung nach dem unterschiedlich starken Einfluss der EUKonditionalität auf den Demokratisierungsgrad in den post-sozialistischen Staaten soll konkret am Beispiel der Rechtsstaatlichkeit überprüft werden. Gemäß der

\footnotetext{
${ }^{69}$ Es kommt nur zur Regelübernahme, wenn der Nutzen die Kosten der Übernahme übersteigt.

${ }^{70}$ Bei der EU spielen hauptsächlich Anreize eine Rolle (positive politische Konditionalität). Neben materiellen Anreizen in Form von Hilfsprogrammen/-geldern zählen zu den positiven Anreizen außerdem die verschiedenen Formen institutioneller Anbindung an die EU bis hin zur Mitgliedschaft. Diese Leistungen werden zunächst lediglich in Aussicht gestellt und in der Regel erst dann eingelöst, wenn es zur Regelübernahme kommt.
} 
Franziska Smolnik: Zwischen Anspruch und Wirklichkeit: Die EU-Konditionalität als Demokratisierungsinstrument. Eine Studie zur externen Demokratieförderung an den Beispielen Georgien und Mazedonien

Theorie der internationalen Sozialisation handelt es sich bei rechtsstaatlichen Verfahren um grundlegende Regeln der Europäischen Union (siehe Kapitel 2.1.).

Eine Beschränkung auf den Bereich der Rechtsstaatlichkeit ist aus mehreren Gründen sinnvoll.

Einerseits bietet sich eine solche AV an, da der Demokratie-Begriff äußerst komplex ist $^{71}$. Den Begriff Demokratie und somit auch den in der Fragestellung genannten Demokratisierungsgrad zu operationalisieren und zu messen, ist äußerst schwierig wenn es auch mittlerweile einige Indizes gibt, die dies versuchen ${ }^{72}$. Die

Konzentration auf den Teilaspekt der Rechtsstaatlichkeit bietet dafür die

Möglichkeit, den vielschichtigen Begriff der Demokratie auf einen greifbareren

Gegenstand für die empirische Analyse zu beschränken, ohne das übergeordnete Forschungsfeld zu verlassen ${ }^{73}$. In Bezug auf Demokratie ist Rechtsstaatlichkeit dabei nicht nur ein peripherer Faktor, sondern im Gegenteil äußerst zentral. So sehen beispielsweise Linz und Stepan ${ }^{74}$ in der Rechtsstaatlichkeit eine von fünf miteinander verbundenen Bedingungen für eine konsolidierte Demokratie. Ebenso äußert sich Alex Pravda, wenn er schreibt:

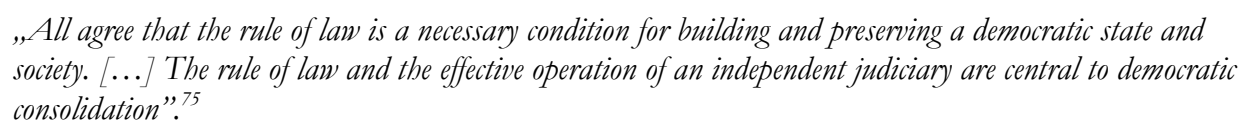

Auch die genannten Indizes verwenden Rechtsstaatlichkeit als einen von mehreren Indikatoren, die sich im Demokratie-Status (Bertelsmann Transformation Index) bzw. dem Score Democracy (Freedomhouse) wieder finden. Die Ergebnisse der Arbeit können somit auch Aufschluss über den Einfluss der EU-Konditionalität auf die demokratische Entwicklung im Allgemeinen geben.

Andererseits ist der Fokus auf den Bereich der Rechtsstaatlichkeit auch aufgrund der Relevanz für die praktische Politik gerechtfertigt. Besonders seit Mitte der 1990er Jahre hat die Förderung von Rechtsstaatlichkeit in Drittstaaten rapide zugenommen.

\footnotetext{
${ }^{71}$ Siehe hierzu exemplarisch Lauth 2004: $10 \mathrm{ff}$.

${ }^{72} \mathrm{Zu}$ den bekanntesten zählen der Bertelsmann Transformation Index und der Freedombouse-Index. Diese verwenden zur Messung von Demokratie allerdings nicht identische Indikatoren und machen somit ebenfalls deutlich, wie komplex der Demokratiebegriff ist.

${ }^{73}$ Morlino/Magen 1998: 7.

${ }^{74}$ Linz/Stepan 1996: 7ff. Neben Rechtsstaatlichkeit sehen Linz und Stepan eine unabhängige Zivilund politische Gesellschaft, eine adäquate Staatsbürokratie sowie eine institutionalisierte Wirtschaftsgesellschaft als wichtig an. Zum Zusammenhang zwischen Demokratie und Rechtsstaatlichkeit siehe auch Carothers 1998, Bunce 2006.

75 Pravda 2001: 17.
} 
Franziska Smolnik: Zwischen Anspruch und Wirklichkeit: Die EU-Konditionalität als Demokratisierungsinstrument. Eine Studie zur externen Demokratieförderung an den Beispielen Georgien und Mazedonien

Dennoch schlägt sich dies nicht in den Studien zur externen Demokratieförderung nieder. Es gibt daher immer noch große Wissenslücken zu diesem Bereich, obwohl dessen Bedeutung durchaus anerkannt ist ${ }^{76}$.

Eine Beschränkung auf den Bereich der Rechtstaatlichkeit bietet sich auch deshalb an, da sich die Europäische Union ausdrücklich die Konsolidierung von Rechtstaatlichkeit zum Ziel gesetzt hat - nicht nur in den Mitgliedstaaten, sondern auch in Drittländern über die Außenbeziehungen bzw. die Heranführungsprozesse. Im Gegensatz zu den von der EU in ihren externen Beziehungen eingeforderten demokratischen Reformen und der Einführung der Marktwirtschaft hat die Rechtsstaatlichkeit bislang allerdings auch in Bezug zur EU nur geringe wissenschaftliche Aufmerksamkeit erfahren.

\section{Operationalisierung der abhängigen Variable}

Wie gezeigt, begreift die EU Rechtsstaatlichkeit als ein fundamentales Prinzip, dessen Konsolidierung in Drittstaaten allgemein Ziel der EU-Außenpolitik ist und speziell im Zusammenhang mit den Heranführungsstrategien für die östlichen EU-Nachbarn von vorrangiger Bedeutung ist. Im Rahmen der vorliegenden Arbeit spielt daher insbesondere der Rechtsstaatlichkeitsansatz der EU eine wichtige Rolle. Allerdings wird bei der näheren Betrachtung deutlich, dass die EU bisher eine konkrete, allgemein angewandte Definition dieses Konzepts schuldig bleibt ${ }^{77}$. Auch die verschiedenen Strategien der EU in Bezug auf ihre östlichen Nachbarn geben keine Auskunft darüber, welche Elemente konkret mit dem Konzept der Rechtsstaatlichkeit gefasst werden. Erst in den auf die jeweiligen Länder abgestimmten Dokumenten, beispielsweise in Aktionsplänen und Länderberichten, werden einzelne Elemente von Rechtsstaatlichkeit herausgegriffen.

Aus diesem Grund soll hier auf die von Thomas Carothers im Zuge der Transformationsforschung etablierte Definition von Rechtsstaatlichkeit zurückgegriffen werden. Carothers definiert Rechtsstaatlichkeit angelehnt an die

\footnotetext{
${ }^{76}$ Siehe hierzu auch Carothers 1998.

77 Kochenev 2004. Kochenev wertet in seiner Studie verschiedene Dokumente der EU aus, die im Erweiterungsprozess der OME deren Fortschritt im Bereich Rechtsstaatlichkeit anmerken bzw. anmahnen. Dabei kann Kochenev zwar grobe Schwerpunktbereiche ermitteln; berücksichtigt man allerdings, dass die Anforderungen der EU sich im Verlauf der Weiterentwicklung der Heranführungsstrategien weiter verstärkt haben und die EU strengere Auflagen erteilt, hält sich der Erkenntniswert von Kochenevs Studie für die nun angewandten Strategien in Grenzen.
} 
Franziska Smolnik: Zwischen Anspruch und Wirklichkeit: Die EU-Konditionalität als Demokratisierungsinstrument. Eine Studie zur externen Demokratieförderung an den Beispielen Georgien und Mazedonien

Klassiker Albert Venn Dicey und Friedrich August von Hayek als ein System, in welchem die Rechte öffentlich bekannt sind, wo die Rechte eine klare Bedeutung haben und bei jedem gleichermaßen angewendet werden. Weiter heißt es bei Carothers:
„They [Anm... the laws] enshrine and uphold the political and civil liberties [...]. In particular, anyone accused of a crime has the right to a fair, prompt hearing and is presumed innocent until proved guilty. The central institutions of the legal system, including courts, prosecutors and police, are reasonably fair, competent and efficient. Judges are impartial and independent, not subject to political influence or manipulation. Perhaps most important, the government is embedded in a comprehensive legal framework, its officials accept that the law will be applied to their own conduct, and their government seeks to be law- abiding." $" 78$

Die oben genannten Faktoren von Thomas Carothers stimmen im Wesentlichen mit den (Sub-)Indikatoren des im Freedombouse-Rating, Nations in Transit' enthaltenen Indikators Judicial Framework and Independence überein. Ein Rückgriff auf diese Daten ist daher sinnvoll. Zur Messung der abhängigen Variable Grad der Rechtsstaatlichkeit wird dementsprechend der Freedombouse-Indikator Judicial Framework and Independence herangezogen ${ }^{79}$.

Dieser Indikator setzt sich aus folgenden Elementen zusammen: Verfassungsreform, Schutz der Menschenrechte, Reform des Strafgesetzbuchs, Unabhängigkeit der Justiz, Status der Rechte ethnischer Minderheiten, Garantie der Gleichheit vor dem Gesetz, Behandlung von Verdächtigen und Gefangenen sowie Compliance mit gerichtlichen Entscheidungen. Die Befunde des Judicial Framework and IndependenceIndikators übersetzt Freedomhouse in eine numerische, ordinal skalierte Ordnung, wobei die Zahl 1 für den höchsten Grad demokratischen Fortschritts und 7 für den geringsten Grad steht. Weniger der absolut erreichte Skalenwert ist allerdings für die Untersuchung von Interesse, sondern insbesondere die Entwicklung der Indikatorwerte über den Untersuchungszeitraum hinweg. Um eine noch genauere Einschätzung bezüglich der AV zu erhalten, soll in dieser Arbeit neben den aggregierten Daten von Freedomhouse die Unabhängigkeit der Justiz separat als Indikator betrachtet werden, der, wie oben angegeben, auch als SubIndikator des Freedombouse Judicial Framework and Independence-Indikators integriert ist ${ }^{80}$.

\footnotetext{
${ }^{78}$ Carothers 1998: 95-96.

${ }^{79}$ Eine solche Vorgehensweise bietet sich auch aus pragmatischen Gründen an, da die eigenständige sorgfältige empirische Überprüfung mehrerer gewählter Indikatoren im Rahmen der Arbeit kaum bewerkstelligt werden könnte.

80 Auf diese Weise sollen nicht nur detaillierte Informationen zuzüglich zu den Zahlenwerten des Freedomhouse-Indexes erhalten werden. Da der Freedombouse-Indikator selbst gewisse
} 
Franziska Smolnik: Zwischen Anspruch und Wirklichkeit: Die EU-Konditionalität als Demokratisierungsinstrument. Eine Studie zur externen Demokratieförderung an den Beispielen Georgien und Mazedonien

Angelehnt an die Minimum Standards of Judicial Independence der International Bar Association ${ }^{81}$ soll in diesem Zusammenhang insbesondere auf die Umsetzung der Unabhängigkeit der Richter und des Gerichtswesens gegenüber dem Einfluss der Exekutive bzw. sonstiger unbefugter Dritter, die transparente und nach meritokratischen Prinzipien erfolgende Berufung, Beförderung und Entlassung von Richtern sowie die adäquate finanzielle Ausstattung und Selbstverwaltung geachtet werden.

\subsection{Die Größe des Anreizes der EU-Konditionalität - die unabhängige Variable}

Der Erfolg der internationalen Sozialisation ist gemäß der angenommenen rationalistischen Handlungslogik umso höher, je größer der von der EU gewährte Anreiz ist. Hierdurch wird die Nutzenseite der rationalen Kalkulation des Ziellands zugunsten einer Regelübernahme gestärkt ${ }^{82}$. Um die Frage nach dem unterschiedlich starken Einfluss der EU-Konditionalität in den post-sozialistischen Ländern zu beantworten, bietet sich dementsprechend die genauere Betrachtung der in Aussicht gestellten Anreize an. Die unabhängige Variable stellt hier die Größe des von der EU im Rahmen der Konditionalität in Aussicht gestellten Anreizes dar ${ }^{83}$. Der stärkste Anreiz der EU ist die Aussicht auf eine EU-Mitgliedschaft, die neben ökonomischen und sicherheitspolitischen auch soziokulturelle Vorteile bietet. Eine Mitgliedschaft bringt unter anderem Stimmrechte in der EU, uneingeschränkten Zugang zum EU-Binnenmarkt sowie weitere finanzielle Vorteile mit sich ${ }^{84}$. Obwohl die EU auch unterhalb der Mitgliedschaft verschiedene Assoziierungsarrangements anbietet, wird der Beitrittsperspektive ein ungemein größeres Wirkpotential

\footnotetext{
Vergleichsschwächen aufweist, die Indikatorwerte ergeben sich beispielsweise aus Länderberichten von verschiedenen Vorortautoren, soll die nähere Betrachtung der Justiz außerdem dazu beitragen, möglichst gründliche Angaben für die AV zu erhalten.

${ }^{81}$ International Bar Association 1982.

${ }^{82}$ Wie in Kapitel 2.2 erläutert wurde, nutzt die EU hauptsächlich positive Konditionalität, also Anreize. Da Sanktionen im Rahmen der EU-Konditionalität keine entscheidende Rolle einnehmen, wird daher lediglich die Größe der Anreize betrachtet.

83 An dieser Stelle soll noch einmal betont werden, dass die Verschiedenheit der Anreize einem Vergleich der EU-Konditionalitäten nicht entgegensteht. Wie Morlino und Magen konstatieren und in Kapitel 2.2 erläutert wurde, sind zwar die Anreize verschieden, die Heranführungsstrategien unterscheiden sich allerdings nicht derart, dass ein Vergleich unzulässig wäre (Morlino/Magen 2004:5).

${ }^{84}$ Siehe hierzu auch Vachudova 2001: 65.
} 
Franziska Smolnik: Zwischen Anspruch und Wirklichkeit: Die EU-Konditionalität als Demokratisierungsinstrument. Eine Studie zur externen Demokratieförderung an den Beispielen Georgien und Mazedonien

zugeschrieben $^{85}$. Die Beitrittsoption ist der hier verwendete Indikator. Dabei stellt die Beitrittsperspektive einen hohen Anreiz dar, während sämtliche EU-

Vergünstigungen, die sich unterhalb der Beitrittsperspektive bewegen, einen niedrigen Anreiz darstellen. Die zentrale Hypothese der Arbeit lautet daher: Bietet die EU im Rahmen derpolitischen Konditionalität eine Beitrittsperspektive, so ist es wahrscheinlich, dass das Drittland die Regeln der EU (bier: solche binsichtlich einer Verbesserung der Rechtsstaatlichkeit) übernimmt.

Da die - wenn auch mittel- bzw. längerfristige - Aussicht auf eine EU-Mitgliedschaft einen qualitativ anderen Anreiz bietet als die verschiedenen abgestuften Formen einer Kooperation, wird festgelegt, dass die unabhängige Variable zwischen einer EU-Konditionalität A) mit hohen Anreizen (Beitrittsperspektive) und B) mit niedrigen Anreizen (keine Beitrittsperspektive) variiert.

\subsection{Adaptionskosten - Bedingungsvariable $\mathrm{A}$}

Die Theorie der internationalen Sozialisation geht von Kosten und Nutzen kalkulierenden Akteuren aus. Während die unabhängige Variable die Nutzenseite abdeckt, muss die Frage der Kosten noch in das Analysedesign aufgenommen werden. Für $\mathrm{SEK}^{86}$ sind die Kosten gleichbedeutend mit Adaptionskosten, die aufgrund der Übernahme der Regeln im Zielland entstehen. Ihr Analyserahmen sieht diese Adaptionskosten in Abhängigkeit von einem sich durch die Regelübernahme ergebenden Machtverlust für die (potentiellen) Regierungsparteien des Ziellands. Dabei nehmen die Autoren an, dass es das oberste Ziel der Regierungsparteien ist, die eigene Macht zu erhalten. Je mehr die zu übernehmenden Regeln die Machterhaltung negativ beeinflussen, desto höher sind die Adaptionskosten zu bewerten.

Die Operationalisierung der Adaptionskosten in Abhängigkeit vom Machtverlust für die Regierungsparteien erweist sich insbesondere auch gegenüber der bereits in Fußnote 53 erwähnten Operationalisierung der Adaptionskosten durch Rückgriff auf die Veto-Spieler-Theorie als sinnvoll. Die Veto-Spieler-Theorie berücksichtigt nicht, dass das Ziel der von ihr betrachteten Akteure nicht zwingend das Finden von Sachlösungen sein muss, sondern in vielen Fällen vor allem der Machterwerb bzw.

85 Siehe hierzu auch Vachudova 2001: 12ff.; Merkel 2007: 429f.

${ }^{86}$ Schimmelfennig/Engert/Knobel 2006: $10 \mathrm{f}$. 
Franziska Smolnik: Zwischen Anspruch und Wirklichkeit: Die EU-Konditionalität als Demokratisierungsinstrument. Eine Studie zur externen Demokratieförderung an den Beispielen Georgien und Mazedonien

der Machterhalt für die entsprechenden Akteure wichtig ist. Nicht die Anzahl oder Positionen der Vetospieler sind dann ausschlaggebend, sondern gewisse Entscheidungen und Lösungen werden aufgrund des Machterhaltungswillens boykottiert $^{87}$. Gerade diese Komponente spielt, wie SEK gezeigt haben, aber im Zusammenhang mit der internationalen Sozialisation von Drittstaaten eine zentrale Rolle.

\section{Operationalisierung der Adaptionskosten}

Die Adaptionskosten werden in dieser Arbeit als Bedingungsvariable (condition variable) integriert. Bedingungsvariablen sind solche Variablen, die die Größe des Einflusses der UV beeinflussen. Sind die Adaptionskosten hoch, so wird angenommen, dass der Einfluss der UV sich verringert, wohingegen niedrige Adaptionskosten den Einfluss der UV noch positiv verstärken ${ }^{88}$.

In Anlehnung an die Konzeption der Adaptionskosten bei SEK ${ }^{89}$ soll auch in dieser Arbeit der Machtverlust der Regierungspartei(en) betrachtet werden. Es wird demgemäß die Hypothese aufgestellt, dass es wahrscheinlich ist, dass der Einfluss der UV positiv verstärkt wird, wenn diese neuen Regeln keinen bžw. nur einen geringen Machtverlust für die regierende(n) Partei(en) zur Folge haben.

Machtverlust definieren SEK in ihrer Arbeit auf zweierlei Weise: zum einen gehen sie davon aus, dass der Verlust institutioneller Macht der Regierungspartei(en) im Staatsapparat eine wichtige Rolle spielt, zum anderen, dass auch der mögliche Machtverlust in Form einer antizipierten Gefährdung der territorialen Integrität betrachtet werden muss. Erst wenn sowohl der institutionelle Machtverlust als auch die Gefährdung der territorialen Integrität gering sind, kann man, so SEK, von niedrigen Adaptionskosten ausgehen.

Obwohl dem generell zugestimmt wird, sollen Schimmelfennig, Engert und Knobels Indikatoren in dieser Arbeit präzisiert werden: So führen der Verlust bzw. Einbußen an institutioneller Macht für die Regierungspartei(en) nicht per se zu hohen Adaptionskosten, sondern ob von hohen Adaptionskosten ausgegangen werden

\footnotetext{
${ }^{87}$ Schmidt 2004.

88 "The values of condition variables govern the size of the impact that IV $s$ [Anm.: unabbängige V ariablen] or IntV $s$ [Anm.: intervenierende Variablen] have on DVs [Anm.: abhängige Variablen] or other IntV s." Van Evera 1997: 11.

${ }^{89}$ Schimmelfennig/Engert/Knobel 2006: 59.
} 
Franziska Smolnik: Zwischen Anspruch und Wirklichkeit: Die EU-Konditionalität als Demokratisierungsinstrument. Eine Studie zur externen Demokratieförderung an den Beispielen Georgien und Mazedonien

kann, hängt vom vorliegenden Parteityp ab. Während SEK davon ausgehen, dass ein erwarteter institutioneller Machtverlust in jedem Fall mit hohen Kosten gleichzusetzen ist, wird hier argumentiert, dass vor allem dann von hohen Adaptionskosten auszugehen ist, wenn politische Macht weniger an Institutionen als an bestimmte Personen bzw. Personengruppen gebunden ist, deren persönliche Macht bzw. deren Machterhaltungspraktiken durch die Regelübernahme gefährdet sind und die somit in der Regel einen Regierungswechsel nicht überdauern und daher einer Regelübernahme ablehnend gegenüberstehen ${ }^{90}$.

Drei verschiedene Parteitypen sollen hier unterschieden werden: charismatische, klientelistische und programmatische Parteien. Diese sind jeweils durch folgende Kriterien charakterisiert: Charismatische Regierungsparteien definieren sich über eine charismatische Führungspersönlichkeit, ideologische bzw. programmatische Aspekte spielen wenn nur eine untergeordnete Rolle. Klientelparteien zeichnen sich durch Patronage ${ }^{91}$, teilweise auch durch die Verteilung von Pfründen (prebends) aus bzw. durch die Extraktion staatlicher Ressourcen ${ }^{92}$; außerdem kommt es zu einer Politisierung der Bürokratie. Auch hier spielen programmatische und ideologische Aspekte nur eine untergeordnete Rolle ${ }^{93}$. Programmatische Parteien dagegen vertreten vorrangig ein (an gesellschaftlichen Cleavages ausgerichtetes) politisches Programm und vertreten eine bestimmte Ideologie. Die Verbindung zwischen Wahlvolk und Partei ist bei programmatischen Parteien daher am engsten und programmatische Parteien sind somit vergleichsweise beständig.

Demgemäß wird zunächst von hohen Adaptionskosten ausgegangen, wenn die jeweiligen Regierungsparteien stark personalisiert (charismatische Parteien) bzw. klientelistisch organisiert (Klientelparteien) sind, da diese Parteitypen einen Machtwechsel oder auch nur Machtverlust in der Regel nicht überleben und gerade hier die Übernahme von EU-Regeln zu einer empfindlichen Beeinträchtigung der Machterhaltungspraktiken bzw. des Machterhalts führt.

\footnotetext{
${ }^{90}$ Kitschelt/Wilkinson 2007: 10ff.; Kitschelt 1995: 449ff.

${ }^{91}$ Patronage wird nach van de Walle definiert als die Praxis staatliche Ressourcen zu nutzen, um Posten und Dienstleistungen an Klienten zu vergeben (Van de Walle 2007: 51ff).

${ }_{92}^{2}$ Neben der eigenen materiellen Bereicherung werden so auch Patronage und Pfründe finanziert.

93 Während Kitschelt den Begriff Klientelpartei verwendet, spricht Kopecky von Parteikolonialisierung des Staates; Kopecky 2006: 258ff.; Kitschelt 1995: 449ff. Programmatische Aspekte können allerdings insofern eine Rolle spielen, als sie auf die Klientelgruppe ausgerichtet sind und diese eingrenzen, wie beispielsweise eine Ausrichtung an ethnischen cleavages. Siehe hierzu auch Fußnote 98.
} 
Franziska Smolnik: Zwischen Anspruch und Wirklichkeit: Die EU-Konditionalität als Demokratisierungsinstrument. Eine Studie zur externen Demokratieförderung an den Beispielen Georgien und Mazedonien

Eine programmatische Orientierung ist dagegen generell mit geringen

Adaptionskosten verbunden, da programmatische Parteien durch ihre Ausrichtung an gesellschaftlichen Interessen vergleichsweise stabil sind und somit die Übernahme von EU-Regeln ihre Machterhaltungspraktiken bzw. ihre Macht insgesamt weniger negativ beeinflusst. Dennoch ist in diesem Fall eine genauere Überprüfung des jeweiligen Parteiprogramms hinsichtlich der Kompatibilität mit den zu übernehmenden Regeln wichtig. Sind die zu übernehmenden Regeln nicht mit dem zugrunde liegenden Programm vereinbar, sind auch hier die Adaptionskosten hoch ${ }^{94}$.

\subsection{Asymmetrische Interdependenz - Bedingungsvariable B}

Neben den Adaptionskosten soll eine weitere Bedingungsvariable in den Analyserahmen einbezogen werden, die SEK lediglich im Rahmen ihrer Theorie erwähnen ohne aber näher darauf einzugehen ${ }^{95}$. Wie bereits kurz erwähnt, hängt der Einfluss der EU-Konditionalität von der asymmetrischen Interdependenz zwischen EU und Drittstaat ab. Keohane und Nye definieren Interdependenz folgendermaßen: "Interdepence, most simply defined, means mutual dependence"." Asymmetrische Interdependen₹ bedeutet dementsprechend, dass diese Abhängigkeit nicht auf beide Parteien gleichermaßen verteilt ist. Dazu führen Keohane und Nye aus:

\footnotetext{
„We must also be careful not to define interdependence entirely in terms of situations of evenly balanced mutual dependence. It is asymmetries in dependence that are most likely to provide sources of influence for actors in their dealings with one another.
}

Asymmetrische Interdependen₹ resultiert gemäß Vachudova ${ }^{98}$ vor allem aus der wirtschaftlichen Abhängigkeit der Drittstaaten von der EU. Auch die Theorie der internationalen Sozialisation betont, dass die Sozialisation durch positive

\footnotetext{
${ }^{94}$ Der von SEK genannte zweite Indikator ist hier in die jeweiligen Parteitypen einbezogen und findet gegebenenfalls im empirischen Teil Eingang. Die bezüglich der Übernahme von EU-Regeln wahrgenommene Gefährdung der territorialen Integrität führt insbesondere dann zu hohen Adaptionskosten, wenn im Fall einer programmatischen Regierungspartei sich diese entlang ethnischer Zugehörigkeiten ausrichtet und das Programm die Dominanz einer ethnischen Gruppe betont, oder wenn im Fall von einer klientelistischen Partei, die auf eine Besserstellung der Minderheiten gerichteten EU-Regeln als Machtverlust für das eigene Netzwerk wahrgenommen werden. Generell, wie SEK argumentieren, kann aber nicht davon ausgegangen werden, dass die Übernahme von EURegeln und die damit möglicherweise einhergehende Föderalisierung bzw. Stützung anderer Autonomiearrangements die territoriale Integrität eines Staates gefährdet, versucht die EU doch hierdurch Sezessionsprozesse zu vermeiden.

${ }^{95}$ Schimmelfennig/Engert/Knobel 2006: 20.

${ }^{96}$ Keohane/Nye 1977: 8.

${ }^{97}$ Ebd. 1977: 10.

98 Vachudova 2001: 7.
} 
Franziska Smolnik: Zwischen Anspruch und Wirklichkeit: Die EU-Konditionalität als Demokratisierungsinstrument. Eine Studie zur externen Demokratieförderung an den Beispielen Georgien und Mazedonien

Konditionalität dann erfolgreich ist, wenn der sozialisierende Akteur - hier die EU eine gegenüber dem Adressaten vergleichsweise stärkere Verhandlungsposition einnimmt. Levitsky und Way ${ }^{99}$ argumentieren ähnlich, wenn sie den Einfluss westlicher Demokratisierungsmaßnahmen sowohl abhängig von Leverage als auch von Linkage sehen. Während die dem Begriff Linkage zugeordneten Indikatoren die Verbindungen und Ströme in wirtschaftlichen, sozialen, Kommunikations- und ähnlichen Formen meinen und somit eher auf den indirekten Einfluss der Diffusion westlich-demokratischer Werte abzielen, sind mit Leverage die Verhandlungsposition des Westens vis à vis Drittstaaten sowie der mögliche Einfluss westlichen Handelns in diesen Ländern gemeint. Levitsky und Way nennen drei Indikatoren, die westliche Leverage bestimmen: die Größe und die wirtschaftliche wie militärische Stärke des Drittlandes, mögliche mit dem Ziel der Demokratisierung konkurrierende Interessen der westlichen Länder sowie mögliche Gegenmächte, die alternativ zum Westen wirtschaftliche und sicherheitspolitische Unterstützung bieten können.

Gemäß der Theorie der internationalen Sozialisation wird die Hypothese aufgestellt, dass es wahrscheinlich ist, dass der Einfluss der UV geringer ist, wenn die asymmetrische Interdependenz, zwischen sozialisierendem Akteur und Drittstaat ebenfalls gering ist.

Zur Messung der asymmetrischen Interdependenz soll auf zwei der von Levitsky und Way genannten Indikatoren zurückgegriffen werden: Die Größe, wirtschaftliche und militärische Stärke des Drittstaates sowie die Existenz von Alternativmächten. Dem Ziel der Demokratisierung entgegenstehende Interessen westlicher Akteure und Gegenmächte, die Levitsky und Way vor allem im wirtschaftlichen und strategischen Bereich ausmachen, werden nicht als Indikator einbezogen. Vor allem aus pragmatischen Gründen wird auf diesen Indikator verzichtet, da die Operationalisierung von Interessen den Rahmen dieser Arbeit überschreitet und kein zusätzlicher, wesentlicher Erkenntnisgewinn erzielt werden kann. Eine Aussparung dieses Indikators ist auch deshalb gerechtfertigt, weil sowohl wirtschaftliche als auch sicherheitspolitische Aspekte in den beiden anderen Indikatoren integriert sind. Zum anderen hat gerade die positive politische Konditionalität der EU, vor allem auch durch die Erfahrungen der Beitrittsprozesse in den OME an Stringenz gewonnen ${ }^{100}$.

\footnotetext{
${ }^{99}$ Levitsky/Way 2007: 50ff.

${ }^{100}$ Für den Fall der Beitrittsperspektive siehe hierzu Vachudova 2001: 12ff. Dass auch die weiteren Anreize an die Erfüllung der Bedingungen geknüpft werden und dies von der EU strikter überprüft
} 
Franziska Smolnik: Zwischen Anspruch und Wirklichkeit: Die EU-Konditionalität als Demokratisierungsinstrument. Eine Studie zur externen Demokratieförderung an den Beispielen Georgien und Mazedonien

So machen auch SEK bei ihrer Beschreibung der Wirkungsweise der EU-

Konditionalität darauf aufmerksam, dass die spezifische Organisationsform der EU dazu führt, dass diese sowohl was die Drohung, Leistungen bei Nicht-Erfüllung der Bedingungen einzubehalten, als auch das Versprechen, die Leistungen tatsächlich einzulösen, vergleichsweise konsequent ist und Länder nicht aufgrund strategischer oder ökonomischer Faktoren diskriminiert ${ }^{101}$.

Die ausgewählten Indikatoren sollen in Anlehnung an Levitsky und Way wiederum operationalisiert werden: Die Größe wird durch die geographische Größe sowie die Bevölkerungszahl gemessen. Die militärische Stärke bemisst sich anhand der Höhe der Militärausgaben sowie der Stationierung externen Militärs im eigenen Land. Zur Messung der wirtschaftlichen Stärke werden die Bruttoinlandsprodukt (BIP)/KopfDaten in Kaufkraftstandards (KKS), die Arbeitslosigkeitsraten sowie die Ressourcenausstattung bzw. die geographische Lage erfasst, während Alternativmächte gemäß Levitsky und $\mathrm{Way}^{102}$ solche Mächte sind, die dem Drittstaat alternativ zur EU militärische und wirtschaftliche Unterstützung bieten können. Unterschieden werden soll hier zwischen einer hohen asymmetrischen Interdependenz zu Lasten des Drittstaates, wenn die Größe, die militärische und wirtschaftliche Stärke gering und keine Alternativmächte vorhanden sind; die asymmetrische Interdependenz ist gering, wenn A) die Größe, die militärische und wirtschaftliche Stärke groß sind (unabhängig vom Vorhandensein von Alternativmächten) oder B) die Größe, die militärische und wirtschaftliche Stärke niedrig sind, dafür aber Alternativmächte vorhanden $\operatorname{sind}^{103}$.

wird, zeigen auch die eingeführten Benchmarks und Monitoring-Maßnahmen, Lang/Schwarzer 2006: $119 f$.

${ }^{101}$ Schimmelfennig/Engert/Knobel 2006: 52ff. Dennoch soll hier nicht geleugnet werden, dass insbesondere wirtschaftliche Interessen die Konditionalitätspolitik der EU beeinflussen, wie auch in Kapitel 2.1 erwähnt. Auf mögliche diesbezügliche Unterschiede soll gegebenenfalls bei den Fallbeispielen hingewiesen werden, ohne dass dies aber in die Messung der asymmetrischen Interdependenz. eingehen soll.

102 Levitsky/ Way 2007: 51.

${ }^{103}$ Es wird angenommen, dass aufgrund der geringen Größe sowie geringen wirtschaftlichen und militärischen Stärke der Einfluss von Alternativmächten besonders ins Gewicht fällt, da das Drittland auf externe Hilfe angewiesen ist. 
Franziska Smolnik: Zwischen Anspruch und Wirklichkeit: Die EU-Konditionalität als

Demokratisierungsinstrument. Eine Studie zur externen Demokratieförderung an den Beispielen

Georgien und Mazedonien

5.

Methode und Fallauswahl

Um die vorgestellte(n) Hypothese(n) zu untersuchen, soll ein Fallvergleich zweier Länder durchgeführt werden. Vergleiche in der Politikwissenschaft erlauben die Falsifikation angenommener kausaler Zusammenhänge und tragen somit zur Weiterentwicklung und Präzisierung von Theorien bei. Gemäß Sartori ${ }^{104}$ ist daher auch das zentrale Ziel eines Vergleichs die Überprüfung von Hypothesen. Die hier gewählte Methode des Vergleichs zweier Fälle wird der Kategorie der small n-Studien zugeschrieben. Die möglicherweise wirkungsvollere Kontrollmethode der large nStudie eignet sich für diese Arbeit weniger, da sie eine hohe Anzahl von Fallbeispielen voraussetzt, was den Rahmen dieser Arbeit sprengen würde. Aufgrund des Mangels an Theorie geleiteten Arbeiten in diesem Bereich gibt es außerdem kaum verwertbares Material, um in dieser Arbeit eine large n-Studie durchzuführen. Neben einer schwächeren Kontrollleistung und geringeren Reichweite der ermittelten Ergebnisse als bei Vergleichen mit hoher Fallzahl, bieten Vergleiche mit einer kleinen Fallzahl jedoch einen entscheidenden Vorzug: Sie ermöglichen nicht nur die generelle Überprüfung, ob es einen kausalen Zusammenhang gibt, sondern auch die Betrachtung über dessen Gestaltung. Aufgrund des dargestellten Mangels an Theorie geleiteten, analytischen Forschungsarbeiten ist eine intensive Aufarbeitung des empirischen Materials notwendig, für welche sich der Vergleich zweier Länder eignet. Hierbei soll der Bereich der externen Demokratisierung im Allgemeinen und der der EU als Demokratisierungsakteur in ihren Außenbeziehungen im Speziellen theoretisch fundiert analysiert und die hier wirkenden Mechanismen offen gelegt werden.

Die zu untersuchenden Fälle werden gemäß des most-similar-systems-design ausgewählt. Dabei werden solche Fälle verglichen, die möglichst ähnliche Hintergrundvariablen aufweisen, um die externe Varianz gering zu halten. Aus dieser Gruppe werden dann solche Fälle für die Untersuchung ausgewählt, die unterschiedliche Ausprägungen bei der unabhängigen Variable aufweisen ${ }^{105}$.

Aufgrund des Forschungsgegenstands kommen für die vorliegende Untersuchung also solche Länder in Frage, mit denen die EU Beziehungen unterhält und in deren

104 Sartori 1994: $15 \mathrm{ff}$.

105 Jahn: $233 \mathrm{ff}$. 
Franziska Smolnik: Zwischen Anspruch und Wirklichkeit: Die EU-Konditionalität als Demokratisierungsinstrument. Eine Studie zur externen Demokratieförderung an den Beispielen Georgien und Mazedonien

Rahmen sie das Instrument der politischen Konditionalität anwendet, um eine Anpassung an die Prinzipien und Regeln der EU zu erreichen. Um allerdings gemäß des most-similar-systems-design möglichst ähnliche Fälle auszuwählen, soll die zu untersuchende Grundgesamtheit aus den post-sozialistischen Staaten des (süd-)osteuropäischen und südkaukasischen Raumes bestehen ${ }^{106}$. Diese Staaten sind einerseits geprägt durch eine Epoche sozialistischer Politik und andererseits durch den Anfang der 1990er Jahre stattfindenden Umgestaltungsprozess.

Aus der Grundgesamtheit sollen gemäß der Varianz auf der UV in dieser Arbeit die Fälle Georgien und Mazedonien miteinander verglichen werden. Beide Länder sind Adressaten der EU-Konditionalität; während aber Mazedonien eine Beitrittsperspektive besitzt und offizieller EU-Beitrittskandidat ist, bietet die EU Georgien bisher keine Beitrittsperspektive und verweigert Georgien somit ihren stärksten Anreiz.

Sowohl Georgien als auch Mazedonien eignen sich in besonderer Weise für einen Vergleich, da sowohl ein demokratischer westlicher Balkan als auch ein demokratischer Südkaukasus für die EU von großem Interesse sind. Beide Regionen grenzen spätestens seit der Erweiterung von 2007 an die EU und werden von dieser als Sicherheitsrisikozone definiert. Auf dem Balkan und im Südkaukasus nicht nur Stabilität, sondern auch gefestigte Demokratien zu schaffen, trägt somit aus Sicht der EU ebenfalls zur Stärkung der eigenen Sicherheit bei ${ }^{107}$. Hiervon zeugt nicht nur die Gewährung einer potentiellen Beitrittsperspektive für alle Länder des westlichen Balkans, sondern auch die Entwicklung und Etablierung der Europäischen Nachbarschaftspolitik, die insbesondere dazu dienen soll, Nachbarländer ohne eine Beitrittsperspektive an die EU zu binden und die Werte der EU dort zu verankern, um so eine Art Pufferzone um die EU zu schaffen. Die Untersuchung der gewählten

\footnotetext{
106 Sowohl die zentralasiatischen Staaten - aufgrund ihres spezifischen historischen und kulturellen Entwicklungsverlaufs - als auch die bereits 2004 bzw. 2007 in die EU aufgenommenen Länder aufgrund ihres bereits vollzogenen Beitritts - sind hier ausgeklammert. Obwohl die Vergleichsmöglichkeit der bereits der EU beigetretenen Länder mit den jetzigen Adressaten einer EUKonditionalitätspolitik im Prinzip gegeben ist, sollen diese Länder gerade in Hinblick auf den gewählten Untersuchungszeitraum von 2000-2007 und die in diesem Zeitraum bereits erhaltene EUMitgliedschaft nicht in die Grundgesamtheit integriert werden. Auch Bosnien-Herzegowina (aufgrund des Semi-Protektorats der internationalen Gemeinschaft) und Belarus (aufgrund der Abwesenheit vertraglich geregelter Beziehungen zwischen der EU und Belarus) eignen sich nicht für eine Inklusion in die Grundgesamtheit.

${ }^{107}$ European Security Strategy 2003.
} 
Franziska Smolnik: Zwischen Anspruch und Wirklichkeit: Die EU-Konditionalität als Demokratisierungsinstrument. Eine Studie zur externen Demokratieförderung an den Beispielen Georgien und Mazedonien

Fälle kann somit auch dazu beitragen, eine Einschätzung zu erhalten, inwieweit die außenpolitischen Strategien der EU ihre selbst gesetzten Ziele erreichen.

Zur Bearbeitung der Fragestellung werden sowohl Primär- als auch

Sekundärliteratur bzw. -daten ausgewertet. Der in dieser Arbeit untersuchte Zeitraum erstreckt sich von 2000 bis 2007. Obwohl das Partnerschafts- und Kooperationsabkommen zwischen der EU und Georgien bereits 1999 in Kraft trat soll der Untersuchungszeitraum dennoch mit dem Jahr 2000 beginnen, da seit dem Europäischen Rat in Feira 2000 die Staaten des westlichen Balkans - und somit auch Mazedonien - offiziell den Status potentieller Beitrittskandidaten besitzen.

\section{Der Fall Mazedonien}

\subsection{Mazedonien und die Reformanreize der EU}

Mazedonien ${ }^{108}$ unterhält seit 1996 vertragliche Beziehungen mit der EU. Während das damals abgeschlossene Abkommen und auch das 1997 unterzeichnete Kooperationsabkommen noch keine Beitrittsperspektive beinhalteten, änderte sich dies im Jahr 1999. In ihrer Kommunikation an den Rat der Europäischen Union und das Europäische Parlament vom 26.05.1999 hält die Europäische Kommission fest, dass im Rahmen des Stabilisierungs- und Assoziierungsprozesses den Staaten des westlichen Balkans eine Beitrittsperspektive zusteht ${ }^{109}$. Insbesondere seit dem Zusammentreffen des Europäischen Rats in Feira vom 19. und 20.06.2000 genießen alle Staaten des westlichen Balkans offiziell den Status potentieller Beitrittskandidaten $^{110}$. Bestätigt wurde dies sowohl auf dem Zagreber Gipfeltreffen vom 24.11.2000 als auch dem Gipfeltreffen in Thessaloniki vom 16.06.2003. So heißt es in der Zagreber Abschlusserklärung der EU- Regierungs- bzw. Staatschefs:

\footnotetext{
"In this context, the way is now open to all the countries of the region [Anm... Western Balkans] to move closer to the European Union as part of the stabilization and association process [...]. It reaffirms the European perspective of the countries participating in the stabilization and association process and their status as potential candidates for membership in accordance with the Feira conclusions. "'111
}

\footnotetext{
${ }^{108}$ Im Folgenden wird der Name Mazedonien für das aufgrund eines bis heute nicht beigelegten Namenstreits mit Griechenland sowohl bei der EU als auch den UN offiziell unter dem provisorischen Namen Former Yugoslav Republic of Macedonia (FYROM) geführten Landes verwendet.

${ }^{109}$ Europäische Kommission 1999: 4ff.

110 Europäisches Parlament 2000.

${ }^{111}$ Europäische Kommission 2000.
} 
Franziska Smolnik: Zwischen Anspruch und Wirklichkeit: Die EU-Konditionalität als Demokratisierungsinstrument. Eine Studie zur externen Demokratieförderung an den Beispielen Georgien und Mazedonien

In Zagreb wurde außerdem deutlich gemacht, dass der Übergang von einem potentiellen Beitrittskandidaten zu einem regulären Beitrittskandidaten davon abhängt, inwieweit die Länder die Kopenhagen-Kriterien ${ }^{112}$ von 1993 erfüllen, welche bereits die Richtlinie für die ostmitteleuropäischen Beitrittskandidaten waren. In der Thessaloniki-Agenda ${ }^{113}$ für den westlichen Balkan wiederum wird betont, dass die Integration der Länder des westlichen Balkans in die Strukturen der Europäischen Union sowie letztlich die EU-Mitgliedschaft dieser Länder für die EU eine hohe Priorität besitzen, wobei der Reformerfolg der Länder die Geschwindigkeit der Anbzw. Einbindung an/in die europäischen Strukturen bestimmt.

Mazedonien schließt als erstes der Westbalkanländer ein Stabilisierungs- und Assoziiierungsabkommen $(S A A)^{114}$ mit der EU ab. Mit der Unterzeichnung des Abkommens im April 2001 wird die Assoziierung Mazedoniens an die EU besiegelt; in Kraft tritt das Abkommen allerdings erst im April 2004. Bereits im März 2004 hat die mazedonische Regierung einen Antrag auf Mitgliedschaft bei der EU eingereicht, nachdem als erstes Land des westlichen Balkans bereits Kroatien seinen Antrag 2003 übermittelte. Am 16.12.2005 verleiht der Europäische Rat Mazedonien offiziell den Status eines Beitrittskandidaten ${ }^{115}$. Neben Kroatien ist Mazedonien damit das einzige Land des westlichen Balkans, das nicht nur über eine generelle Beitrittsperspektive verfügt, sondern bereits offiziell Beitrittskandidat der EU ist, auch wenn noch keine Beitrittsverhandlungen stattgefunden haben.

\subsection{Adaptionskosten Mazedoniens}

Untersucht man die mazedonischen Regierungsparteien bezüglich des zugrunde liegenden Parteityps, so lässt sich feststellen, dass zwar alle Regierungsparteien an ethnischen Cleavages ausgerichtet sind und sich entsprechend in ethnisch albanische und ethnisch mazedonische Parteien einteilen lassen ${ }^{116}$, dies allerdings nicht

\footnotetext{
112 Die Kopenhagen-Kriterien wurden 1993 beim Kopenhagener Gipfeltreffen als Aufnahmebedingungen für die OME festgelegt. Zu den Kriterien zählen die Bereitschaft, die Regeln des aquis communitaire zu übernehmen, tragfähige demokratische Institutionen, Rechtsstaatlichkeit, Menschenrechte, Respekt und Schutz ethnischer Minderheiten sowie eine funktionierende Marktwirtschaft (Börzel/ Risse 2004: 10).

113 Thessaloniki-Agenda für den westlichen Balkan 2003.

114 Rat der Europäischen Union 2001.

115 Rat der Europäischen Union 2006.

116 Zwar bezieht sich der Staatsname Mazedonien auf die größte Bevölkerungsgruppe der Mazedonier, es handelt sich bei der Republik Mazedonien aber um einen ethnisch gemischten Staat. Neben den
} 
Franziska Smolnik: Zwischen Anspruch und Wirklichkeit: Die EU-Konditionalität als Demokratisierungsinstrument. Eine Studie zur externen Demokratieförderung an den Beispielen Georgien und Mazedonien

Ausdruck ihres programmatischen Charakters, sondern vielmehr der die Parteien beherrschenden ethnisch organisierten Klientelsysteme ist. Auch die seit 1992 bestehende Tradition, dass die Regierung aus einer Koalition mindestens je einer ethnisch mazedonischen und ethnisch albanischen Partei besteht, darf nicht in erster Linie als fortschrittliches Power-Sharing zwischen den Ethnien verstanden werden, sondern ist auf die Dominanz der Klientelparteien zurückzuführen. Wie schon zur Zeit des Sozialismus hat der mazedonische Staat wirtschaftliche wie politische Chancen und Macht monopolisiert, die von den Mitgliedern der regierenden klientelistisch organisierten Parteien - welche als Patronagesysteme fungieren appropriiert werden. Die Aufnahme mindestens einer ethnisch albanischen Partei in die Regierung hat dementsprechend lediglich dazu geführt, dass eine Teilgruppe der Albaner in das staatliche Patronagenetz integriert worden ist ${ }^{117}$. Wie bereits die ethnisch mazedonischen Parteien spalteten sich daraufhin auch die albanischen Parteien in verschiedene, gegenseitig um Einfluss konkurrierende Klientelsysteme auf. Die Verfahrensweise, je eine ethnisch-mazedonische und eine ethnischalbanische Partei in einer Regierungskoalition zu vereinen, bleibt auch weiterhin wichtig, da die fehlende Herrschaftslegitimität über die Vergabe von Ämtern und Vorteilen kompensiert werden muss. Wie im Abschnitt zur Bedingungsvariable der Adaptionskosten dargelegt wurde, erklärt das System der Klientelparteien und Patronagenetze in Mazedonien verschiedene Besonderheiten der Parteienlandschaft: So ändern die Regierungsparteien ihre politischen Positionen oft und radikal, um möglichst lange an der Macht teilzuhaben; ideologische oder programmatische Konsequenz ist dagegen weniger wichtig. Daneben findet nach Wahlen eine umfassende Neubesetzung der politischen und administrativen Ämter statt, um die eigene Klientel zufrieden zu stellen. Außerdem ist die Parteienlandschaft

(vorwiegend orthodoxen) Mazedoniern (64,18\%) lebt eine große (vorwiegend muslimische) albanische Minderheit in Mazedonien (25,17\%); außerdem gibt es noch verschiedene kleinere Gruppen. Die Angaben beziehen sich auf den aktuellsten Zensus von 2002 (Oschlies 2003).

117 Robert Hislope geht so weit, dass er die Regierungskoalition zwischen der ethnisch mazedonischen Partei Innere Makedonisch Revolutionäre Organisation - Demokratische Partei für die Makedonische Nationale Einheit und der ethnisch albanischen Demokratischen Partei der Albaner als eine Koalition einstuft, ,that cynically distributed the spoils of office, de facto divided the territory into personal fiefdoms [...]" (Hislope 2003). 
Franziska Smolnik: Zwischen Anspruch und Wirklichkeit: Die EU-Konditionalität als Demokratisierungsinstrument. Eine Studie zur externen Demokratieförderung an den Beispielen Georgien und Mazedonien

sehr fragmentiert, da sich einzelne Politiker immer wieder von ihrer Partei lossagen und ihre eigene Partei und somit ihr eigenes Klientelnetz gründen ${ }^{118}$.

Die ethnische Komponente der Regierungsparteien und die traditionell gemischte Regierungskoalition ist dabei auch in Bezug auf das friedliche Zusammenleben der Ethnien von Bedeutung ${ }^{119}$. Die Einbindung ethnisch albanischer und ethnisch mazedonischer Parteien in der Regierung stellt eine - wenn auch äußerst fragile Balance zwischen den Partizipationsforderungen der albanischen Bevölkerung einerseits und den Forderungen der sich als Titularnation begreifenden Mazedonier andererseits dar. Das Arrangement lässt allerdings eine Zwickmühle für die beteiligten Regierungsparteien erkennen, da sie zwar in Hinblick auf ihre jeweiligen Wähler Standhaftigkeit gegenüber den Forderungen des jeweiligen Koalitionspartners zeigen müssen, eine tatsächliche Radikalisierung aber niedergehalten werden muss, da dies die Koalition und somit auch die eigenen Möglichkeiten zur Abschöpfung der staatlichen Ressourcen gefährdet. Diese Problematik wird noch dadurch verschärft, dass es, wie beschrieben, mehrere ethnisch ausgerichtete Klientelparteien gibt, die ihrerseits an den staatlichen Töpfen teilhaben möchten. Die Fragilität des interethnischen Friedens macht ein Artikel von Transitions Online exemplarisch anhand der ethnisch albanischen Partei Democratic Union of Integration (BDI) deutlich:

\footnotetext{
"Its fiery rhetoric notwithstanding, the BDI understands its role to be primarily about channelling benefits to its constituents through the control of certain ministries. [...] But as soon as it is no longer able to dole out jobs and subsidies, it may well revert to ethnic politics in order to preserve its role as the leading party of Macedonia's Albanians, which would make this a pivotal moment in the relationship between the central government and the Albanian minority. ${ }^{120}$ ",
}

In diesem Zusammenhang ist auch der Ausbruch von Gewalt 2001 zu betrachten. Im Frühjahr dieses Jahres kam es zu kämpferischen Auseinandersetzungen zwischen albanischen Guerilla-Truppen und mazedonischen Polizei- und Sicherheitskräften. Erst nach 8 Monaten konnten die Ausschreitungen unter internationaler Vermittlung beigelegt werden. Der Konflikt wurde im August 2001 mit dem Vertrag von Ohrid beendet, welcher mit Unterstützung der USA und der EU zwischen Mazedoniens

\footnotetext{
118 Je mehr allerdings der mazedonische Staat durch oftmals von außen herangetragene Forderungen nach Privatisierung an Möglichkeiten zur Verteilung von Pfründen verliert, desto mehr werden die Regierungsparteien kriminalisiert sowie wirtschaftliche und politische Macht miteinander verknüpft. Hensell 2003: 133f.; Hislope 2003.

119 Büchsenschütz 2001: $11 \mathrm{ff}$.

${ }^{120}$ Loza/Krauthamer/Gardner 2006: 2.
} 
Franziska Smolnik: Zwischen Anspruch und Wirklichkeit: Die EU-Konditionalität als Demokratisierungsinstrument. Eine Studie zur externen Demokratieförderung an den Beispielen Georgien und Mazedonien

größten Parteien - sowohl albanischen als auch mazedonischen - geschlossen wurde und weit reichende Reformen zur Gleichstellung der Albaner beinhaltete ${ }^{121}$. Während der Konflikt einerseits als Ausdruck der in Teilen der Bevölkerung vorhandenen ethnischen Feindseligkeiten verstanden werden kann, so ist er aber auch das Resultat einer Strategie albanischer Klientelsysteme, die untereinander um die Teilhabe an staatlichen Pfründen ringen. Durch ihre Radikalisierung gelang es mehreren Guerillakämpfern mit ihrer eigens gegründeten Partei an der Regierungskoalition beteiligt zu sein und somit Zugang zu staatlichen Ressourcen zu erhalten. ${ }^{122}$

\section{Zusammenfassung Adaptionskosten}

Wie gezeigt wurde, können die Adaptionskosten in Mazedonien für den gesamten Untersuchungszeitraum von 2000-2007 als hoch angenommen werden.

Ausschlaggebend ist hierfür die starke Dominanz von Klientelparteien, deren Machterhaltungs- und Bereicherungspraktiken von umfassenden politischen Reformen bedroht sind bzw. deren Existenzgrundlage entzogen würde. Das bewusste Changieren zwischen nationalistischer Härte einerseits und interethnischem Dialog andererseits ist insbesondere Garant für den Status als Regierungspartei. Würden also zum einen die Extraktionsmöglichkeiten und somit die Möglichkeit zur Verteilung von Pfründen bzw. zur Patronagepraxis aufgrund der Übernahme von EU-Regeln wegfallen, müssen die Regierungsparteien befürchten, dass sie sich ihre Unterstützung nicht mehr erkaufen können. Zum anderen bedeutetet eine EU forcierte transparente Gleichstellung der Ethnien auch, dass die im Werben um Wählerstimmen wichtige aggressiv nationalistische Rhetorik erheblich an Zugkraft verlieren würde und somit wiederum die eigene Macht gefährdet wäre.

\subsection{Asymmetrische Interdependenz}

\section{Größe, wirtschaftliche und militärische Stärke}

Mazedonien ist mit 2,06 Mill. Einwohnern und einer Größe von ca. 25000 km² (etwas mehr als die Fläche von Mecklenburg-Vorpommern) nach Montenegro das

\footnotetext{
${ }^{121}$ Kim 2005: 2f. Der Originaltext des Ohrider Abkommen lässt sich hier http://faq.macedonia.org/politics/ einsehen.

122 Hensell 2003: 143.
} 
Franziska Smolnik: Zwischen Anspruch und Wirklichkeit: Die EU-Konditionalität als Demokratisierungsinstrument. Eine Studie zur externen Demokratieförderung an den Beispielen Georgien und Mazedonien

zweitkleinste Land des westlichen Balkans. Obwohl Mazedonien am Knotenpunkt wichtiger Handelsrouten liegt, war es die ärmste Republik des ehemaligen Jugoslawien. Mazedonien verfügt über keine nennenswerten Rohstoffvorkommen; im Gegenteil verringert sich die Bedeutung des Bergbaus seit 1991 fortwährend ${ }^{123}$. Vergleicht man das Bruttoinlandsprodukt/Kopf von Mazedonien mit den entsprechenden Durchschnittsdaten für die EU-27 $7^{124}$ (Tabelle 1), so wird deutlich, wie sehr Mazedonien über den gesamten Untersuchungszeitraum hinweg der EU im wirtschaftlichen Bereich unterlegen ist bzw. auf welch niedrigem wirtschaftlichen Niveau es sich generell befindet. Auch wenn das BIP/Kopf von 2000-2007 eine positive Entwicklung verzeichnet so bleibt das BIP/Kopf dennoch auf einem äußerst niedrigen Stand. Zieht man als Vergleichsgruppe nicht die EU-27, sondern die EU15 heran, wird der Unterschied noch eklatanter. Auch die Länderklassifikation der Weltbank, die Mazedonien von 2000-2007 als lower-middle-income-country führt, spiegelt das geringe Niveau des mazedonischen BIP/Kopf wider ${ }^{125}$. Das durch den Vergleich der BIP-Daten gezeichnete Bild wird noch offensichtlicher, wenn man die Arbeitslosigkeitsstatistiken für Mazedonien und für die EU-27 bzw. EU-15 heranzieht (Tabelle 2). Die Arbeitslosenrate Mazedoniens bleibt über den gesamten Untersuchungszeitraum hinweg über der 30\% Marke und ist somit selbst für die Balkan-Länder sehr hoch. Insbesondere 2006 ist die Arbeitslosenrate Mazedoniens der 40\%-Marke sehr viel näher als der 30\%-Marke und relativiert somit die gering positive Entwicklung der BIP/Kopf-Daten.

Auch was die militärische Stärke angeht, ist Mazedonien als Fliegengewicht zu betrachten. Die Militärausgaben Mazedoniens sind gering, entsprechen allerdings der geographischen Größe und der Bevölkerungszahl (Tabelle 3). Nach einer vergleichsweise drastischen Erhöhung 2001 (auf \$325 Mill. oder 6,6\% des mazedonischen BIP dieses Jahres) im Zusammenhang mit den gewalttätigen Auseinandersetzungen pendelten sich die Militärausgaben auf ca. \$120-130 Mill. ein. Dass Mazedoniens militärische Stärke auch trotz einiger Reformen im Zuge einer Anpassung an NATO-Strukturen gering ist, zeigt sich dadurch, dass Mazedonien

\footnotetext{
123 Bundesagentur für Außenwirtschaft 2007.

124 Obwohl die Erweiterungen der EU erst 2004 und 2007 stattgefunden haben, sind die Daten entsprechend den jetzigen 27 EU-Mitgliedsländern berechnet.

125 World Bank 2007.
} 
Franziska Smolnik: Zwischen Anspruch und Wirklichkeit: Die EU-Konditionalität als Demokratisierungsinstrument. Eine Studie zur externen Demokratieförderung an den Beispielen Georgien und Mazedonien

lange Zeit nicht in der Lage war, seine Außengrenzen und die eigene territoriale Integrität zu sichern. Dies wird an den verschiedenen NATO-Missionen und der die NATO 2003 ablösenden EU-Mission Concordia deutlich, die auf Bitte der mazedonischen Regierung in Mazedonien stationiert waren, um die Sicherheitslage zu stabilisieren. Bis heute ist Mazedonien aus Kapazitätsgründen nicht in der Lage, eigenständig terroristische Bedrohungen oder Angriffe abzuwehren ${ }^{126}$.

\section{Mögliche Gegenmächte zur EU}

Neben der EU und ihren Mitgliedstaaten unterhält Mazedonien vor allem sehr gute Beziehungen zu den USA. Die USA sind auch das Land, das als mögliche Alternativmacht zur EU betrachtet werden muss. Eine weitere Großmacht, die als Gegenspieler zur EU denkbar wäre, ist Russland. Im Gegensatz zu Mazedoniens Nachbarn Serbien, das Russland vor allem in der Kosovo-Frage aber auch in wirtschaftlicher Hinsicht stark unterstützt, spielt Russland in Bezug auf Mazedonien aber keine nennenswerte Rolle.

Die USA sehen Mazedonien vor allem als einen Stabilitätsgaranten im westlichen Balkan und honorieren, dass Mazedonien sich bereit erklärt hat, die logistische Versorgung für die von der NATO geführte Kosovo Force (KFOR) zu beherbergen und NATO-Truppen im Rahmen der KFOR, darunter auch US-Soldaten, die Stationierung in Mazedonien zu ermöglichen. Gleichermaßen haben die USA Mazedonien bei der Modernisierungsreform des Militärs 2002-2007 und der damit verbundenen Anpassung an NATO-Standards stark unterstützt - sowohl finanziell als auch durch das Entsenden von Ausbildern und Experten ${ }^{127}$. Zu Beginn des IrakKrieges stellte sich Mazedonien sogleich auf die Seite der USA und bekräftigte damit die gute Zusammenarbeit ${ }^{128}$. Dies zeigte sowohl Mazedoniens Verbundenheit mit den USA - die vor allem aufgrund der NATO-Präsenz im eigenen Land als Frieden sichernde Kraft betrachtet wurden - als auch den Einfluss der USA auf das Land

\footnotetext{
126 Koneska 2007: 6f.

127 Kim 2005:11ff.

128 Als eines der 10 Länder der Vilnius-Gruppe (neben Mazedonien Albanien, Bulgarien, Kroatien, Estland, Lettland, Litauen, Rumänien, Slowakei und Slowenien. Diese Staaten schlossen sich 2000 zusammen, um gemeinsam ihren Beitritt zur NATO vorzubereiten) unterstützte Mazedonien zum Unmut Frankreichs und Deutschlands 2003 in einem öffentlichen Brief die Entwaffnung Saddam Husseins und trug so dazu bei, eine geschlossene Haltung der EU-Staaten in Bezug auf den Irak-Krieg zu unterminieren. Seit 2004 unterstützt Mazedonien außerdem die USA in Afghanistan und im Irak mit 48 bzw. 28 entsendeten Soldaten.
} 
Franziska Smolnik: Zwischen Anspruch und Wirklichkeit: Die EU-Konditionalität als Demokratisierungsinstrument. Eine Studie zur externen Demokratieförderung an den Beispielen Georgien und Mazedonien

deutlich. 2004 wurde diese Verbundenheit aus Sicht der Mazedonier noch einmal bekräftigt, als die USA sich im Namenstreit zwischen Griechenland und Mazedonien zur großen Verärgerung Griechenlands auf die Seite der Mazedonier stellten und das Land unter dem Namen Republik Mazedonien anerkannten ${ }^{129}$.

Dennoch stellen die Beziehungen zu den USA keine rivalisierende Position zur EUIntegration dar, denn die Beziehungen zwischen Mazedonien und den USA beschränken sich weitestgehend auf den militärischen Bereich; im wirtschaftlichen Bereich spielen die USA auch aus mazedonischer Perspektive nur eine geringe Rolle. Dies belegen die Zahlen der Import- und Exportbeziehungen zwischen Mazedonien und den USA bzw. der EU (Tabelle 4) ${ }^{130}$. Auch was die militärische Zusammenarbeit anbetrifft, so handelt es sich nicht um eine rivalisierende, sondern eine zur EUIntegration komplementäre Kooperation. So heißt es im Congressional Research ServiceBericht von 2005:

"The United States continues to support multilateral efforts to stabilize Macedonia, but has increasingly looked to the European Union to play a larger international role in the Balkans, starting with Macedonia". 131

Unter anderem wird dies daran deutlich, dass die EU die vormals durch NATOTruppen geführte Stabilität sichernde Mission in Mazedonien 2003 übernahm und die EU-Mission Concordia so als die erste EU-Militäroperation überhaupt einen wichtigen Baustein in der Europäischen Sicherheits- und Verteidigungspolitik darstellt. Mazedonien steht somit für ein positives Beispiel einer konstruktiven Zusammenarbeit zwischen der EU und den USA auf dem Balkan.

\section{Zusammenfassung Asymmetrische Interdependenz}

Aufgezeigt wurde eine stark asymmetrische Interdependenz zwischen der EU und Mazedonien zu Lasten Mazedoniens. Hierfür sprechen alle betrachteten Indikatoren. Vor allem die wirtschaftliche Schwäche Mazedoniens wird während des Untersuchungszeitraums nicht signifikant abgebaut. Auch das militärische Potential

\footnotetext{
${ }^{129}$ Die Anerkennung geschah wenige Tage vor einem von mazedonischen Nationalisten organisierten, umstrittenen Referendum im November 2004, das die im Rahmen des Ohrider Abkommens vorgesehene Neufestlegung der Gemeindegrenzen und eine damit verbundene Besserstellung der albanischen Minderheit verhindern sollte. Um die moderaten Kräfte im Land zu unterstützen, hat die USA den Namen Mazedonien unilateral anerkannt.

${ }^{130}$ Insgesamt rangieren die USA auf Platz 11 als Handelspartner weit hinter der EU auf Platz 1 mit einem Anteil am mazedonischen Handel von $48 \%$ vs. $1 \%$ (Eurostat 2008).

${ }^{131}$ Kim 2005: 2.
} 
Franziska Smolnik: Zwischen Anspruch und Wirklichkeit: Die EU-Konditionalität als

Demokratisierungsinstrument. Eine Studie zur externen Demokratieförderung an den Beispielen

Georgien und Mazedonien

Mazedoniens bleibt über den gesamten Untersuchungszeitraum hinweg äußerst gering. Als Gegenmacht zur EU kommen lediglich die USA in Frage, deren Rolle sich allerdings weitestgehend auf die Unterstützung Mazedoniens im sicherheitspolitischen Bereich beschränkt. Auch hier zeigt aber die Übertragung der Aufgaben an die EU durch die Übernahme der Militäroperation Concordia 2003, dass der Einfluss der USA zurückgeht. Im wirtschaftlichen Bereich stellen die USA dagegen keine Alternative zur EU dar.

\subsection{Grad der Rechtsstaatlichkeit}

Der Freedomhouse-Indikator zeigt, dass Mazedonien im Bereich der Rechtsstaatlichkeit generell eine positive Entwicklung zu verzeichnen hat (Tabelle 5). Während der Skalenwert für das Jahr 1999/2000 noch bei 4,25 Punkten lag, hat er sich bis 2007 auf 3,75 Punkte verbessert. Diese positive Entwicklung wurde allerdings unterbrochen - so weist der Indikator für das Jahr 2002 4,75 Punkte und somit das schlechteste Ergebnis im gesamten Untersuchungszeitraum auf. Dieser Rückgang im Bereich der Rechtsstaatlichkeit muss im Zusammenhang mit dem Konflikt von 2001 betrachtet werden; die folgenden Jahre weisen eine schrittweise Verbesserung der Indikatorwerte auf, wobei die Werte in den Jahren 2005-2007 bei 3,75 Punkten stagnieren.

Tabelle 5:

\section{Grad der Rechtsstaatlichkeit für Mazedonien}

Judicial Framework and Independence

\begin{tabular}{|l||r|r|r|r|r|r|r|r|}
\hline & $1999-2000$ & 2001 & 2002 & 2003 & 2004 & 2005 & 2006 & 2007 \\
\hline \hline Mazedonien & 4,25 & 4,25 & 4,75 & 4,5 & 4 & 3,75 & 3,75 & 3,75 \\
\hline
\end{tabular}

Quelle: Freedom House Nations in Transit 2007

Die zusätzliche Untersuchung der Justiz in Hinblick auf ihre Unabhängigkeit kann die numerischen Ergebnisse des Freedombouse-Indexes weiter erklären.

Zu Beginn des Untersuchungszeitraums weist der Justizbereich große Mängel auf. Neben der finanziellen Unterversorgung des Bereichs und des daraus resultierenden desolaten Zustands der Gerichte, einschließlich fehlender Computerausstattung, ungenügender Veröffentlichung neuer Gesetze, fehlender Weiter- und Ausbildungsmöglichkeiten und der - vor allem im Gegensatz zu Selbständigen - 
Franziska Smolnik: Zwischen Anspruch und Wirklichkeit: Die EU-Konditionalität als Demokratisierungsinstrument. Eine Studie zur externen Demokratieförderung an den Beispielen Georgien und Mazedonien

geringen Gehälter, ist insbesondere auch der politische Einfluss auf richterliche Entscheidungen, aber auch auf Karriereverläufe der Richter und Staatsanwälte zu bemängeln. Hierbei spielt der Republican Judicial Council (RJC) eine wichtige Rolle - ein Gremium, welches offiziell relativ unabhängig für die Ernennung, Entlassung und Beförderung von Richtern und Staatsanwälten verantwortlich ist, in der Praxis jedoch diese Aufgaben an die regierenden Parteien abgibt. Eine solche illegitime politische Einmischung ist auch bei richterlichen Entscheidungen zu verzeichnen, insbesondere dann wenn diese die Interessen einzelner Politiker oder Politikergruppen berühren ${ }^{132}$. Im Jahr 2003 werden einige, wenn auch nicht ausreichende Reformen durchgeführt. So wurde mit dem Law on Court Budget die Verantwortlichkeit für die Budgeterstellung und -verwaltung der Gerichte vom Justizministerium auf Vertreter des Gerichtswesens selbst übertragen. Führt dies auch nicht zwangsläufig zu einer besseren finanziellen Ausstattung, so trägt diese Neuerung dennoch dazu bei, die Unabhängigkeit der Gerichte zu stärken ${ }^{133}$.

Obwohl insbesondere die Mängel im Zusammenhang mit der Autonomie der Justiz von der Exekutive - hier vor allem die Politisierung des Gerichtswesens, ein fehlendes leistungsbezogenes Ernennungs- und Beförderungssystem, fehlende Transparenz - in den Berichten der EU angesprochen werden und eine Reform in diesen Bereichen als äußerst dringend angemahnt wird, gibt es hier 2003 keine positiven Erfolge zu verzeichnen. Für den gesamten Bereich der Justiz wird Mazedonien von der EU nur eine sehr langsame Reformgeschwindigkeit zugesprochen, obwohl sie in früheren Fortschrittsberichten mehrmals ausdrücklich eine umfassende Justizreform mit dem Ziel einer größeren Unabhängigkeit als zentrales Element einer EU-Angleichung gefordert hatte ${ }^{134}$.

Das Jahr 2004 weist leichte Fortschritte im Justizbereich auf. So wurde beispielsweise Ende 2004 ein Strategie- und Aktionsplan zur Justizreform ${ }^{135}$ vorgestellt, der vor allem zur Verbesserung der Unabhängigkeit und Effizienz der Justiz beitragen soll und somit die Forderungen der EU aufnimmt. Die hierfür notwendigen Verfassungsänderungen wurden im Herbst 2005 verabschiedet; dies bedeutet

\footnotetext{
132 American Bar Association 2002.

133 American Bar Association 2003: $15 f$.

134 Europäische Kommission 2004: 8.

135 The Reform of the Judicial System in the Republic of Macedonia 2005.
} 
Franziska Smolnik: Zwischen Anspruch und Wirklichkeit: Die EU-Konditionalität als Demokratisierungsinstrument. Eine Studie zur externen Demokratieförderung an den Beispielen Georgien und Mazedonien

allerdings nicht gleichzeitig auch deren effektive Implementierung. Dennoch kann allein die Verabschiedung der Verfassungsänderungen ${ }^{136}$, die von einem breiten politischen Konsens getragen werden, als Erfolg gewertet werden, bilden sie doch den rechtlichen Rahmen, um die Unabhängigkeit der Justiz und deren Effizienz zu gewährleisten.

Obwohl notwendige rechtliche Reformen und Anpassungen durchgeführt wurden, gibt es weiterhin Probleme bei der tatsächlichen Umsetzung. So konnten sich die politischen Vertreter im Parlament 2006 weder auf einen Direktor der gegründeten Juristischen Akademie noch auf die Ernennung der Staatsanwälte oder auf die Zusammensetzung des RJC einigen ${ }^{137}$. Auch 2007 war der Reformeifer, der durch die Verabschiedung des Strategie- und Aktionsplans suggeriert wurde, nicht nachhaltig. Die geplante Aus- und Weiterbildungsakademie konnte zwar ihre Arbeit aufnehmen und die neue Gerichtsstruktur wurde graduell etabliert, in Bezug auf den RJC gab es allerdings kaum Erfolge zu vermelden. Auch wenn der RJC den Kampf gegen Korruption und Befangenheit aufnahm, so kam es auch 2007 nicht zur Besetzung aller Mitgliedspositionen, was die Handlungsfähigkeit des Gremiums nach wie vor einschränkt ${ }^{138}$. Auch die Unterfinanzierung der Justiz besteht weiterhin als Problem fort und trägt zur Beeinträchtigung der Unabhängigkeit der Justiz bei.

Die nähere Betrachtung des Justizbereichs bezüglich seiner Unabhängigkeit bestätigt also den Trend, der durch den Freedomhouse-Index abgebildet wurde. Während legislative Anpassungen relativ schnell vollzogen werden konnten, scheitert es oftmals an deren tatsächlicher Implementierung. Insbesondere solche Maßnahmen, die den Einfluss der Politik stark beschneiden, wenn nicht unmöglich machen würden, werden aufgrund offensichtlich fehlenden politischen Willens nicht umgesetzt bzw. durchgeführt. Die Unabhängigkeit der Justiz hat sich daher zwar analog zum Freedomhouse-Indikator über den Untersuchungszeitraum hinweg verbessert, Schwachstellen bleiben allerdings bestehen.

\footnotetext{
136 Zu diesen Änderungen gehört die Etablierung spezieller Gerichte zur Bearbeitung von Fällen der organisierten Kriminalität und die Einrichtung eines separates Verwaltungsgerichts, das den Obersten Gerichtshof entlasten soll. Zudem werden die Zusammensetzung und die Aufgaben des RJC geändert, um dessen Unabhängigkeit zu gewährleisten. Ebenso wurde die Etablierung einer Aus- und Weiterbildungsakademie vereinbart, um ein nach Leistungskriterien arbeitendes Ernennungs- und Beförderungssystem zu etablieren.

137 Europäische Kommission 2006: 43.

${ }^{138}$ Europäische Kommission 2007: 10.
} 
Franziska Smolnik: Zwischen Anspruch und Wirklichkeit: Die EU-Konditionalität als Demokratisierungsinstrument. Eine Studie zur externen Demokratieförderung an den Beispielen Georgien und Mazedonien

\subsection{Mazedonien - Interaktion der Variablen}

Wie beschrieben ist Mazedonien seit 2000 ein potentieller EU-Beitrittskandidat, 2005 wurde es von der EU als offizieller Beitrittskandidat anerkannt. Die Integration in die EU ist dabei über den gesamten Untersuchungszeitraum hinweg ein die Mazedonier einendes Ziel, das unabhängig von ethnischer Zugehörigkeit, politischer Ausrichtung und sozialer Gruppe vertreten wird. Auch die politischen Parteien sehen in der EUIntegration eine Priorität ${ }^{139}$. Besonders deutlich wurde die hohe Akzeptanz der EU auch im Eurobarometer von $2007^{140}$, das erstmals die mazedonische Bevölkerung einbezieht. 87\% der Befragten gaben an, dass sich eine EU-Mitgliedschaft positiv auf ihr Leben auswirken würde. Die Autoren des Eurobarometers schließen daraus auf ein äußerst offenes und Reform unterstützendes Klima in Mazedonien. Dabei assoziieren die Mazedonier mit der EU neben der Freizügigkeit vor allem wirtschaftlichen Aufschwung und Frieden. Die allgemein hohe Zustimmung in Mazedonien zur EU-Integration scheint insofern in engem Zusammenhang zur Schwäche Mazedoniens und somit auch im Zusammenhang mit der stark asymmetrischen Interdependen₹ zu Lasten Mazedoniens gegenüber der EU zu stehen. Da die EU-Integration als Heilmittel vor allem gegen die wirtschaftliche, aber auch sicherheitspolitische Schwäche Mazedoniens gesehen wird, und zwar auf sämtlichen Ebenen der Bevölkerung und quer durch die (Regierungs-)Parteien, unterstützt die stark asymmetrische Interdependenz eine Reform begünstigende Atmosphäre und verstärkt somit den Anreiz der Beitrittsperspektive.

Die - bedingt durch die asymmetrische Interdependen z - auch von den Regierungsparteien geäußerte Zustimmung zum EU-Integrationsprozess und die daraus resultierende proklamierte Unterstützung der Reformen spiegelt sich ebenfalls in der weitestgehend positiven Entwicklung des Rechtsstaatlichkeitsgrads wider. Auch wenn der Wert des Freedombouse-Indikators für das Jahr 2002 zunächst eine vergleichsweise starke Verschlechterung im Bereich der Rechtsstaatlichkeit aufweist, so kann dies nicht direkt auf eine fehlende Wirkung des 2001 abgeschlossenen Stabilisierungs- und Assoziizerungsabkommens bzw. auf eine allgemeine Einflusslosigkeit der Aussicht auf eine EU-Mitgliedschaft zurückgeführt werden. Wie bereits erläutert,

139 Siehe hierzu Malesko/Maleska 2005.

${ }^{140}$ Europäische Kommission 2007a. 
Franziska Smolnik: Zwischen Anspruch und Wirklichkeit: Die EU-Konditionalität als Demokratisierungsinstrument. Eine Studie zur externen Demokratieförderung an den Beispielen Georgien und Mazedonien

muss dieser Einbruch in enger Abhängigkeit zu dem gewaltsamen Konflikt von 2001 gesehen werden. Das damals vermittelte Abkommen von Ohrid beinhaltete ebenso wie das $S A A$ Forderungen, deren Umsetzung für eine weitere Integration in europäische Strukturen Voraussetzung sind. Dass sich diese Forderungen allerdings im Gegensatz zum $S A A$ und den weiteren Auflagen der EU in Hinblick auf eine Integration in europäische Strukturen vornehmlich auf die Verbesserung der Gleichstellung der ethnischen Gruppen beziehen und Reformen im Bereich der Justiz ausklammern, ist ein Grund dafür, dass die Fortschritte in diesem Bereich zunächst wenig beachtlich sind. Die mazedonischen Anstrengungen konzentrierten sich mithin - zumindest vordergründig - zunächst auf die Umsetzung der Ohrider Forderungen ${ }^{141}$. Obgleich die Unterzeichnung des $S A A$ in Bezug auf die Rechtsstaatlichkeit und insbesondere auf den Justizbereich keine sich zeitlich unmittelbar niederschlagenden Ergebnisse hervorbrachte ${ }^{142}$, so erwies sich das Abkommen dennoch als wichtiges Signal einer weiterhin für Mazedonien offenen EU, welches der mazedonischen Führung auch über das Jahr 2001 hinaus die Möglichkeit gibt, eine breite Unterstützung für die zu implementierenden Reformen - auch in Bezug auf eine Verbesserung der Rechtstaatlichkeit - zu gewinnen. Wie bereits die Unterzeichnung des $S A A$, so muss auch die Gewährung des Kandidatenstatus 2005 als ein wichtiger Reformmotor gesehen werden ${ }^{143}$. Dass die Beitrittsperspektive der EU für Reformen zur Verbesserung der Rechtsstaatlichkeit und speziell auch für Reformen in Bezug auf die Unabhängigkeit der Justiz verantwortlich ist, wird besonders durch die Reaktion auf anstehende oder bereits veröffentlichte Fortschrittsberichte und EU-Abkommen deutlich ${ }^{144}$. So kam es beispielsweise noch vor Einreichen des offiziellen Beitrittsgesuchs im Frühjahr 2004 zur Verabschiedung des Law on Court Budget, während die Verabschiedung des Strategie- und Aktionsplans zur Justizreform schon im Zusammenhang mit der anstehenden EU-Entscheidung bezüglich des Beitrittsgesuchs gesehen werden muss. Der Strategie- und Aktionsplan bezieht sich explizit auf die EU-Mitgliedschaftsambitionen Mazedoniens und die zu erfüllenden Kopenhagener Kriterien sowie die im $S A A$ und den Fortschrittsberichten

\footnotetext{
${ }^{141}$ International Crisis Group 2006: 4.

142 Wobei der Unterzeichnung des $S A A$ durchaus auch ein konkreter Einfluss - bei der Beendigung der gewaltsamen Auseinandersetzungen im Sommer 2001 - zugesprochen wird (Lungescu 2006).

143 Siehe hierzu Ernst 2001: 5; Ernst 2005: 3.

144 International Crisis Group 2006: 5.
} 
Franziska Smolnik: Zwischen Anspruch und Wirklichkeit: Die EU-Konditionalität als

Demokratisierungsinstrument. Eine Studie zur externen Demokratieförderung an den Beispielen

Georgien und Mazedonien

niedergelegten Forderungen. Da die EU mehrfach deutlich gemacht hat, dass gerade Verbesserungen im Bereich der Justiz für eine nähere An- bzw. Einbindung in europäische Strukturen unabdingbar sind, wird die Justizreform ${ }^{145}$ - zumindest offiziell - zur Priorität der mazedonischen Führung und ist somit wohl mit dafür verantwortlich, dass noch kurz vor der Entscheidung des Europäischen Rats im Dezember 2005 über die Gewährung eines offiziellen Beitrittskandidatenstatus die im Strategieplan vorgeschlagenen Gesetzesänderungen im Herbst 2005 verabschiedet wurden. Auch die Ende 2007 erneut zunehmende Aktivität bei der Besetzung der noch offenen Stellen des RJC ist im Zusammenhang mit dem schlechten Zeugnis in Form des EU-Fortschrittsberichts 2007 und der für 2007 erhofften, aber ausgebliebenen Einladung zur Aufnahme von Beitrittsverhandlungen von Seiten der EU zu sehen ${ }^{146}$.

Wichtig für den positiven Einfluss der EU-Beitrittsperspektive ist allerdings, das wird hieraus auch ersichtlich, nicht nur die generell proklamierte EU-Perspektive für die Länder des westlichen Balkans, sondern auch die schrittweise Konkretisierung dieser Option, beispielsweise durch die Unterzeichnung des $S A A$, die Ernennung zum offiziellen Beitrittskandidaten oder auch das Abkommen zur Visaerleichterung, das im September 2007 unterzeichnet wurde. Dies bedeutet im Umkehrschluss aber auch, dass ein Ausbleiben solch konkreter Schritte den Reformprozess verlangsamen, wenn nicht sogar gefährden könnte. Darüber hinaus birgt die Ausrichtung der Reformen an solchen Stichterminen die Gefahr, dass Gesetze zwar eilig verabschiedet werden, ohne allerdings ihre tatsächliche Umsetzung zur Folge bzw. ohne überhaupt die Umsetzbarkeit der Beschlüsse einbezogen zu haben ${ }^{147}$. Bereits im vorangestellten Kapitel kristallisierte sich allerdings heraus, dass nicht nur die Eile der Gesetzesänderungen für eine fehlende oder unzureichende Implementierung verantwortlich ist, sondern sich Verzögerungen oder gar Stillstand bei den Reformen vor allem aufgrund fehlenden politischen Willens einstellen. Gerade den Gesetzesänderungen, die sich auf besonders politisierte Bereiche beziehen und deren erfolgreiche Umsetzung den Einfluss der regierenden politischen Parteien beschneiden würden, fehlte die politische Unterstützung. Wie beispielsweise

145 The Reform of the Judicial System in the Republic of Macedonia 2005.

146 Southeast European Times 2007.

147 Siehe hierzu auch Kleppmann/ Divjakoski 2007: 6. 
Franziska Smolnik: Zwischen Anspruch und Wirklichkeit: Die EU-Konditionalität als Demokratisierungsinstrument. Eine Studie zur externen Demokratieförderung an den Beispielen Georgien und Mazedonien

im Zusammenhang mit der Ernennung des Direktors der neu eingerichteten Juristischen Akademie oder der Besetzung der Mitgliedsposten des reformierten RJC besonders deutlich wurde, scheinen hier die Adaptionskosten in Form eines Machtverlusts für die regierenden klientelistisch organisierten Parteien bedeutend. Erwartete Machteinbußen aufgrund eingeschränkter bzw. wegfallender Extraktionsund Verteilungsmöglichkeiten scheinen hier den positiven Einfluss der EUBeitrittsperspektive zu verringern ${ }^{148}$.

\section{Der Fall Georgien}

\subsection{Georgien und die Reformanreize der EU}

Georgien und die EU unterhalten seit 1992 bilaterale Beziehungen, die seit 1999 durch ein Partnerschafts- und Kooperationsabkommen (PKA) ${ }^{149}$ geregelt werden. Dieses Abkommen dient als rechtlicher Rahmen für die Zusammenarbeit zwischen der EU und Georgien, das neben der Intensivierung der wirtschaftlichen Kooperation auch die Festigung der demokratischen Institutionen und der Rechtsstaatlichkeit in Georgien sowie eine Annäherung georgischen Rechts an den Acquis der EU zum Ziel hat. Dabei wird bereits in der Präambel die Wichtigkeit von Demokratie, Rechtsstaatlichkeit und der Menschenrechte betont sowie deren Einhaltung in Artikel 2 als Fundament des Abkommens verpflichtend gemacht ${ }^{150}$. Im Gegenzug bietet das Abkommen weitreichende Möglichkeiten für eine engere wirtschaftliche Kooperation und die Gewährung von finanziellen Mitteln. Auch in dem im Rahmen des PKA verabschiedeten Strategiepapier für 2002-2006 ${ }^{151}$ bzw. dem modifizierten Strategiepapier für 2003-2006 $6^{152}$ wird die Konditionalität der Leistungen hervorgehoben. Insbesondere das modifizierte Strategiepapier für 2003-2006 betont die Knüpfung von Hilfsgeldern und Unterstützung an die Durchführung von Reformen - vor allem in den Bereichen Regierungsführung (Governance),

\footnotetext{
148 Siehe hierzu auch International Crisis Group 2006: $5 \mathrm{f}$.

149 Partnerschafts- und Kooperationsabkommen zwischen der EU und Georgien 1999.

150 Ebd.: 5.

${ }^{151}$ Europäische Kommission 2001: 5ff.

152 Europäische Kommission 2003. Aufgrund der starken Verschlechterung der politischen Lage in Georgien 2001 und 2002 wurde außerhalb der eigentlichen Fristen ein modifiziertes

Länderstrategiepapier verabschiedet, welches der neuen Situation besser Rechnung tragen soll und für den Zeitraum von 2003-2006 konzipiert ist.
} 
Franziska Smolnik: Zwischen Anspruch und Wirklichkeit: Die EU-Konditionalität als Demokratisierungsinstrument. Eine Studie zur externen Demokratieförderung an den Beispielen Georgien und Mazedonien

Rechtsstaatlichkeit und Schutz der Menschenrechte; explizit soll das in das Abkommen eingebaute Instrument der Konditionalität effektiver genutzt werden ${ }^{153}$. Die im Rahmen der EU-Konditionalität für Georgien gebotenen Reformanreize reichen allerdings im Vergleich zu Mazedonien nicht bis zu einer Beitrittsperspektive. Weder das Rahmendokument PKA noch die Aufnahme Georgiens in die Europäische Nachbarschaftspolitik (ENP) und das Inkrafttreten des ENP-Aktionsplans ${ }^{154} 2006$ beinhalten die Aussicht auf eine EU-Mitgliedschaft. Zwar knüpft die ENP ebenso wie das PKA die nun konkretisierten Anreize an Reformfortschritte - wobei die Stärkung der Rechtsstaatlichkeit als erster Prioritätsbereich im georgischen ENPAktionsplan festgelegt ist - eine Beitrittsperspektive ist aber weiterhin ausgeklammert ${ }^{155}$.

\subsection{Adaptionskosten Georgiens}

Untersucht man die georgischen Regierungsparteien hinsichtlich ihres Parteityps, so lässt sich feststellen, dass sowohl unter Eduard Schewardnadze (im Untersuchungszeitraum von 2000 bis Ende 2003) als auch unter Michail Saakaschwili (im Untersuchungszeitraum von 2004 bis 2007) die dominanten Regierungsparteien ${ }^{156}$ durch eine starke Personalisierung gekennzeichnet sind. Die Regierungsparteien bilden sich in Georgien nicht aus der Gesellschaft entlang vorhandener Konfliktlinien (cleavages), sondern werden um einen charismatischen Führer bzw. einen kleinen Führungszirkel herum aufgebaut. Sowohl Schewardnadze als auch Saakaschwili stehen für diese Art Parteiführer und Parteityp. Da aber nicht die Parteiprogramme zählen, sondern hauptsächlich die Ausstrahlung der Führungspersönlichkeit, fehlt es den georgischen Regierungsparteien an eigenen, nur

\footnotetext{
153 Ebd.: 25.

${ }^{154}$ Europäische Kommission 2004a; Europäische Kommission 2006a. Obwohl Kritiker der ENP in der Schwerpunktsetzung auf eine Annäherung des jeweiligen Rechtsbestand an den Acquis der EU eine Verwässerung der Abgrenzung zwischen Erweiterungsstrategie und ENP sehen wollen, gibt es zum jetzigen Zeitpunkt keine offiziellen Angaben dazu, dass die ENP langfristig auch in eine EUMitgliedschaft mündet.

155 Europäische Kommission 2006a: 4ff.

156 Georgien zeichnet sich sowohl vor als auch nach 2003 durch ein dominantes politisches Parteiensystem aus. Dies bedeutet, dass es eine sehr starke Regierungspartei gibt, die aufgrund einer stark fragmentierten Opposition mit sehr begrenztem Einfluss selbst über große Machtbefugnisse verfügt. Die regierende Partei kontrolliert dabei die staatlichen Ressourcen, die Regierungsbehörden sowie den Verwaltungsapparat (Nodia/Scholtbach 2006: 110f.).
} 
Franziska Smolnik: Zwischen Anspruch und Wirklichkeit: Die EU-Konditionalität als Demokratisierungsinstrument. Eine Studie zur externen Demokratieförderung an den Beispielen Georgien und Mazedonien

von ihnen vertretenen Ideologien, mit denen sie sich voneinander abgrenzen könnten:
„Georgian political parties are identified and, in some cases, even equated with their leaders. Such has been the case for all major parties and especially for the ruling ones. [...] The predominance of persons over policies has undermined the need for clear political platforms. Parties are neither socially demanded, nor expected to present coherent programmes. [...] Thus voter choice is based on leader credibility rather than on programme credibility and feasibility." $" 157$

Da die Regierungsparteien also vor allem wegen ihres Parteiführers bzw. ihres Führungspersonals existieren und von diesen abhängen, verkraften sie einen Wechsel auf der Führungsebene in der Regel nicht, sondern lösen sich auf bzw. fallen in kleinere Parteien auseinander. Auch die Bürgerunion Schewardnadzes konnte die verlorenen Präsidentschaftswahlen im Herbst 2003, die zur so genannten Rosenrevolution führten, nicht überleben.

Dass es vor allem bei den georgischen Regierungsparteien keinen erfolgreichen Führungswechsel gegeben hat, sondern das Ende des Regierungsmandats auch das Ende der Partei bedeutete, lässt sich neben der starken Personalisierung der Partei allerdings auch auf den stark vorherrschenden Parteiklientelismus zurückführen. So baut die Führungspersönlichkeit bzw. der Führungszirkel unter Zuhilfenahme persönlicher Beziehungen und Netzwerke sowie durch die Verteilung von Pfründen den Einfluss der Partei aus ${ }^{158}$. Ideologische Gründe spielen kaum eine Rolle bei der Parteimitgliedschaft. Durch die Nutzung von Klientelstrukturen und die Sicherstellung der Loyalität der Klienten durch die Verteilung von Posten wird die Klientelpartei gestützt, die ihre Stellung wiederum zur persönlichen Selbstbereichung nutzt. Sowohl für die Ära Schewardnadze als auch für die Ära Saakaschwili sind eine starke Politisierung der Verwaltung, die Vergabe von Posten nicht nach meritokratischen Prinzipien ${ }^{159}$, sondern aufgrund persönlicher Beziehungen sowie eine Verquickung von Staat, Regierung, Partei und Beamtenapparat charakteristisch $^{160}$.

\footnotetext{
157 Transparency International Georgia 2007: 1.

158 Während die Bürgerunion Schewardnadzes als „Partei der Macht“ verschiedene Gruppen in sich vereinigt hat, ist Saakaschwilis Vereinte Nationale Bewegung wesentlich zentralisierter um eine kleine Führungsspitze unter Führung Saakaschwilis organisiert (Sigwart 2006: 40ff.)

${ }^{159}$ Mit Amtsantritts Saakaschwilis wurden nicht nur die Regierungsposten neu besetzt, sondern wie schon unter Schewardnadze fand auf Grundlage von Klientelbeziehungen eine umfangreiche Neuverteilung der Posten in öffentlichen Einrichtungen statt (International Crisis Group 2007: 15). 160 Reisner 2005: 14ff.
} 
Franziska Smolnik: Zwischen Anspruch und Wirklichkeit: Die EU-Konditionalität als Demokratisierungsinstrument. Eine Studie zur externen Demokratieförderung an den Beispielen Georgien und Mazedonien

Auf den Punkt gebracht lässt sich dieses System als ,winner takes all, loser looses all ${ }^{161 \text { “ }}$ beschreiben, da das Prinzip des Parteiklientelismus dazu führt, dass sich die Vertreter der Regierungspartei zwar auf Staatskosten bereichern, wenn sie aber eine Wahl verlieren, diese Privilegien an einen anderen Führungszirkel und entsprechende Klienten übergehen - wie es auch nach der Rosenrevolution geschah.

Wie in Mazedonien spielt auch in Georgien die klientelistische Organisation der Regierungsparteien eine wichtige Rolle im Zusammenhang mit der Wahrung des territorialen Status Quo. So nutzte Schewardnadze eine Strategie der Kooptation, um Separations- bzw. Autonomietendenzen - wie sie Anfang der 1990er Jahre zur defacto Abspaltung von Abchasien und Südossetien führten ${ }^{162}-\mathrm{zu}$ unterbinden und setzte sie als Ersatz für eine tatsächliche regionale Integrations- und Minderheitenpolitik ein. Neben der lange Zeit nur durch eine funktionale Allianz zwischen Schewardnadze und dem lokalen Führer Aslan Abaschidze vereitelten vollkommenen Abspaltung Adschariens ${ }^{163}$, band Schewardnadze insbesondere in der von Tbilisi relativ isolierten, mehrheitlich von ethnischen Armeniern besiedelten und an Armenien grenzenden Bergregion Javakhetien, aber auch in der an der Grenze zu Aserbaidschan liegenden, mehrheitlich von ethnischen Aseris bewohnten Provinz Kvemo-Kartli, einflussreiche lokale Clanfiguren in sein Klientelsystem ein. Er tauschte so Loyalität und die Unterbindung bzw. Zurückdrängung von, in der Bevölkerung durchaus vorhandenen, Autonomiebestrebungen gegen lukrative Abgeordnetenposten in Tbilisi ein ${ }^{164}$.

Was die ethnischen Minderheiten in Kern-Georgien ${ }^{165}$ anbetrifft, so fehlt ebenso wie bei Schewardnadze auch bei Saakaschwili eine fundierte Minderheitenpolitik. Auch Saakaschwili bedient sich der Kooptationsstrategie Schewardnadzes und kooperiert

\footnotetext{
161 Nodia/ Scholtbach 2006: 102.

162 Siehe hierzu Huber 2004: 37ff. Das während der Sowjetunion als autonomes Gebiet zur Georgischen Sozialistischen Sowjetrepublik gehörende Südossetien sowie die ehemals autonome Republik Abchasien spalteten sich im Zuge des Zusammenbruchs der Sowjetunion und der Errichtung eines unabhängigen georgischen Staats Anfang der 1990er Jahre von Georgien unter kriegerischen Auseinandersetzungen von Georgien ab.

163 Schewardnadze duldete die autoritäre Amtsführung bzw. Ausbeutung Abaschidzes in Adscharien, während Abaschidze im Gegenzug von einer vollkommenen Ablösung absah.

164 Abaschidze allerdings konnte aufgrund der Niederlage Schewardnadzes 2003 seine Vormachtstellung in Adscharien nicht aufrechterhalten und wurde mithilfe gesellschaftlichen aber auch militärischen Drucks im Frühsommer 2004 des Amtes enthoben und Adscharien wieder vollständig integriert.

165 Georgien ohne die abtrünnigen Republiken Abchasien und Südossetien.
} 
Franziska Smolnik: Zwischen Anspruch und Wirklichkeit: Die EU-Konditionalität als Demokratisierungsinstrument. Eine Studie zur externen Demokratieförderung an den Beispielen Georgien und Mazedonien

weiterhin mit den bereits unter Schewardnadze eingebundenen Clanchefs ${ }^{166}$. Zusätzlich zu dieser Strategie betreibt Saakaschwili eine „Georgisierung“ der Minderheiten-Regionen, indem ethnische Georgier angesiedelt werden bzw. hauptsächlich ethnische Georgier Stellen in den Lokal- und Regionalverwaltungen erhalten. Hierbei hilft eine Wahlbezirksaufteilung, die ethnische Georgier zu Lasten der Minderheiten bevorzugt und somit gegen das Gebot der Gleichheit des Stimmrechts aller Stimmberechtigten verstöß $\mathrm{t}^{167}$.

\section{Zusammenfassung Adaptionskosten}

Sowohl unter Schewardnadzes Bürgerunion als auch ab 2003 unter Saakaschwilis Vereinter nationaler Bewegung sind die Regierungsparteien stark personalisiert und klientelistisch organisiert. Sowohl aufgrund der Ausrichtung auf eine Führungspersönlichkeit als auch aufgrund der klientelistisch geprägten Regierungsführung ist das Überleben der Parteien mit dem Status als Regierungspartei verbunden; umfassende politische Reformen gefährden daher stark die institutionelle Macht der Regierungsparteien. Dass Kooptationsstrategien auch zur Unterdrückung von Autonomietendenzen eingesetzt werden bzw. eine integrierende Minderheitenpolitik ersetzen, begründet die Einschätzung, dass die Adaptionskosten für den gesamten Untersuchungszeitraum hoch sind, zusätzlich. Aus Sicht der Regierungsparteien bedeutet eine Regelübernahme nicht nur die direkte Bedrohung der eigenen Existenz, sondern auch einen indirekten Einflussverlust durch den Wegfall Kooptation bedingter Kontrolle.

\subsection{Asymmetrische Interdependenz}

\section{Größe, militärische und wirtschaftliche Stärke}

Georgien gehört ebenso wie Mazedonien zu den kleinen Ländern. Mit einer Fläche von knapp $70000 \mathrm{~km}^{2}$ ist es nur fast so groß wie Bayern, allerdings misst die

\footnotetext{
${ }^{166}$ Lohm 2006: 14f. Kooptation und Klientelismus spielen unter Saakaschwili ebenso in Bezug auf die abtrünnigen Republiken Südossetien und Abchasien eine Rolle, wenn auch das Bild hier komplexer ist. Während Saakaschwili einerseits bei der georgischen Bevölkerung mit dem Versprechen der Wiedereingliederung der abtrünnigen Republiken um Unterstützung wirbt und indirekt daran gemessen wird, so profitiert die Zentralregierung andererseits selbst von durch den Status Quo möglichen Schmuggel und Schattenwirtschaft (Sigwart 2006: 46f.).

${ }^{167}$ International Crisis Group 2006a: $10 f$.
} 
Franziska Smolnik: Zwischen Anspruch und Wirklichkeit: Die EU-Konditionalität als Demokratisierungsinstrument. Eine Studie zur externen Demokratieförderung an den Beispielen Georgien und Mazedonien

Bevölkerung lediglich ein Drittel des deutschen Bundeslandes; in Georgien leben 4,5 Mill. Menschen. Was die wirtschaftlichen Voraussetzungen angeht, so verfügt Georgien über sehr fruchtbares Ackerland und einige mineralische Bodenschätze; vor allem aber die geostrategisch günstige Lage zwischen den öl- und erdgasreichen Anrainerstaaten des Kaspischen Meeres und die sich daraus ergebende Stellung als Transitland für Gas und Öl nach Europa machen Georgien zu einem Rentierstaat und interessant für ausländische Investoren.

Vor allem durch das neue Image, das Georgien durch die westlich gebildete Elite der Rosenrevolution 2003 gewinnt, gelingt es Georgiens Führung, neues Vertrauen bei internationalen Gebern und Investoren aufzubauen ${ }^{168}$ und somit eine Verbesserung im wirtschaftlichen Bereich zu erzielen. Tabelle 6 zeigt, dass das BIP/Kopf ab 2003 eine konstant positive Entwicklung durchläuft, auch wenn das Niveau über den gesamten Untersuchungszeitraum hinweg äußerst niedrig ist. Die positive Entwicklung schlägt sich daher in der Länderklassifikation der Weltbank auch nur bedingt nieder, als Georgien ab 2003 nicht mehr als lower-income-country gilt, sondern von 2003-2007 in die Gruppe der lower-middle-income-countries fällt ${ }^{169}$. Besonders der Bau der BTC-Ölpipeline (2005 fertig gestellt) vom aserbaidschanischen Baku, über Tbilisi nach Ceyhan in der Türkei sowie die Baku-Tbilisi-Erzurum-Erdgaspipeline (2006 in Betrieb genommen) - ebenfalls von Aserbaidschan in die Türkei - ziehen viele Investoren an. Es sind vor allem diese Pipelines und die damit verbunden Direktinvestitionen, die Georgiens Wirtschaft in der Zeit nach der Rosenrevolution stärken ${ }^{170}$.Die wirtschaftliche Entwicklung ist allerdings nicht nur positiv, wie die Arbeitslosenstatistik zeigt. Tabelle 7 lässt sich entnehmen, dass sich die Arbeitslosenzahlen im Gegensatz zum BIP/Kopf um Untersuchungszeitraum verschlechtert haben.

Wie im wirtschaftlichen Bereich, so lässt sich auch was die militärische Stärke betrifft ein Unterschied zwischen der Regierungszeit von Schewardnadze und Saakaschwili feststellen. Während der Regierung Schewardnadze im Untersuchungszeitraum der

\footnotetext{
168 Während vor dem Jahr 2000 Georgiens marode Wirtschaft noch durch erhebliche internationale Fördergelder aufrechterhalten wird, verringern internationale Geber ihre Zahlungen ab 1999. 2002 suspendiert der IWF seine Finanzhilfen aufgrund der Nichteinhaltung von Auflagen, andere internationale Geber folgen (Papava 2006: 660).

169 World Bank 2007.

170 Reisner 2005: 25f.
} 
Franziska Smolnik: Zwischen Anspruch und Wirklichkeit: Die EU-Konditionalität als Demokratisierungsinstrument. Eine Studie zur externen Demokratieförderung an den Beispielen Georgien und Mazedonien

Arbeit (2000 bis Ende 2003) befindet sich das georgische Militär in einem sehr schlechten Zustand. Martina Huber fasst dies prägnant zusammen, wenn sie schreibt:

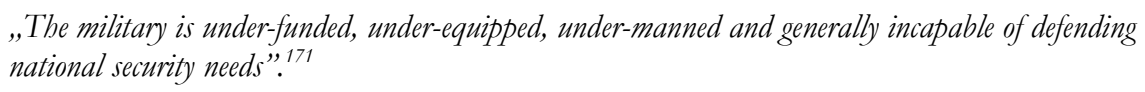

Allerdings sind nicht nur die georgischen Streitkräfte für die geringe militärische Stärke Georgiens während der Ära Schewardnadze verantwortlich. Zusätzlich zur geringen militärischen Kapazität befinden sich auf dem georgischen Gebiet mehrere Armeen, die nicht unter der Kontrolle der georgischen Zentralregierung stehen. Neben der separaten Armee Adschariens unterhalten auch die beiden abtrünnigen Republiken Südossetien und Abchasien ${ }^{172}$ eigene Streitkräfte. Des Weiteren sind russische Soldaten in Georgien stationiert: Zur Zeit Schewardnadzes unterhält Russland drei Militärbasen auf georgischem Gebiet, außerdem sind russische Soldaten im Rahmen der Peacekeeping-Missionen in Südossetien und Abchasien stationiert $^{173}$.

Nach der Rosenrevolution 2003 macht Saakaschwili die Reform der Streitkräfte zu einer der Prioritäten seiner Amtszeit. Dies wird besonders durch die drastisch erhöhten Militärausgaben deutlich (Tabelle 8). Wurden im Jahr 2000 nur ca. \$27 Mill. ausgegeben, so waren es $2005 \$ 230$ Mill., was eine Erhöhung von 0,6\% auf 3,5\% des georgischen BIP darstellt. Neben der deutlichen Erhöhung der Militärausgaben sprechen außerdem die Wiedereingliederung der adscharischen Armee im Zusammenhang mit der Reintegration Adschariens 2004 und die Überantwortung der russischen Militärbasen für eine Vergrößerung der militärischen Stärke unter Saakaschwili ${ }^{174}$. Russische Soldaten sind allerdings weiterhin in den abtrünnigen Republiken als Friedenskräfte stationiert. Daneben unterhalten Südossetien und Abchasien bis heute unabhängige Streitkräfte ${ }^{175}$.

\section{Mögliche Gegenmächte zur EU}

Nicht allein die EU ist ein wichtiger politischer Partner Georgiens. Vor allem die USA und traditionell Russland spielen im sicherheitspolitisch-militärischen sowie

\footnotetext{
171 Huber 2004: 42.

172 Die südossetischen Streitkräfte verfügen über ca. 2000 Mann, die achasischen über ca. 5000.

173 Siehe hierzu Devdariani 2005.

174 Die Kommandostelle in Tbilisi wurde bereits Ende 2006 geschlossen wurde, im Juni und November 2007 folgten die Schließungen der russischen Militärbasen in Achalkalaki und Batumi. ${ }^{175}$ Felgenhauer 2007.
} 
Franziska Smolnik: Zwischen Anspruch und Wirklichkeit: Die EU-Konditionalität als Demokratisierungsinstrument. Eine Studie zur externen Demokratieförderung an den Beispielen Georgien und Mazedonien

wirtschaftlichen Bereich für Georgien eine bedeutende Rolle. Mit den USA und Russland sind gleichermaßen auch die beiden Alternativmächte zur EU benannt, die im Folgenden näher betrachtet werden sollen.

Nicht erst seit 2001, aber insbesondere nach den Angriffen auf das World Trade Center engagieren sich die USA in Georgien. Die Befürchtung, dass das instabile Georgien $\mathrm{zu}$ einem Hort terroristischer Gruppierungen sowie der organisierten Kriminalität werden könnte, führt zu einem verstärkten militärischen Engagement der USAmerikaner. Das von 2002-2004 von den USA auf Ersuchen der georgischen Regierung durchgeführte Georgian Train and Equip Program (GTEP) soll in diesem Zusammenhang die Anti-Terror-Kapazitäten des maladen georgischen Militärs stärken. An GTEP schließt sich 2005 das Sustainment and Stability Operations Program an, welches darauf abzielt, georgische Soldaten für einen Einsatz in Irak im Rahmen des amerikanischen Anti-Terror-Kampfes zu trainieren ${ }^{176}$. Diese Programme sowie zusätzliche finanzielle Aufwendungen der USA unterstützen die georgischen Reformbemühungen im Bereich des Militärs - speziell auch in Hinblick auf eine mögliche spätere NATO-Mitgliedschaft Georgiens, die modernisierte und gemäß den NATO-Standards organisierte Streitkräfte voraussetzt. Die USA erweisen sich hier als der wichtigste Lobbyist für die NATO-Mitgliedschaftsambitionen Georgiens ${ }^{177}$. So dürfte es vor allem US-amerikanischer Fürsprache zu verdanken sein, dass Georgien trotz vorhandener Reformdefizite 2006 einen Intensiven Dialog mit der NATO aufnimmt und damit einen weiteren wichtigen Schritt hin zur NATOMitgliedschaft tätigt. Daneben engagieren sich die USA außerdem stark für die Wiederherstellung der georgischen territorialen Integrität und werden daher in Georgien auch als wichtiges Pendant zum russischen Einfluss in diesem Bereich gesehen $^{178}$.

Die US-amerikanisch-georgische Zusammenarbeit erstreckt sich neben dem militärischen Bereich aber auch auf wirtschaftliche Aspekte, reicht das georgisch-

\footnotetext{
176 Während sich Georgien bereits am KFOR-Einsatz im Kosovo beteiligt hatte, hat Georgien ab 2003 auch Truppen in den Irak entsandt.

177 Nachdem Georgien bereits seit 1994 durch das „Partnership for Peace“- Programm mit der NATO verbunden war, sprach es sich konkret erstmals 1999 für eine Integration in das nordatlantische Verteidigungsbündnis aus. Auf dem Prager NATO-Gipfel 2002 reichte Georgien offiziell seinen Beitrittsantrag ein. 2004 wurde ein individueller Partnerschaftsaktionsplan für Georgien formuliert (NATO Parliamentary Assembly 2007).

178 Peters/Bittner 2006: 180ff.; Reisner 2005: $16 f$.
} 
Franziska Smolnik: Zwischen Anspruch und Wirklichkeit: Die EU-Konditionalität als Demokratisierungsinstrument. Eine Studie zur externen Demokratieförderung an den Beispielen Georgien und Mazedonien

amerikanische Handelsvolumen auch nicht an das georgisch-europäische und das georgisch-russische heran (Tabelle 9). Die USA kooperieren mit Georgien vor allem im energiewirtschaftlichen Bereich, da Georgien ein wichtiges Transitland für kaspisches Erdöl und Erdgas darstellt. Die Realisierung der BTC-Pipeline ist deshalb vor allem auf die Unterstützung der USA zurückzuführen ${ }^{179}$. Des Weiteren sind die USA im Bereich der finanziellen Unterstützung eines der Hauptgeberländer für Georgien ${ }^{180}$. Sozusagen als Belohnung für Georgiens Demokratisierungsengagement wurde Georgien 2005 darüber hinaus in den Millenium Challenge Account $(M C A)^{181} \operatorname{der}$ USA aufgenommen. Innerhalb von 5 Jahren stehen Georgien damit knapp \$300 Mill. zur Verfügung, die für Maßnahmen zur Verbesserung der Infrastruktur und zur Wirtschaftsförderung in den ländlichen Regionen Georgiens bestimmt sind.

Während die USA vor allem seit 2001 in Georgien eine starke Präsenz zeigen, sieht Russland Georgien traditionell als Teil seines Einflussgebiets an. Der Hegemonieanspruch Russlands richtet sich dabei explizit gegen die USamerikanische sowie eine EU-Präsenz in Georgien ${ }^{182}$.

Die sicherheitspolitische Verbindung zwischen Georgien und Russland wird durch die bis vor kurzem von Russland auf georgischem Gebiet unterhaltenen Militärbasen sowie die fortbestehende Präsenz russischer Soldaten im Rahmen der Friedensmissionen in den abtrünnigen Republiken Südossetien und Abchasien deutlich. Auch Russlands weitere umfangreiche Unterstützung der de-facto Republiken zeugt direkt vom russischen Einfluss in der Region, aber auch indirekt vom russischen Einfluss auf die georgische Politik ${ }^{183}$.

Daneben bestehen enge wirtschaftliche Beziehungen bzw. Abhängigkeiten insbesondere im Energiebereich; 80\% des georgischen Energiebedarfs werden von russischen Lieferungen gedeckt, außerdem haben sich russische Unternehmen zu

\footnotetext{
179 Peuch 2005.

180 OECD 2008.

${ }^{181}$ Berechtigt für den Abschluss eines Vertrages im Rahmen des MCA sind offiziell solche Länder, die bereits ein deutliches Bemühen zeigen, politische und wirtschaftliche Freiheiten zu stärken, in Bildungs- und Gesundheitsversorgung zu investieren, die Korruption bekämpfen und Rechtsstaatlichkeit sowie Bürgerrechte schützen (Allgemein zur Millenium Challenge Corporation siehe http://www.mca.gov/; speziell zu Georgien siehe http://www.mcg.ge/?l=1\&i=1\&i2=0). 182 Ministerstvo Inostrannyx Del Rossijskoj Federacij 2007. In dieser offiziellen Stellungnahme zur russischen Außenpolitik wird Georgien gedroht, dass auch eine Einbindung in euro-atlantische Strukturen eine Lösung der Konflikte zu seinen Gunsten nicht ermöglichen wird.

183 Peters/Bittner 2006: 176f.
} 
Franziska Smolnik: Zwischen Anspruch und Wirklichkeit: Die EU-Konditionalität als Demokratisierungsinstrument. Eine Studie zur externen Demokratieförderung an den Beispielen Georgien und Mazedonien

einem beträchtlichen Teil in georgische Unternehmen der Energieversorgung eingekauft ${ }^{184}$.

Während zur Zeit Schewardnadzes 2000-2003 die zunehmende Westbindung Georgiens zu Spannungen zwischen Russland und Georgien führt, die georgische Führung in offiziellen Stellungnahmen aber zwischen der EU und den USA auf der einen, und Russland auf der anderen Seiten laviert, verschlechtern sie sich nach der georgischen Offensive gegen Südossetien im Sommer 2004 erheblich $^{185}$, da Russland - entgegen georgischer Wiedereingliederungsversuche bzw. -interessen - die Sezessionsrepubliken weiterhin in ihrer Unabhängigkeit unterstützt. Auch die Durchsetzung der Auflösung der russischen Militärbasen bis 2008 durch einen Vertrag aus dem Jahr $2005^{186}$ trägt zu einer weiteren Entfremdung der Nachbarn bei. Bereits 2006 erreichen die Spannungen zwischen Georgien und Russland ihren Höhepunkt: Nachdem Georgien russische Offiziere aufgrund eines Spionageverdachts festgenommen hat, antwortet Russland mit dem Abbruch der Land-, See-, Luft-, Post- und Bankverbindungen nach Georgien ${ }^{187}$. Allerdings dürfen diese Ereignisse nicht darüber hinwegtäuschen, dass Russlands Einfluss in Georgien weiterhin sehr groß ist und Russland für Georgien sowohl im sicherheitspolitischen als auch im wirtschaftlichen Bereich nach wie vor äußerst wichtig ist und entsprechende Unterstützungsleistungen bereitstellen kann bzw. bereitstellt: So sind russische Investitionen in strategisch bedeutsame Wirtschaftssektoren bzw. der Aufkauf wichtiger georgischer Energieversorger auch trotz der öffentlich ausgetragenen Kontroversen zwischen Georgien und seinem nördlichen Nachbarn 2006 in großem Maße möglich ${ }^{188}$. Tabelle 9 macht außerdem deutlich, dass gerade in den letzten Jahren die Exporte aus Russland nach Georgien zugenommen haben.

\footnotetext{
${ }^{184}$ Sigwart 2006: 56.

${ }^{185}$ Nachdem es Saakaschwili als eine der ersten Amtshandlungen gelang, das abtrünnige Adscharien wieder vollständig zu integrieren, startete Saakaschwili im Sommer 2004 eine weitere Offensive gegen die de-facto Republik Südossetien, ebenfalls mit dem Ziel einer Wiedereingliederung. Diese Offensive scheiterte nicht nur, sondern erhöhte die Spannungen zwischen Kern-Georgien und Südossetien weiter.

186 Russland „übererfüllte“ die Forderung und räumte bereits bis Ende 2007 die beiden verbliebenen Militärbasen in Batumi und Achalkalaki (Felgenhauer 2007).

187 Kaufmann 2006: 118f.

188 International Crisis Group 2007: $117 f$.
} 
Franziska Smolnik: Zwischen Anspruch und Wirklichkeit: Die EU-Konditionalität als

Demokratisierungsinstrument. Eine Studie zur externen Demokratieförderung an den Beispielen

Georgien und Mazedonien

\section{Zusammenfassung Asymmetrische Interdependenz}

Während trotz Steigerungen im Bereich der militärischen und wirtschaftlichen

Potentiale in der Regierungszeit Saakaschwilis gegenüber der Regierungszeit

Schewardnadzes beide Faktoren dennoch insgesamt für den Untersuchungszeitraum als niedrig einzustufen sind, so stellen sowohl die USA als auch Russland potentielle Gegenmächte zur EU dar, die alternativ wirtschaftliche und militärische Unterstützung bieten.

Zwar ähneln sich die politischen Zielsetzungen der EU und der USA im Sinne einer Unterstützung der Demokratisierungstendenzen, die USA heben sich aber aufgrund ihres wesentlich stärkeren, sicherheitspolitisch-militärischen sowie lange Zeit auch stärkeren energiepolitischen Engagements von der EU ab.

Auch Russland muss aufgrund seines Selbstverständnisses als Hegemonialmacht im Südkaukasus, aber insbesondere aufgrund seines trotz der Spannungen über den gesamten Untersuchungszeitraum hinweg großen wirtschaftlichen und auch sicherheitspolitischen Einflusses in Georgien als potentielle Gegenmacht zur EU eingestuft werden. Der Grad der asymmetrischen Interdependenz zwischen Georgien und der EU muss daher als gering bewertet werden.

\subsection{Grad der Rechtsstaatlichkeit}

Zieht man zur Messung des Rechtsstaatlichkeitsgrads den Freedombouse-Indikator heran (Tabelle 10), so lässt sich ein interessanter Trend erkennen: Trotz der von westlichen Politikern und Journalisten oft als Demokratisierungsschub dargestellten Rosenrevolution nimmt der Grad der Rechtsstaatlichkeit in der Zeit der Regierung von Saakaschwili im Gegensatz zu der Regierungszeit Schewardnadzes ab. Liegt der Wert für das Jahr 2000 noch bei 4 Punkten, so hat er sich bis 2007 auf 4,75 Punkte, also um 0,75 Punkte verschlechtert. Allerdings muss man beachten, dass auch in der Regierungszeit Schewardnadzes, die in den Untersuchungszeitraum fällt, die Entwicklung der Rechtsstaatlichkeit negativ ist und 2003 - im Jahr der Rosenrevolution - der Rechtsstaatlichkeitsgrad nur bei 4,5 Punkten liegt. Dennoch ist interessant, dass der Freedomhouse-Indikator für das Jahr 2003 noch nicht das schlechteste Ergebnis zeigt, sondern die negative Spitze der Entwicklung erst im Jahr 2005 mit 5 Punkten zu verzeichnen ist. 
Franziska Smolnik: Zwischen Anspruch und Wirklichkeit: Die EU-Konditionalität als

Demokratisierungsinstrument. Eine Studie zur externen Demokratieförderung an den Beispielen

Georgien und Mazedonien

Tabelle 10:

\section{Grad der Rechtsstaatlichkeit für Georgien}

Judicial Framework and Independence

\begin{tabular}{|l||r|r|r|r|r|r|r|r|}
\hline & $1999-2000$ & 2001 & 2002 & 2003 & 2004 & 2005 & 2006 & 2007 \\
\hline \hline Georgien & 4 & 4 & 4,25 & 4,5 & 4,5 & 5 & 4,75 & 4,75 \\
\hline
\end{tabular}

Quelle: Freedomhouse Nations in Transit 2007

Im Folgenden soll die Untersuchung des zusätzlichen Indikators der Unabhängigkeit des Justizbereichs die obigen Zahlenwerte weiter aufschlüsseln.

Diesbezüglich lassen sich zwei größere Justizreformen ausmachen, die allerdings beide nur bedingt positive Ergebnisse hervorbringen. Bereits seit 1998 wird in Georgien eine erste Justizreform durchgeführt, an der neben Schewardnadze als Staatspräsident auch Saakaschwili als Abgeordneter, von 2000-2001 als Justizminister, teilhaben. Während die Reform anfänglich relativ erfolgreich verläuft und verschiedene Neuerungen durchgeführt werden, gerät die Reform vor allem aufgrund fehlenden politischen Willens schnell ins Stocken. David Usupaschwili nennt die Justizreform eine Reform nach dem „Oasen-Prinæip ‘d89, da die Reformen nur auf einzelne Sektoren zielen. Zu den positiven Errungenschaften, die die Unabhängigkeit der Justiz stärken sollen, zählen die Einführung der Veröffentlichung von Gerichtsentscheiden, die Etablierung von Zugangsexamina für angehende Richter und die Bildung eines Justizrates, der die Gerichtsbarkeit von der Exekutive lösen soll. Allerdings besteht der Justizrat in der Zeit Schewardnadzes zu gleichen Anteilen aus Mitgliedern der Exekutive, Legislative und Judikative, so dass eine tatsächliche Unabhängigkeit nicht gegeben ist. Auch die Zugangsexamina sind unter Schewardnadze von 2000-2003 wenig wirksam, denn gegen Bezahlung lässt sich diese Barriere leicht umgehen ${ }^{190}$. Zwar werden 2002 in Georgien mehr Gesetze als in jedem anderen post-sowjetischen Staat verabschiedet, deren tatsächliche Implementierung, insbesondere wenn sich diese zu Lasten der herrschenden Elite ausgewirkt hätte, bleibt zwischen 2000 und 2003 aber weitestgehend aus. Das Hauptproblem zur Zeit Schewardnadzes ist allerdings die epidemische Verbreitung von Korruption - nicht nur, aber insbesondere auch im Bereich der Justiz.

Bestechungsgelder, um Urteile nach eigenen Wünschen ausfallen zu lassen, zählen

189 Usupaschwili 2004: 99.

190 Siehe hierzu Chanturia 2007. 
Franziska Smolnik: Zwischen Anspruch und Wirklichkeit: Die EU-Konditionalität als Demokratisierungsinstrument. Eine Studie zur externen Demokratieförderung an den Beispielen Georgien und Mazedonien

zur Normalität ${ }^{191}$. Obwohl also einzelne Reformbemühungen von 2000-2003 stattfinden, sind diese als oberflächlich einzuschätzen und führen nicht zu substantiellen Verbesserungen.

Mit der Übernahme der Regierung durch Michail Saakaschwili ist es dementsprechend vor allem die Korruption, gegen die sich die Hauptbemühungen der neuen Regierung richten. Offiziell um die Gerichte von korrupten Richtern zu befreien, wird kurz nach Übernahme der Regierung im Februar 2004 eine Gesetzesänderung verabschiedet, die den unter Schewardnadze eingeführten Justizrat (jetzt Oberster Justizrat (OJ)) zu einem Beratungsgremium des Staatspräsidenten degradiert, der diesem vorsitzt und letztlich alle wichtigen Entscheidungen trifft. Diese Verfassungsänderung führt zu einer noch stärkeren Abhängigkeit des OJ von der Exekutive in Form des Staatspräsidenten. Durch den Vorsitz des OJ hat Saakaschwili als Staatspräsident die Berechtigung, Richter zu ernennen, zu befördern bzw. zu entlassen ${ }^{192}$. Entgegen offiziellen Darstellungen sehen internationale Experten hierin eine Möglichkeit zur Neubesetzung der Richterposten durch loyale Gefolgsleute sowie die Entlassung unabhängiger und unbequemer Richter ${ }^{193}$. Neben dieser Verfassungsänderung führt insbesondere auch das Gesetz zur Reorganisation der Gerichte der ersten Instanz zu einem noch größeren Einfluss der Exekutive auf den Justizbereich. Im Zuge der Reorganisation, die 2005-2006 durchgeführt wird, werden die 75 Gerichte erster Instanz zu 15 Regionalgerichten zusammengelegt. Die durch die Fusion überflüssig gewordenen Richter werden auf eine Reserveliste gesetzt, sie beziehen zwar weiterhin Gehalt, dürfen allerdings nicht als Richter arbeiten. Für die Auswahl, welche Richter weiterhin beschäftigt bleiben und welche ihren Dienst quittieren müssen, gibt es keine klaren Regeln, der Auswahlprozess ist intransparent. Auch in der Reorganisation der Gerichte sehen Experten daher ein Instrument der Regierung, unliebsame Richter lautlos zu entfernen, zumal bis Ende 2006 nur ein Drittel der neuen Richterposten besetzt ist ${ }^{194}$.

\footnotetext{
191 Horoschak 2007: 1f.

192 International Crisis Group 2007: 22.

${ }^{193}$ Europäische Kommission für Demokratie durch Recht 2004.

194 American Bar Association 2005: 28f.; Di Puppo 2006. Seit 2003 sind ca. 75\% der Richter von ihren

Posten entfernt worden.
} 
Franziska Smolnik: Zwischen Anspruch und Wirklichkeit: Die EU-Konditionalität als Demokratisierungsinstrument. Eine Studie zur externen Demokratieförderung an den Beispielen Georgien und Mazedonien

Die Reorganisation gehört bereits zu der 2005 beginnenden zweiten Justizreform ${ }^{195}$, deren Ziele mit Hilfe der zu diesem Zweck von Sommer 2004 bis Sommer 2005 nach Georgien entsandten EU-Rule-of-Law-Mission-to-Georgia EUJUST Themis formuliert worden sind und die auch im späteren Aktionsplan der $E N P^{196}$ eine der Prioritäten darstellen. Ziel der Reform ist es laut der georgischen Regierung, die Unabhängigkeit der Justiz zu stärken. Zu diesem Zweck wurde im Dezember 2006 der Oberste Justizrat erneut reformiert: Der georgische Staatspräsident muss nun seinen Vorsitz an den Vorsitzenden des Obersten Gerichts abgeben, mehr als 50\% der Ratsmitglieder müssen von den Selbstverwaltungsorganen der Gerichte gewählt werden und der Status des OJ als Beratungsgremium des Staatspräsidenten wird zu Gunsten der Unabhängigkeit des Rates geändert. Als unzureichend kritisiert wird allerdings auch diese Reform des OJ, da Exekutive und Legislative zusammen immer noch über mehr Stimmen als die Judikative verfügen ${ }^{197}$ und so eine vollständige Unabhängigkeit nicht erreicht wird ${ }^{198}$. Gemäß dem Reformplan der georgischen Regierung wird 2005 außerdem das Gesetz zur Gründung einer Justizhochschule verabschiedet, die zur Weiterbildung sowie Qualifizierung von Richtern beitragen soll und 2007 ihre Arbeit aufnimmt. Problematisch ist allerdings auch hier, dass weiterhin objektive und transparente Kriterien für die Ernennung und Beförderung von Richtern fehlen.

Ebenfalls im Einklang mit dem Reformplan werden im Jahr 2006 auch die Gehälter und Renten der Richter erstmals seit 1998 erhöht. Dieser Maßnahme dürfte es mit zu verdanken sein, dass in der Regierungszeit Saakaschwilis die Bestechlichkeit von Richtern und Justizbeamten stark zurückgegangen ist ${ }^{199}$. Obwohl also die Korruption im Justizbereich rückläufig ist, bedeutet dies nicht, dass auch der externe Einfluss auf richterliche Entscheidungen generell abgenommen hat. Im Gegenteil ist seit 2003 ein Anstieg unzulässigen Einflusses der Exekutive, der Staatsanwaltschaft sowie lokaler

\footnotetext{
195 Overview of Implmentation of the European Neighbourhood Policy EU-Georgia Action Plan 2007.

196 Europäische Kommission 2006a: 4ff.

${ }^{197}$ Dies ist gerade in Georgien wichtig, da durch die Dominanz der Regierungspartei, die sowohl die Exekutive stellt als auch das Parlament dominiert, ein Zusammenschluss der Mitglieder der Exekutive und Judikative im Justizrat durchaus wahrscheinlich ist.

198 Tabatadze et. al. 2007: 10ff.

${ }^{199}$ Dolidze 2007: 6ff. Allerdings ist es weiterhin möglich, sich nach Bekanntgabe des Urteils durch eine „Kaution“ temporär oder endgültig freizukaufen. Bezüglich der Meldung bzw. Verrechnung dieser Gelder existieren keine Regelungen (International Crisis Group 2007: 15).
} 
Franziska Smolnik: Zwischen Anspruch und Wirklichkeit: Die EU-Konditionalität als

Demokratisierungsinstrument. Eine Studie zur externen Demokratieförderung an den Beispielen Georgien und Mazedonien

Machtinhaber in den Regionen zu verzeichnen. Insbesondere in politisch sensiblen Fällen fehlt es an Transparenz bzw. Determiniertheit. Erst mit der Verabschiedung des Gesetzes zur Regelung von Kommunikation mit Richtern im Juli 2007 wird die vormals weit verbreitete Einmischung in laufende Prozesse von Seiten der Regierung eingeschränkt. Allerdings ist auch in diesem Aspekt die Justizreform nicht konsequent, widerspricht doch das bereits 2006 eingeführte Verbot, Gerichtsprozesse aufzunehmen bzw. zu filmen, einer Politik der größeren Transparenz ${ }^{200}$.

Durch die genauere Betrachtung des Justizbereichs unter dem Aspekt der Unabhängigkeit der Justiz ist deutlich geworden, dass sich hier tatsächlich eine Verschlechterung der Rechtsstaatlichkeit feststellen lässt. Im Hinblick auf die Unabhängigkeit der Justiz scheint die im Gegensatz zur Regierungszeit Schewardnadzes beim Freedombouse-Indikator schlechtere Wertung der Rechtsstaatlichkeit für die Jahre 2004 - 2007 vor allem aber zweifelhaften gesetzlichen Neuregelungen zu verdanken sein und nicht unbedingt einem generellen Abbau von Rechtsstaatlichkeit im Vergleich zu den Vorjahren. Während unter Schewardnadze zwar Gesetze verabschiedet wurden, die eine Verbesserung der Rechtsstaatlichkeit zum Ziel hatten, zeitigten diese allerdings aufgrund ihrer fehlenden Umsetzung keine positiven Auswirkungen, so dass angenommen werden kann, dass in der Praxis die Rechtsstaatlichkeit im gesamten Untersuchungszeitraum durchweg niedrig ist.

\subsection{Georgien - Interaktion der Variablen}

Betrachtet man die Untersuchungsergebnisse der AV, so kann man feststellen, dass die EU-Anreize unterhalb der Beitrittsperspektive - zumindest für den in dieser Arbeit betrachteten Zeitraum - in Georgien nicht ausreichten, um relevante Fortschritte im Bereich der Rechtsstaatlichkeit zu erzielen. Die von der EU verfolgte Strategie der positiven Konditionalität war hier wenig wirksam. Auch die im Rahmen der ENP vergrößerten Anreize einer intensiven Kooperation zwischen der EU und Georgien sowie einer vorgesehenen umfangreichen (wirtschaftlichen) Integration Georgiens in die Strukturen der EU konnten bislang keine positiven Ergebnisse

200 Tabatadze et. al. 2007: 30ff. 
Franziska Smolnik: Zwischen Anspruch und Wirklichkeit: Die EU-Konditionalität als Demokratisierungsinstrument. Eine Studie zur externen Demokratieförderung an den Beispielen Georgien und Mazedonien

hervorbringen. Dies ist umso bemerkenswerter, als die EU bereits im Strategiepapier für 2002-2006 auf die Wichtigkeit von Rechtsstaatlichkeit hinweist und im modifizierten Strategiepapier für 2004-2006 201 Verbesserungen im Bereich der Rechtsstaatlichkeit und insbesondere Reformen im Justizbereich als eine der Reformprioritäten anmahnt. Auch im Aktionsplan der ENP ${ }^{202}$ wird der Forderung nach Rechtsstaatlichkeit Rechnung getragen, sie nimmt daher als erster Prioritätsbereich eine prominente Stelle ein. Interessant ist, dass das Ausbleiben relevanter Fortschritte im Bereich der Rechtsstaatlichkeit nicht bedeutet, dass gar keine Reformversuche in diesem Bereich unternommen wurden. Wie in Abschnitt 7.4 dargestellt wurde, begann man bereits 1998 unter Schewardnadze eine Justizreform durchzuführen. Anstrengungen in diesem Bereich wurden bereits im Strategiepapier der EU für 2002-2006 zur Kenntnis genommen. Auch im modifizierten Strategiepapier für die Jahre 2004-2006 werden die Reformschritte in diesem Bereich erwähnt, allerdings wird hier auch deutlich gemacht, dass eines der Hauptprobleme die tatsächliche Implementierung der verabschiedeten Gesetze ist. Wie bereits im ersten Strategiepapier wird der georgischen Regierung erneut vorgeworfen, dass sie sich zwar offiziell der Verbesserung der Rechtsstaatlichkeit verschreibt, der Rhetorik aber keine entsprechenden Taten folgen lasse.

Offensichtlich aufgrund fehlenden politischen Willens stagnieren die Reformen seit 2001:

$$
\begin{aligned}
& \text { "In general terms, the main difficulty for Georgia is to deliver on the expressions of good intentions } \\
& \text { that characterise the analysis and the rhetoric of its leaders and politicians. There is an excellent } \\
& \text { understanding of the problems and the issues at stake". }
\end{aligned}
$$

Auch unter Präsident Saakaschwili wurde bzw. wird eine Justizreform durchgeführt. Während die EU auf die die Unabhängigkeit der Gerichte einschränkenden Verfassungsänderungen von Anfang 2004 aufgrund der besonderen Umstände der Rosenrevolution kaum Einfluss nehmen konnte, wurde aber während der EURechtsstaatlichkeitsmission 2004-2005 in enger Absprache mit der EU die neue Justizreform geplant. Auch hier reichten allerdings die Anreize der EU ohne eine Beitrittsperspektive offensichtlich nicht aus, um substantielle Fortschritte zu erzielen. Fast identisch mit den Mahnungen im Strategiepapier für 2004-2006 wird daher in

${ }^{201}$ Europäische Kommission 2001: 5; Europäische Kommission 2003: $21 \mathrm{f}$.

202 Europäische Kommission 2006a: 4f.

${ }^{203}$ Europäische Kommission 2001: 6. 
Franziska Smolnik: Zwischen Anspruch und Wirklichkeit: Die EU-Konditionalität als Demokratisierungsinstrument. Eine Studie zur externen Demokratieförderung an den Beispielen Georgien und Mazedonien

einer Evaluation der EU-Rechtsstaatlichkeitsmission durch das Institute for Security Studies der EU ${ }^{204}$ erneut der fehlende Wille bei den georgischen Beamten, insbesondere auf höherer bzw. höchster politischer Ebene, für das nur schleppende Vorankommen und insbesondere die tatsächliche Umsetzung der Gesetzesänderungen verantwortlich gemacht.

Dieser „Reformleerlauf“" verwundert insofern, als Saakaschwili offiziell einen eindeutig pro-westlichen und auch pro-europäischen Kurs verfolgt und er seit seiner Amtseinführung immer wieder bekräftigt, dass das Ziel seines Landes eine weitere Annäherung an die EU und letztlich die EU-Mitgliedschaft $\operatorname{sei}^{205}$.

Dass die von der EU gebotenen Anreize kaum Auswirkungen auf die georgische Politik im Bereich der Rechtsstaatlichkeit hatten, hängt auch mit der geringen asymmetrischen Interdependen z zwischen Georgien und der EU zusammen, die sich durch das Vorhandensein von alternativen Mächten, namentlich der USA und Russland, ergibt und den Einfluss der Anreize verringerte bzw. verringert. Insbesondere im Hinblick auf den sicherheitspolitischen Bereich, der für Georgien aufgrund der ungelösten Sezessionskonflikte und des starken Einflusses Russlands in diesen Gebieten aber auch in Kern-Georgien eine wichtige Rolle spielt, wurde die EU zur Zeit Schewardnadzes nicht als Akteur wahrgenommen, sondern besaß den einflusslosen Status eines sicherheitspolitischen Non-Players ${ }^{206}$. Wie dargelegt, nahm Schewardnadze eine lavierende Haltung zwischen den USA und Russland ein - die EU spielte nur eine untergeordnete Rolle. Diese Haltung hat sich unter anderem daraus ergeben, dass die georgische Führung sowohl Russland als wichtigen Faktor im Zusammenhang mit einer möglichen Lösung der Sezessionskonflikte und der Sicherheit Georgiens angesehen sowie gleichzeitig auch die Nähe zu den USA als Gegengewicht zu diesem russischen Einfluss gesucht hat. Im Gegensatz zu den USA und Russland hat also die EU bzw. haben deren Anreize nicht die wichtigsten Interessen Georgiens bedient.

Obwohl sich im Rahmen des unter Saakaschwili verabschiedeten ENP-Aktionsplans die EU eindeutig für eine Lösung der Konflikte unter Beibehaltung der territorialen Integrität Georgiens ausspricht, bleibt das Engagement der EU dennoch auch nach

\footnotetext{
204 Helly 2006: 97.

205 Stellvertretend als eine von zahlreichen diesbezüglichen Äußerungen siehe Saakaschwili 2004: 4.

206 Nodia 2004: $21 \mathrm{f}$.
} 
Franziska Smolnik: Zwischen Anspruch und Wirklichkeit: Die EU-Konditionalität als Demokratisierungsinstrument. Eine Studie zur externen Demokratieförderung an den Beispielen Georgien und Mazedonien

der Rosenrevolution hinter den georgischen Erwartungen zurück - insbesondere auch in Bezug auf eine eindeutige Positionierung der EU gegen den Hegemonieanspruch Russlands bzw. Russlands Einfluss in den Konfliktregionen. Die EU-Anreize zur Reform sind somit weiterhin wenig wirksam ${ }^{207}$. Die geringe asymmetrische Interdependenz zwischen Georgien und der EU verringert auch insgesamt den Einfluss der EU-Anreize, denn neben der Sicherheit spielt auch für die georgische Wirtschaft nicht nur die EU eine Rolle, sondern auch die USA und - besonders offenkundig im Energiebereich - Russland. Da sich die Hauptanreize der EU aber vor allem auf wirtschaftliche Zugeständnisse beziehen sind diese weniger bedeutsam als von der EU angenommen. Die Aufnahme Georgiens in den MCA der USA hat Georgien außerdem gezeigt, dass Kooperation und finanzielle Hilfsgelder nicht zwingend an konkrete Reformschritte geknüpft sein müssen ${ }^{208}$. Betrachtet man die Bedingungsvariable der Adaptionskosten, so ergibt sich ein ähnliches Bild wie beim Fallbeispiel Mazedonien. Auch hier werden Reformen nur insoweit durchgeführt, als sie die Einflussmöglichkeiten bzw. den Machterhalt der regierenden Partei bzw. des regierenden Führungszirkels nicht schmälern. Werden dennoch solche Gesetze verabschiedet, die eine Verringerung des Einfluss zur Folge hätten, hapert es bei der Implementierung. Dies gilt aufgrund der konstant hohen Adaptionskosten für den gesamten Untersuchungszeitraum. Oftmals ist hierfür, wie schon angesprochen, der fehlende politische Wille auf höchster Ebene verantwortlich, wie beispielsweise auch bei den von der EU-

Rechtsstaatlichkeitsmission begleiteten Reformen.

So heißt es in entsprechenden Berichten:

$$
\begin{aligned}
& \text { "[...] the government has taken significantly less initiative in the sphere of judiciary reform because } \\
& \text { strengthening the judiciary now will result in more effective oversight of the current government. In other } \\
& \text { words, the order and pace of reforms are coordinated with explicit political interests in mind."209 }
\end{aligned}
$$

\footnotetext{
207 Die Aktivitäten der EU beziehen sich fast ausschließlich auf humanitäre Hilfe und den Wiederaufbau. Direkt politisch greifen sie in die Lösung der Konflikte nicht ein.

208 Interessanterweise spiegelt sich dieses Bild auch in der Meinung der Bevölkerung wider. Gemäß dem Georgian Public Opinion Barometer 2006 sind zwar 74\% der Georgier für eine EU-Mitgliedschaft. Fragt man allerdings nach der Abhängigkeit von anderen Ländern, von der 31,4\% der Befragten überzeugt sind, werden Russland und die USA genannt. 59\% der Befragten gaben an, dass Georgien von Russland abhängig sei, 41,4\% sahen Georgien in Abhängigkeit zu den USA(Sumbadze 2006: 9f.). ${ }^{209}$ Horoschak 2007: 8.
} 
Und zynischer:

"It is clear that the authorities care more about furnishing the courts with modern office equipment than about any other component of the judiciary reform. State has no strategy of weakening the prosecutor's office control of the court system."210

Da eine konsequente Demokratisierung den Macht- und Einflussbereich der herrschenden Elite und ihres Klientelnetzwerkes gefährdet, schmälern die hohen Adaptionskosten in Form der starken Dominanz von charismatischen und klientelistisch organisierten Regierungsparteien die sowieso schon niedrigen Anreize, was eine im Gegensatz zu Mazedonien äußerst ungünstige Anreizstruktur zur Folge hat. Insbesondere zur Zeit Schewardnadzes in den 1990er Jahren, abgeschwächt aber auch unter Saakaschwili stellte bzw. stellt sich eine Konkurrenzsituation bzw. ein Gegenrechnen von Anreizen und (Adaptions-)Kosten allerdings gar nicht erst ein. Obwohl die EU aufgrund der sich stark verschlechterten Situation am Anfang des neuen Jahrtausends ihre Hilfsleistungen kürzte, sprudeln die Hilfsgelder seit der Rosenrevolution erneut, obwohl, wie dargelegt, nach 2003 im Prioritätsbereich der EU keine Fortschritte erzielt werden konnten ${ }^{211}$.

\section{Mazedonien und Georgien: Eine Gegenüberstellung}

Nachdem die Untersuchungsergebnisse der ausgewählten Variablen für die hier behandelten Fälle Georgien und Mazedonien zunächst einzeln dargestellt wurden, sollen nun beide Länder miteinander verglichen werden. Hierbei sollen auch die jeweils für Georgien und Mazedonien in die Falldarstellung integrierten Kapitel zur Interaktion der Variablen einbezogen werden, da vor allem so Aufschluss darüber gegeben werden kann, wie die Variablen zusammenspielen. Gemäß dem im Kapitel zur Fallauswahl und Methode beschriebenen Vorteilen eines Vergleichs mit kleiner Fallzahl - die Möglichkeit nicht nur das „ob“, sondern auch das „wie“ eines

\footnotetext{
${ }^{210}$ Chkeidze 2007: 9.

${ }^{211}$ Barbara Christophe geht in ihrer Analyse daher so weit, dass sie die Übernahme des Präsidentenamts durch Saakaschwili als eine Art organisierten Putsch ansieht mit dem expliziten Ziel, die versiegten internationalen Geldquellen mit Hilfe eines medial inszenierten Reformerimages wieder zum Fließen zu bringen, um die eigenen Ansprüche des Machtzirkels, aber auch die Forderungen der Klienten befriedigen zu können. Christophe 2005: 83ff.
} 
Franziska Smolnik: Zwischen Anspruch und Wirklichkeit: Die EU-Konditionalität als

Demokratisierungsinstrument. Eine Studie zur externen Demokratieförderung an den Beispielen

Georgien und Mazedonien

Kausalzusammenhangs zu untersuchen - kommt diesen Abschnitten in der weiteren Gegenüberstellung eine wichtige Rolle zu. Zunächst wird im folgenden Abschnitt der Einfluss der unabhängigen auf die abhängige Variable anhand der Gegenüberstellung der Fälle überprüft. Hierbei soll festgestellt werden, ob sich die anfangs aus der Theorie abgeleitete zentrale Hypothese für die gewählten Länder bestätigt.

Abschließend werden die in der Arbeit untersuchten beiden Bedingungsvariablen für die beiden Fälle gegenübergestellt.

\subsection{Die Größe des EU-Anreizes als Ursache für den unterschiedlich starken Einfluss der EU-Konditionalität}

Wie bei der Darstellung der unabhängigen Variablen deutlich geworden und wie bei der Auswahl der Fälle vorausgesetzt worden ist, verfügen Mazedonien und Georgien nicht über gleich hohe Anreize im Rahmen der EU-Konditionalität. Während Mazedonien als Land des westlichen Balkans bereits seit 2000 offiziell als potentieller Beitrittskandidat benannt und Ende 2005 offizieller EU-Beitrittskandidat wurde, verfügt Georgien im gesamten Untersuchungszeitraum nicht über eine derartige Beitrittsperspektive. Gemäß der eingangs formulierten zentralen Hypothese müsste Mazedonien daher einen höheren Rechtsstaatlichkeitsgrad aufweisen als Georgien, da hier der Nutzen einer Regelübernahme besonders groß ist. Vergleicht man die Ergebnisse der abhängigen Variablen, also den Grad der Rechtsstaatlichkeit, für Mazedonien und Georgien, so bestätigen diese den angenommenen Kausalzusammenhang.

Während Mazedonien im Jahr 2000 gemäß dem Freedomhouse-Indikator Judicial Framework and Independence mit 4,25 Punkten noch 0,25 Punkte schlechter gewertet wurde als Georgien (4,0 Punkte), liegt Mazedonien am Ende des Untersuchungszeitraums 2007 mit 3,75 Punkten einen ganzen Punkt vor Georgien $(4,75 \text { Punkte })^{212}$.

Wie bereits im Rahmen der Fallbetrachtungen gezeigt wurde, handelt es sich allerdings weder bei Mazedonien noch bei Georgien um graduelle Entwicklungen.

212 Freedombouse weist in der Methodologie zum Nations in Transit- Index aus, dass eine Veränderung von 0,75-1 Punkt eine bedeutende positive bzw. negative Veränderung bedeutet, wohingegen eine Veränderung zwischen 0,25 und 0,5 Punkten eine kleinere positive bzw. negative Veränderung meint. Die Unterscheidung in bedeutende und kleinere Veränderungen bezieht sich auf die Veränderungen innerhalb eines Jahres, also auf zwei aufeinander folgende Jahreswerte. 
Franziska Smolnik: Zwischen Anspruch und Wirklichkeit: Die EU-Konditionalität als

Demokratisierungsinstrument. Eine Studie zur externen Demokratieförderung an den Beispielen

Georgien und Mazedonien

Bis 2002 liegt Mazedonien hinter Georgien im Bereich der Rechtsstaatlichkeit zurück (4,75 vs. 4,25 Punkte), im Jahr 2003 weisen Mazedonien und Georgien mit je 4,5 Punkten gleiche Wertungen auf. Dabei konnte im Kapitel zur Interaktion der Variablen für Mazedonien deutlich gemacht werden, dass dieses Ergebnis nicht direkt darauf zurückgeführt werden kann, dass der hohe Anreiz einer Beitrittsperspektive keine ausreichende Wirkung gehabt hat, sondern dass die Entwicklung wesentlich durch die 2001 stattgefundenen gewalttätigen Ausschreitungen beeinflusst wurde. Dieses Ergebnis führt aber zu dem Schluss, dass auch der Anreiz einer EU-Mitgliedschaft derartige Dynamiken nicht unterbinden kann. Der Einfluss der EU-Anreize konnte allerdings an anderer Stelle deutlicher nachgewiesen werden. Es wurde ersichtlich, dass Regelübernahmen häufig in Verbindung mit wichtigen Stichdaten des mazedonischen EU-Integrationsprozesses geschahen, die somit als weitere wichtige Antriebskräfte wirkten. Dennoch muss für Mazedonien festgehalten werden, dass obwohl eine Veränderung von einem Punkt für den Vergleich zweier aufeinander folgender Jahre im Freedombouse-Index als eine bedeutende Veränderung gewertet wird ${ }^{213}$, eine solche Veränderung auf einen Zeitraum von fünf Jahren bezogen zurückhaltender zu bewerten ist.

Was Georgien anbetrifft, so lässt sich der Einfluss der EU-Anreize unterhalb der Beitrittsperspektive nicht nachweisen. Die Entwicklung des Rechtstaatlichkeitsgrads ist hier weitestgehend negativ. Bis einschließlich 2005 haben sich die Werte des Freedombouse-Indikators verschlechtert, von 2004 auf 2005 sogar um 0,5 Punkte. Erst 2006 konnte dieser Trend gestoppt werden. Die Betrachtung der Unabhängigkeit des Justizbereichs hat gezeigt, dass für die Zeit nach der Rosenrevolution vor allem zweifelhafte Gesetzesänderungen für die Verschlechterung der Rechtsstaatlichkeit verantwortlich waren.

Obwohl in der Analyse nur zwischen niedrigen (keine Beitrittsperspektive) und hohen (mit Beitrittsperspektive) Anreizen im Rahmen der EU-Konditionalität unterschieden wurde, soll dennoch darauf hingewiesen werden, dass auch die konkretisierten bzw. erhöhten Anreize der ENP in Georgien nicht zu einer verstärkten Regelübernahme und somit einer bedeutenden Verbesserung des

${ }^{213}$ Freedomhouse Nations in Transit 2007. 
Franziska Smolnik: Zwischen Anspruch und Wirklichkeit: Die EU-Konditionalität als

Demokratisierungsinstrument. Eine Studie zur externen Demokratieförderung an den Beispielen

Georgien und Mazedonien

Rechtsstaatlichkeitsgrads geführt haben. Dies konnte auch durch die Betrachtung des Justizbereichs in Hinblick auf seine Unabhängigkeit bestätigt werden.

\subsection{Die Bedingungsvariablen als Einflussfaktoren auf die} Unabhängige Variable

Wie dargelegt hat Mazedonien im Bereich der Rechtsstaatlichkeit eine weitestgehend positive Entwicklung durchlaufen, die Verbesserungen in diesem Bereich sind allerdings laut Freedombouse-Indikator für den hier betrachteten Zeitraum von sieben Jahren nicht herausragend. Gemäß der zugrunde liegenden Theorie bzw. der kritischen Sichtung des Forschungsstands sind zusätzlich zur zentralen unabhängigen Variable zwei nahe liegende Bedingungsvariablen in die Analyse integriert worden, von denen angenommen wird, dass sie den Einfluss der UV sowohl verringern als auch stärken können. Dies sind zum einen die Adaptionskosten, verstanden als Machtverlust für die Regierungspartei bzw. -parteien, zum anderen die asymmetrische Interdependenz, zwischen EU und Drittstaat. Im Folgenden sollen die Ergebnisse der Untersuchung der beiden Bedingungsvariablen der Fälle Mazedonien und Georgien gegenübergestellt werden.

\section{Adaptionskosten}

Wie in Kapitel 4.3 erläutert, wurden die Adaptionskosten in die Untersuchung mit aufgenommen. Dabei ergaben sich für den gesamten Untersuchungszeitraum sowohl für Mazedonien als auch Georgien hohe Adaptionskosten.

In Mazedonien war hierfür die starke Dominanz von Klientelparteien verantwortlich. Regierungs-, aber auch Oppositionsparteien sind in Mazedonien zwar anhand ethnischer Linien getrennt, diese ethnische Aufteilung ist aber nur bedingt programmatischer Natur. Die Regierungsparteien in Mazedonien sind ethnisch begründete Klientelparteien, die ihren Status als Regierungsparteien nutzen, um Zugang zu staatlichen Ressourcen zu erhalten, mit deren Hilfe der eigene Machterhalt und somit die Appropriationsmöglichkeiten durch die Vergabe von Pfründen und Patronage gesichert werden. Interessanterweise ergab die Untersuchung für Georgien eine gewisse Variation dieses Bildes. Während in Mazedonien traditionellerweise mindestens zwei Parteien an der Regierung beteiligt sind, gibt es in Georgien nur jeweils eine Regierungspartei, die darüber hinaus eine 
Franziska Smolnik: Zwischen Anspruch und Wirklichkeit: Die EU-Konditionalität als

Demokratisierungsinstrument. Eine Studie zur externen Demokratieförderung an den Beispielen

Georgien und Mazedonien

ungewöhnliche Machtfülle besitzt. Die Regierungspartei ist dabei sowohl stark personalisiert als auch klientelistisch organisiert. Ebenso wie in Mazedonien nutzt die Regierungspartei die qua Status erhaltenen Gestaltungs- und Extraktionsmöglichkeiten und bindet dabei ihre Klienten durch Patronage und die Vergabe von Pfründen ein. Während in Mazedonien die Einbindung albanischer Klientelgruppen in die Regierung als Ersatz für eine tatsächliche Gleichstellung der Ethnien und somit aus Sicht der Regierungsparteien als wichtig für die interethnische Stabilität gesehen wird, nutzen auch die georgischen Regierungsparteien Kooptationsstrategien, um befürchtete Autonomiebestrebungen zu unterbinden. Sowohl in Mazedonien wie in Georgien spielen die hohen Adaptionskosten eine große Rolle. So führt das Vorhandensein hoher Adaptionskosten in beiden Fällen dazu, dass politisierte Bereiche von Reformen zur Verbesserung der Rechtsstaatlichkeit ausgespart bleiben oder aber Reformen nur unzureichend durchgeführt werden (Mazedonien und Georgien) bzw. Gesetzesänderungen vorgenommen werden, die die Politisierung bzw. den (illegitimen) Einfluss der Parteien noch verstärken (Georgien). Sowohl in Georgien als auch in geringerem Maße in Mazedonien blieb insbesondere die Unabhängigkeit der Justiz aufgrund des Einflusses der Regierungspartei(en) ungenügend. Während aber in Mazedonien durch den Druck der kritischen EU-Fortschrittsberichte schließlich doch gewisse Verbesserungen in diesem sensiblen Bereich erzielt wurden, war dies in Georgien nicht der Fall. Im Gegenteil wurden hier auch trotz einer durch Experten im Rahmen einer EU-Rechtsstaatlichkeitsmission begleiteten Justizreform kaum Fortschritte erzielt. Beide Fälle scheinen die eingangs genannte Hypothese zu bestätigen, dass hohe Adaptionskosten den Einfluss der Anreize verringern. Wie bereits im Kapitel zur Interaktion dargelegt, muss allerdings für den Fall Georgien angemerkt werden, dass die Anreize generell niedrig waren. Die zusätzlich hohen Adaptionskosten haben daher den Einfluss der ohnehin im Vergleich zu Mazedonien niedrigen Anreize weiter reduziert.

\section{Asymmetrische Interdependenz}

Neben den Adaptionskosten wurde als zweite Bedingungsvariable der Grad der asymmetrischen Interdependen z zwischen der EU als sozialisierendem Akteur und Mazedonien bzw. Georgien als Adressaten der Sozialisation betrachtet. Hierzu 
Franziska Smolnik: Zwischen Anspruch und Wirklichkeit: Die EU-Konditionalität als

Demokratisierungsinstrument. Eine Studie zur externen Demokratieförderung an den Beispielen

Georgien und Mazedonien

wurden folgende Indikatoren verwendet: Größe, militärische und wirtschaftliche Stärke sowie das Vorhandensein von Alternativmächten. Während die Adaptionskosten sowohl für Mazedonien als auch Georgien hoch sind, ergaben sich für den Grad der asymmetrischen Interdependenz indes unterschiedliche Ergebnisse. Zunächst sind sich Mazedonien und Georgien zwar insofern ähnlich, als beide Kleinstaaten mit einer geringen Bevölkerungszahl sind. Auch was die militärische und wirtschaftliche Stärke anbetrifft, so sind diese sowohl für Mazedonien als auch Georgien trotz gewisser Entwicklungen im gesamten Untersuchungszeitraum als gering einzustufen. Der entscheidende Unterschied beider Länder liegt beim Indikator der Alternativmächte. Während für Mazedonien neben der EU keine Mächte vorhanden sind, die alternativ Unterstützung bieten können, gibt es für Georgien gleich zwei solcher Mächte, nämlich Russland und die USA. Beide Länder engagieren sich in Georgien und können jeweils sowohl im sicherheitspolitischen als auch wirtschaftlichen Bereich alternativ zur EU unterstützend tätig werden bzw. sind bereits tätig. Während daher für Mazedonien der Grad der asymmetrischen Interdependenz,zu Lasten Mazedoniens als hoch eingestuft werden muss, ergibt sich für Georgien ein eher niedriger Grad der asymmetrischen Interdependenz:

Wie im Kapitel zur Interaktion der Variablen gezeigt wurde, sind die außenpolitischen Bestrebungen Mazedoniens stark auf eine zukünftige Integration in die EU gerichtet. Aufgrund der eigenen wirtschaftlichen und militärischen Schwäche sowie des Fehlens alternativer Mächte, die Mazedonien vor allem im wirtschaftlichen, aber auch sicherheitspolitischen Bereich ersatzweise unterstützen könnten, sehen sowohl die mazedonische Bevölkerung als auch ihre Vertreter die Mitgliedschaft in der EU als spätestens mittelfristiges Ziel. In Georgien dagegen können die USA und Russland ebenso wirtschaftliche und sicherheitspolitische Unterstützung bieten. Insbesondere im für Georgien kritischen sicherheitspolitischen Bereich zeigen dabei die USA eine größere Initiative als die EU, die in erster Linie im wirtschaftlichen Bereich Anreize bietet - auch um Differenzen mit Russland zu vermeiden. Wie erläutert, wird daher der Einfluss der EU-Anreize aufgrund der geringen asymmetrischen Interdependen ₹ einerseits verkleinert; andererseits lässt sich aber die EU aufgrund eben dieses Vorhandenseins von Alternativmächten in der Wahl ihrer Anreize beeinflussen. 
9. Fazit: Rückbezug zur Theorie und Ausblick

Die empirische Überprüfung konnte die eingangs aufgestellte Hypothese, dass insbesondere die unterschiedlich hohen Anreize der EU-Konditionalität - die sich zum einen in niedrige Anreize (keine Beitrittsperspektive) und hohe Anreize (mit Beitrittsperspektive) einteilen lassen - für den unterschiedlich starken Einfluss der EU-Konditionalität auf die Demokratisierung der post-sozialistischen Staaten verantwortlich sind, bestätigen. Für die beiden Fälle Mazedonien und Georgien hat die Untersuchung gezeigt, dass die Übernahme von EU-Regeln tatsächlich dann wahrscheinlicher ist, wenn die EU einen Mitgliedschaftsanreiz bietet, als wenn keine Beitrittsperspektive vorhanden ist. Gemäß der verwendeten Theorie kann sowohl für Mazedonien als auch Georgien von internationaler Sozialisation seitens der EU ausgegangen werden. In beiden Ländern versucht die EU mithilfe von vertraglichen Beziehungen, in deren Rahmen das Instrument der politischen Konditionalität eine prominente Position einnimmt, eine Regelangleichung an die EU zu erzielen. Im Gegensatz zu Georgien, wo die internationale Sozialisation durch die EU allerdings als weitestgehend gescheitert bewertet werden muss, da, wie gezeigt, trotz gewährter Anreize kaum Regeln des sozialisierenden Akteurs übernommen worden sind, konnte in Mazedonien die Übernahme von EU-Regeln nachgezeichnet werden. Hier war die internationale Sozialisation der EU vergleichsweise erfolgreich. Dennoch kann auch hier noch nicht von einer erfolgreich abgeschlossenen Sozialisation gesprochen werden, da deutlich wurde, dass die Regelübernahme für den Bereich der Rechtstaatlichkeit weder vollständig noch die flächendeckende Regeleinhaltung unabhängig von den Anreizen des sozialisierenden Akteurs ist.

Die Fälle bestätigen, dass der Rückgriff auf rationalistische Annahmen bezüglich der Handlungslogik der Adressatenländer und somit ein Fokus auf die in Aussicht gestellten Anreize berechtigt ist. In Übereinstimmung mit der zentralen Hypothese der Arbeit sind lediglich solche Anreize, die eine Beitrittsperspektive beinhalteten, wirkmächtig genug gewesen, um die Kosten-Nutzen-Kalkulation der Adressatenländer dahingehend zu verändern, dass die Nutzen die Kosten übersteigen und damit die EU-Regeln übernommen werden. Anzumerken ist an dieser Stelle, 
Franziska Smolnik: Zwischen Anspruch und Wirklichkeit: Die EU-Konditionalität als Demokratisierungsinstrument. Eine Studie zur externen Demokratieförderung an den Beispielen Georgien und Mazedonien

dass, wie die Untersuchung Mazedoniens ergeben hat, nicht allein die proklamierte Beitrittsperspektive für die Regelübernahme verantwortlich ist. Wichtig war außerdem die regelmäßige Bestätigung der Mitgliedschaftsoption durch eine tatsächlich stetig voranschreitende EU-Integration in Form von Vertragsabschlüssen und somit die „,intermediäre Einlösung“ von Anreizen.

Desweiteren machte die Untersuchung Georgiens deutlich, dass im Einklang mit der zugrunde gelegten Theorie der internationalen Sozialisation eine nur geringe asymmetrische Interdependen₹ zwischen sozialisierendem Akteur und Adressat den Einfluss der Anreize bezüglich der Regelübernahme weiter schwächt. Die Ergebnisse für das Fallbeispiel Georgien deuten ferner darauf hin, dass der Grad der asymmetrischen Interdependen ₹ und hier insbesondere der Indikator der Alternativmächte nicht nur den Einfluss der EU-Anreize aus Adressatensicht schmälert, sondern das Vorhandensein von Alternativmächten auch die Ausgestaltung der Anreize seitens der EU beeinflusst, wie es die Zurückhaltung der EU angesichts russischer Interessen in Georgien deutlich gemacht hat.

Ebenso wie der Einfluss der asymmetrischen Interdependen₹ konnte auch der Einfluss der weiteren in die Analyse integrierten Bedingungsvariable - der Adaptionskosten aufgezeigt werden. Die Ergebnisse der Falluntersuchung zeigen, dass die hohen Adaptionskosten in Form eines Machtverlusts für die Regierungspartei(en) den Einfluss der EU-Anreize sowohl in Mazedonien als auch Georgien verringern und die Adaptionskosten somit Einfluss auf die Regelübernahme haben. Die Adaptionskosten spielen insbesondere eine bedeutende Rolle dabei, welche Regeln übernommen werden. Wie dargelegt, sind es vor allem solche Regeln, die eine Einschränkung der Machtfülle der Regierungsparteien zur Folge hätten, die unvollständig, spät oder gar nicht übernommen worden sind.

Da die vorliegende Arbeit nur den generellen Einfluss der beiden betrachteten Bedingungsvariablen auf den Einfluss der UV aufzeigen konnte, wären anschließende Studien sinnvoll, die die Betrachtung dieses Einflusses in den Mittelpunkt stellen und die hier als Bedingungsvariablen integrierten Faktoren als unabhängige Variablen untersuchen würden. Studien, deren Fälle gemäß einer Varianz bei den Adaptionskosten bzw. dem Grad der asymmetrischen Interdependen 
Franziska Smolnik: Zwischen Anspruch und Wirklichkeit: Die EU-Konditionalität als Demokratisierungsinstrument. Eine Studie zur externen Demokratieförderung an den Beispielen Georgien und Mazedonien

ausgewählt werden, können vermutlich nähere Erkenntnisse bezüglich der Bedeutung des Einflusses dieser Variablen liefern ${ }^{214}$.

Für die praktische Politik der EU bedeutet das Untersuchungsergebnis, dass die Ambitionen der EU, Drittländer - und hier insbesondere Nachbarländer - mithilfe der verschiedenen Heranführungsstrategien an sich zu binden und durch die Angleichung an die EU zu demokratisieren und stabilisieren, skeptisch zu betrachten ist. Gezeigt wurde, dass Anreize unterhalb der Beitrittsperspektive keinen nennenswerten Einfluss hatten und eine Übernahme von EU-Regeln nicht veranlassen konnten. Auch die zu diesem Zweck ins Leben gerufene Europäische Nachbarschaftspolitik, die zwar gegenüber dem Partnerschafts- und Kooperationsabkommen erhöhte Anreize bietet, ohne allerdings eine Mitgliedschaftsperspektive zu beinhalten, konnte keine Erfolge erzielen. Die EU müsste daher überprüfen, ob ihre Strategie der ,one size fits all“, wie Börzel und Risse ${ }^{215}$ die EU-Politik in diesem Bereich beschrieben haben, tatsächlich sinnvoll und ob die Effizienz von positiver Konditionalität, wenn überhaupt, nicht doch eher auf die Erweiterungsstrategie beschränkt ist. Das Untersuchungsergebnis relativiert dementsprechend auch diejenigen Meinungen, die in der Konditionalität der EU ein generell wirkungsvolles Instrument der externen Demokratisierung und in der EU allgemein einen bedeutenden Demokratieförderer sehen.

\footnotetext{
214 Die gleichzeitige Betrachtung zweier bzw. dreier unabhängiger Variablen, wie sie hier vorgeschlagen wird, erfordert allerdings die Untersuchung von 4 bzw. 9 Fällen. Aufgrund dieses Mehraufwands, der den Rahmen der vorliegenden Arbeit übersteigt, wurde hier zu Gunsten des vorliegenden Analysedesign entschieden.

215 Titel einer 2004 von Börzel und Risse verfassten Studie zur EU (Börzel/Risse 2004).
} 
Franziska Smolnik: Zwischen Anspruch und Wirklichkeit: Die EU-Konditionalität als

Demokratisierungsinstrument. Eine Studie zur externen Demokratieförderung an den Beispielen

Georgien und Mazedonien

10.

\section{Quellenverzeichnis}

American Bar Association (2002): Judicial Reform Index for Macedonia. Washington DC.

American Bar Association (2003): Judicial Reform Index for Macedonia. Washington DC.

American Bar Association (2005): Judicial Reform Index for Georgia. Washington DC.

Bertelsmann Transformation Index. (2006): Status-Index. http://bti2006.bertelsmanntransformation-index.de/37.0.html [zuletzt eingesehen: 09.03.2008].

Börzel, Tanja A.; Risse, Thomas (2000): When Europe Hits Home: Europeanization and Domestic Change, in: European Integration online Papers (EIoP) 5.15. http://eiop.or.at/eiop/pdf/2000-015.pdf [zuletzt eingesehen: 09.03.2008].

Börzel, Tanja A.; Risse, Thomas (2001): Die Wirkung internationaler Institutionen: Von der Normanerkennung zur Normeinhaltung. MPI Collective Goods Preprint 2001.15. Bonn. http://www.coll.mpg.de/pdf dat/2001 15.pdf [zuletzt eingesehen: 09.03.2008].

Börzel, Tanja A.; Risse, Thomas (2004): One Size Fits All! EU Policies for the Promotion of Human Rights, Democracy, and the Rule of Law. Paper presented for the Workshop on Democracy Promotion organized by the Center for Development, Democracy, and the Rule of Law. October 4-5, 2004. Stanford University.

Büchsenschütz, Ulrich (2001): Die Mazedonien-Krise. Bonn.

Bunce, Valery (2006): Global Patterns and Post-Communist Dynamics, in: Orbis 50.4, 601-620.

Bundesagentur für Außenwirtschaft (2007): Mazedonien -Wirtschaftsentwicklung 2006. https://www.bfai.de/DE/Navigation/Publikationen/Recherche-Publikationen/recherchepublikationen-node.html [zuletzt eingesehen: 09.03.2008].

Carothers, Thomas (1998): The Rule of Law Revival, in: Foreign Affairs 77.2, 95106.

Chanturia, Lado (2007): Rechtsstaatliche Rahmenbedingungen für eine neue Justiz im Lichte der Systemtransformation in Georgien. Bremen.

Checkel, Jeffrey T. (2005): International Institutions and Sozialization in Europe. Introduction and Framework, in: International Organization 59.4, 801-826.

Christophe, Barbara (2005): Metarmorphosen des Leviathan in einer postsozialistischen Gesellschaft. Georgiens Provinz zwischen Fassaden der Anarchie und regulativer Allmacht. Bielefeld. 
Franziska Smolnik: Zwischen Anspruch und Wirklichkeit: Die EU-Konditionalität als Demokratisierungsinstrument. Eine Studie zur externen Demokratieförderung an den Beispielen Georgien und Mazedonien

Chkeidze, Giorgi (2007): Interview. European Neighbourhood Policy And Georgia Bulletin 17-18, 8-10.

Cooley, Alexander (2003): Western Conditions and Domestic Choices: The Influence of External Actors on the Post-Communist Transition, in: Freedom House (Hg.): Nations in Transit 2003: Democratization in East Central Europe and Eurasia. New York, 25-38.

Devdariani, Dšaba (2005): Gruzija i Rossija: trudnyj putj k primireniju, in: Coppieters, Bruno; Legvold, Robert (Hg.), Gosudarstvennostj i besopastnostj: Gruzija posle 'revoljucii roz'.Camebridge/Mass., 183-246.

Di Puppo, Lili (2006): Uldis Kinis: 'The most problematic issue in Georgia remains the application of priorities relating to independence of the judiciary'. Caucaz.com. 02.04.2006. http://www.caucaz.com [zuletzt eingesehen: 09.03.2008].

Dolidze, Ana (2007): Judicial Reform, in: Friedrich-Ebert-Stiftung Georgien; Open Society Georgia Foundation, Cordaid Foundation (Hg.), European Neighbourhood Policy and Georgia. Analyses of independent experts. Tbilisi, 6-11.

Ernst, Andreas (2005): Freude in Skopje über EU-Kandidaten-Status. Neuer Impuls für die Fortsetzung der Reformpolitik. NZZ. 19.12.2005, 3.

Ernst, Andreas (2001): Schwieriger Dialog in Mazedonien. Unterschiedliche Forderungen der zerstrittenen Albaner. NZZ. 07.04.2001, 5.

Europäische Gemeinschaften (1988): Document on the European Identity. Published by the Nine Foreign Ministeres. 14 December 1973. Copenhagen, 48-54. http://aei.pitt.edu/4545/01/epc identity doc.pdf [zuletzt eingesehen: 09.03.2008].

Europäische Kommission (1995): Mitteilung der Europäischen Kommission. On the Inclusion of Respect for Democratic Principles and Human Rights in Agreements between the Community and Third Countries. KOM (1995)216. Brüssel

http://ec.europa.eu/external relations/human rights/doc/com95 216 en.pdf [zuletzt eingesehen: 09.03.2008].

Europäische Kommission (1999): Mitteilung der Kommission an den Rat und das Europäische Parlament über den Stabilisierungs- und Assoziierungsprozess für die Länder Südosteuropas. KOM (1999)235. Brüssel

http://ec.europa.eu/enlargement/pdf/enlargement process/accession process/how does a countr $\mathrm{y}$ join the eu/sap/comm pdf com_1999 $0235 \mathrm{f}$ acte de.pdf [zuletzt eingesehen: 09.03.2008].

Europäische Kommission (2000): Abschlusserklärung des Gipfeltreffens vom 24. November 2000 in Zagreb. Brüssel, http://ec.europa.eu/enlargement/enlargement process/accession process/how does a country joi n the eu/sap/zagreb summit en.htm [zuletzt eingesehen: 09.03.2008].

Europäische Kommission (2001): Country Strategy Paper 2002-2006 and TACIS National Indicative Programme 2002-2003 Georgia. Brüssel. http://ec.europa.eu/external relations/georgia/csp/02 06 en.pdf [zuletzt eingesehen: 09.03.2008]. 
Franziska Smolnik: Zwischen Anspruch und Wirklichkeit: Die EU-Konditionalität als Demokratisierungsinstrument. Eine Studie zur externen Demokratieförderung an den Beispielen Georgien und Mazedonien

Europäische Kommission (2003): Country Strategy Paper 2003-2006 and TACIS National Indicative Programme 2004-2006. Brüssel http://ec.europa.eu/external relations/georgia/csp/03 06 en.pdf [zuletzt eingesehen: 09.03.2008].

Europäische Kommission (2004): Commission Staff Working Paper. Former Yugoslav Republic of Macedonia. Stabilization and Association Report 2004. SEC (2004) 373. Brüssel http://ec.europa.eu/enlargement/pdf/the former yugoslav republic of macedonia/cr fyrom en.p df [zuletzt eingesehen: 09.03.2008].

Europäische Kommission (2004a): Mitteilung der Kommission. Europäische Nachbarschaftspolitik. Strategiepapier. KOM (2004) 373. Brüssel. http://ec.europa.eu/world/enp/pdf/strategy/strategy paper_de.pdf [zuletzt eingesehen am 26.03.2008].

Europäische Kommission (2006): Commission Staff Working Document. The Former Yugoslav Republic of Macedonia 2006 Progress Report. SEC (2006) 1287. Brüssel.

http://ec.europa.eu/enlargement/pdf/key documents/2006/nov/fyrom sec 1387 en.pdf [zuletzt eingesehen: 09.03.2008].

Europäische Kommission (2006a): EU/Georgia Action Plan. Brüssel. http://ec.europa.eu/world/enp/pdf/action plans/georgia enp ap final en.pdf, [zuletzt eingesehen: 09.03.2008].

Europäische Kommission (2007): Commission Staff Working Document. The former Yugoslav Republic of Macedonia 2007 Progress Report. SEC (2007) 1432. Brüssel. http://ec.europa.eu/enlargement/pdf/key documents/2007/nov/fyrom progress reports en.pdf [zuletzt eingesehen: 09.03.2008].

Europäische Kommission (2007a): Eurobarometer 67: National Report. Executive Summary. The former Yugoslav Republic of Macedonia. Brüssel.

Europäische Kommission für Demokratie durch Recht (Venedig-Kommission) (2004): Draft Opinion on the Draft Amendments to the Constitution of Georgia. http://www.venice.coe.int/docs/2004/CDL(2004)004-e.asp [zuletzt eingesehen 26.03.2008].

Europäisches Parlament (2000): Europäischer Rat (Santa Maria de Feira) 19./20.06.2000. Schlussfolgerungen des Vorsitzes. http://www.europarl.europa.eu/summits/fei1 de.htm [zuletzt eingesehen: 09.03.2008].

European Security Strategy (2003): A Secure Europe in a Better World. 12.12.2003. Brüssel. http://ue.eu.int/uedocs/cmsUpload/78367.pdf [zuletzt eingesehen am 09.03.2008].

Eurostat (2008). External Trade. http://epp.eurostat.ec.europa.eu [zuletzt eingesehen: 09.03.2008].

Eurostat (2008a). GDP and main components. http://epp.eurostat.ec.europa.eu [zuletzt eingesehen: 26.03.2008]. 
Franziska Smolnik: Zwischen Anspruch und Wirklichkeit: Die EU-Konditionalität als Demokratisierungsinstrument. Eine Studie zur externen Demokratieförderung an den Beispielen Georgien und Mazedonien

Eurostat (2008b). Structural indicators. http://epp.eurostat.ec.europa.eu [zuletzt eingesehen: 26.03.2008].

Federal'naja služba gosudarstvennoj statistiki (2008). Vnešnjaja torgovlja Rossijskoj Federacii so stranami. http://www.gks.ru/bgd/regl/b07_13/IssWWW.exe/Stg/d06/25-08.htm [zuletzt eingesehen: 08.03.2008].

Felgenhauer, Pavel (2007): Russian Soldiers Leave South Georgia, Others deployed in the North. Eurasia Daily Monitor. 14.11.2007.

http://www.jamestown.org/edm/article.php?article id=2372588 [zuletzt eingesehen: 09.03.2008].

Freedomhouse Nations in Transit (2007).

http:/ $/$ www.freedomhouse.hu/index.php?option $=$ com content\&task=view\&id=84 [zuletzt eingesehen 28.03.2008)

GEPLAC (2008): Georgian Economic Trends. Quarterly Review. Tbilisi.

Halm, Dirk (1997): Konditionalität. Entwicklung, Ergebnisse und Probleme eines Konzepts der entwicklungspolitischen Zusammenarbeit. Münster.

Helly, Damian (2006): EUJUST Themis in Georgia. An ambitious bet on rule of law, in: Nowak, Agnieszka, Civilian Crisis Management. The EU way. Chaillot Paper 90, $87-102$.

Hensell, Stephan (2003): Typisch Balkan? Patronagenetzwerke, ethnische Zugehörigkeit und Gewaltdynamik in Mazedonien, in: Internationale Politik und Gesellschaft 4 (2003), 131-146.

Hislope, Robert (2003): Shaking Off the Shakedown State? Crime and Corruption in Post-Ohrid Macedonia. Woodrow Wilson International Center for Scholars. http://www.wilsoncenter.org [zuletzt eingesehen: 09.03.2008].

Horoschak, Lauren (2007): Fighting Corruption in Saakaschwili-era Georgia: Successes, Challenges, and Public Perception. Tbilisi.

Huber, Martina (2004): State-Building in Georgia. Unfinished and at Risk?, Den Haag.

International Bar Association (1982): IBA Minimum Standards of Judicial Independence. London.

International Crisis Group (2006): Wobbling towards Europe. Europe Briefing 41. Skopje/ Brüssel.

International Crisis Group (2006a): Georgia's Armenian and Azeri Minorities. Europe Report 178. Tbilisi/ Brüssel.

International Crisis Group (2007): Georgia: Sliding Towards Authoritarianism? Europe Report189. Tbilisi/ Brüssel. 
Franziska Smolnik: Zwischen Anspruch und Wirklichkeit: Die EU-Konditionalität als Demokratisierungsinstrument. Eine Studie zur externen Demokratieförderung an den Beispielen Georgien und Mazedonien

Internationaler Währungsfond (2007): World Economic Outlook Database. http://www.imf.org/external/pubs/ft/weo/2007/02/weodata/index.aspx [zuletzt eingesehen: 08.03.2008].

Jahn, Detlef (2006): Einführung in die vergleichende Politikwissenschaft. Wiesbaden.

Kaufmann, Walter (2006): Bärendienste. Georgien und Russland in der Eskalationsspirale, in: Osteuropa 10(2006), 117-121.

Keohane, Robert O.; Nye, Joseph S. (1977): Power and Interdependence. World Politics in Transition. Bosten/ Toronto.

Kim, Julie (2005): Macedonia (FYROM): Post-conflict situation and U.S. Policy. CRS Report for Congress.

http://stinet.dtic.mil/cgibin/GetTRDoc?AD=ADA469385\&Location=U2\&doc=GetTRDoc.pdf [zuletzt eingesehen: 09.03.2008].

Kitschelt, Herbert (1995): Formation of Party Cleavages in Post-Communist Democracies: Theoretical Propsitions, in: Party Politics 1.4, 447-472.

Kitschelt, Herbert; Wilkinson, Steven I. (2007): Citizen-politician linkages, in: Dies. (Hg.), Patrons, Clients and Policies. Patterns of Democratic Accountability and Political Competition. Camebridge, 1-49.

Kleppmann, Ulrich; Divjakoski, Stiv (2007): Jahresbilanz Mazedonien. Politik und Wirtschaft, Skopje.

Knodt, Michèle; Jünemann, Annette (2007): Introduction: Theorizing EU external democracy promotion, in: Jünemann, Annette; Knodt, Michèle (Hg.), Externe Demokratieförderung durch die Europäische Union. Baden-Baden, 9-29.

Kochenev, Dimitry (2004): Behind the Copenhagen façade. The meaning and structure of the Copenhagen criterion of democracy and the rule of law, European Online Integration Papers (EIoP) 8.10. http://eiop.or.at/eiop/texte/2004-010a.htm [zuletzt eingesehen: 09.03.2008].

Koneska, Cvete (2007): Macedonian discourse on NATO, in: Western Balkan Security Observer 5, 4-10.

Kopecky, Petr (2006): Political parties and the state in post-communist Europe. The nature of symbiosis, in: Journal of Communist and Transition Politics 22. 3, 251-273.

Kopecky, Petr; Mudde, Cas (2000): What has Eastern Europe taught us about the democratization literature (and vice versa)? in: European Journal of Political Research 37, 517-539.

Kubicek, Paul J. (2003): International norms, the European Union, and democratization: tentative theory and evidenve, in: Ders. (Hg.), The European Union and Democratization. London/ New York, 1-29 
Franziska Smolnik: Zwischen Anspruch und Wirklichkeit: Die EU-Konditionalität als Demokratisierungsinstrument. Eine Studie zur externen Demokratieförderung an den Beispielen Georgien und Mazedonien

LABORSTA (2008). http://laborsta.ilo.org/cgi-bin/brokerv8.exe [zuletzt eingesehen: 28.03.2008].

Lang, Kai-Olaf; Schwarzer, Daniela (2007): Argumente für eine neue Erweiterungsstrategie - die Diskussion über die Aufnahmefähigkeit der EU, in: integration 2, 117-128.

Lauth, Hans-Joachim (2004): Demokratiemessung. Eine konzeptionelle Grundlage für den interkulturellen Bereich. Wiesbaden.

Levitksy, Steven; Way, Lucan A. (2007): Linkage, Leverage, and the Post-Communist Divide, in: East European Politics and Societies 21.1, 48-66.

Linz, Juan J.; Stepan, Alfred (1996): Problems of democratic transition and consolidation. Southern Europe, South America, and Post-Communist Europe. Baltimore/ London.

Lohm, Hedwig (2006): Džavaxeti posle Revoljucii roz: Progress I regress v poiskach nacional'nogo edinstvav Gruzii, European Centre for Minority Issues Working Paper 38, http://ecmi.de/download/working paper 38 rus.pdf [zuletzt eingesehen: 09.03.2008].

Loza, Tihomir; Krauthamer, Ky; Gardner, Andrew (2006): Macedonia: Edging Beyond Ethnicity, in: Transitions Online 9.5.

http: / $/$ www.ceeol.com/aspx /getdocument.aspx?logid=5\&id=b0f14373-d380-479c-a360bd49d2121bf0 [zuletzt eingesehen: 09.03.2008].

Lungescu, Oana (2006): Analysis. EU's Balkan Influence. BBC News. 27.02.2006. http://news.bbc.co.uk/go/pr/fr/-/2/hi/europe/4754486.stm [zuletzt eingesehen: 01.04.2008].

Malesko, Denko; Maleska, Mirjana (2005): Macedonia's Road to the European Union. New Balkan Politics.

http://www.newbalkanpolitics.org.mk/political essays/road2eu.html [zuletzt eingesehen: 09.03.2008].

Merkel, Wolfgang (2007): Gegen alle Theorie? Die Konsolidierung der Demokratie in Ostmitteleuropa, in: Politische Vierteljahresschrift 48. 3, 413-433.

Millenium Challenge Corporation. http://www.mcc.gov/index.php [zuletzt eingesehen: 09.03.2008].

Ministerstvo Inostrannych Del Rossijskoj Federacij (2007): Obzor Vnešnej Politiki Rossijskoj Federacij. http://www.ln.mid.ru/brp 4.nsf/sps/3647DA97748A106BC32572AB002AC4DD [zuletzt eingesehen: 09.03.2008].

Morlino, Leonardo; Magen, Amichai (2004): EU Rule of Law Promotion in Romania,Turkey and Serbia-Montenegro: Domestic Elites and Responsiveness to Differentiated External Influence. Paper presented for the Workshop on Democracy Promotion organized by the Center for Development, Democracy, and the Rule of Law. October 4-5, 2004. Stanford University. 
Franziska Smolnik: Zwischen Anspruch und Wirklichkeit: Die EU-Konditionalität als Demokratisierungsinstrument. Eine Studie zur externen Demokratieförderung an den Beispielen Georgien und Mazedonien

NATO Parliamentary Assembly (2007): Viewing NATO from the South Cacausus. Armenia, Azerbaijan and Georgia. http://www.nato-pa.int/default.asp?SHORTCUT=1283 [zuletzt eingesehen 26.03.2008].

Nodia, Ghia (2004): The South Caucasus, a Region of Geo-Strategic Importance. Specificity and Current Security Issues, in: Dufourcq, Jean; Ponsard, Lionel (Hg.), The South Caucasus. Promoting Values through Cooperation. Rom, 17-24.

Nodia, Ghia; Scholtbach, Alvaro Pinto (2006): The Political Landscape of Georgia. Political Parties: Achievements, Challenges and Prospects, Delft.

OECD (2008): Development Database on Aid from DAC Members: DAC online. http://www.oecd.org/document/33/0,2340,en $26493444736661793 \quad 1 \quad 1 \quad 1 \quad 1,00 . h t m l$ [zuletzt eingesehen: 08.03.2008].

Oschlies, Wolf (2003): Makedonien. Volkszählung und interethnische Turbulenzen, Diskussionspaper der SWP 3(2003). Berlin.

Overview of Implementation of the European Neighbourhood Policy EU-Georgia Action Plan (2007). http://www.eu-integration.gov.ge/eng/Overview.php [zuletzt eingesehen: 09.03.2008].

Papava, Vladimir (2006): The Political Economy of Georgia's Rose Revolution, in: Orbis 50.4, 657-667.

Partnerschafts- und Kooperationsabkommen zwischen der EU und Georgien (1999). http://ec.europa.eu/external relations/ceeca/pca/pca georgia.pdf [zuletzt eingesehen: 09.03.2008].

Peters, Ingo; Bittner, Jan (2006): EU-US Risk Policy in the European Neighbourhood. The cases of Moldova and Georgia, in: Möttölä, Kari (Hg.), Transatlantic Relations and Global Governance. Washington, 149-185.

Peuch, Jean-Christophe (2005): Caucasus/Central Asia: Analysts Expect Security. Economic Gains From BTC Pipeline. Radio Free Europe. 25.05.2005. http://www.rferl.org/featuresarticle/2005/05/F86368E4-B2ED-4996-8CA1-5684CA8516AD.html [zuletzt eingesehen: 09.03.2008].

Pravda, Alex (2001): Introduction, in: Zielonka, Jan; Pravda, Alex (Hg.), Democratic Consolidation in Eastern Europe. International and Transnational Factors. Oxford, $1-27$.

Pridham, Geoffrey (1997): The international dimension of democratisation: theory, practice and inter-regional comparisons, in: Ders. (Hg.), Building democracy? The international dimension of democratization in Eastern Europe. London, 7-29.

Rat der Europäischen Union (2001): Stabilisierungs- und Assoziierungsabkommen zwischen den Europäischen Gemeinschaften und ihren Mitgliedsstaaten einerseits und der ehemaligen jugoslawischen Republik Mazedonien andererseits. 26.03.2001. Brüssel.http://ec.europa.eu/enlargement/pdf/the former yugoslav republic of macedonia/saa03 01 en.pdf [zuletzt eingesehen: 09.03.2008]. 
Franziska Smolnik: Zwischen Anspruch und Wirklichkeit: Die EU-Konditionalität als Demokratisierungsinstrument. Eine Studie zur externen Demokratieförderung an den Beispielen Georgien und Mazedonien

Rat der Europäischen Union (2006): Europäischer Rat (Brüssel) 15./16.12.2005. Schlussfolgerungen des Vorsitzes. 30.01.2006. Brüssel. http://www.consilium.europa.eu/ueDocs/cms Data/docs/pressData/de/ec/87646.pdf [zuletzt eingesehen: 09.03.2008].

Reisner, Oliver (2005): Studien zur länderbezogenen Konfliktanalyse. Georgien, Berlin.

Saakaschwili, Michail (2004): Interview mit Reinhard Meier. Georgien gehört kulturell zu Europa. NZZ. 26.01.2004, 4.

Sandschneider, Eberhard (2003): Externe Demokratieförderung. Theoretische und praktische Aspekte der Außenunterstützung von Transformationsprozessen. http://www.cap.lmu.de/download/2003/2003 sandschneider.pdf [zuletzt eingesehen: 09.03.2008]. Sartori, Giovanni (1994): Compare Why and How. Comparing, Miscomparing and the Comparative Method, in: Dogan, Mattei; Kazancigil, Ali (Hg.), Comparing Nations. Concepts, Strategies, Substance. Oxford/ Camebridge/ Mass., 14-34.

Schimmelfennig, Frank (2005): Strategic Calculation and International Socialization: Membership Incentives, Party Constellations, and Sustained Compliance in Central and Eastern Europe, in: International Organization 59.4, 827-860.

Schimmelfennig, Frank; Engert, Stefan; Knobel, Heiko (2006): International Socialization in Europe. European Organizations, Political Conditionality and Democratic Change. New York.

Schimmelfennig, Frank; Sedelmeier, Ulrich (2005): Introduction: Conceptualizing the Europeanization of Central and Eastern Europe, in: Dies. (Hg.): The

Europeanization of Central and Eastern Europe. Ithaca/ London, 1-28.

Schmidt, Manfred G. (2004): Vetospielertheorem und Politik des mittleren Weges, in: Schmid, Josef (Hg.), Sozialstaat. Reform, Umbau, Abbau? Schwalbach, 99-113.

Schmitter, Phillipe C. (1999): The Influence of the International Context upon the Choice of National Institutions and Policies in Neo-Democracies, in: Whitehead, Laurence (Hg.), The International Dimension of Democratization. Europe and the Americas. New York, 26-53.

Schwanitz, Simone (1997): Transformationsforschung: Area Studies versus Politikwissenschaft? Plädoyer für einen akteurstheoretischen Ansatz, in: Arbeitspapiere des Osteuropa-Institut der FU Berlin 3.

Sigwart, Lara (2006): Der georgische Staat und der Südossetien-Konflikt: rationales Handeln und Struktur als prozedurale Muster. Eine qualitativ-empirische Studie. Berlin.

Single European Act (1987). Office Journal of the European Communities. No L 169/1. http://www.unizar.es/euroconstitucion/Treaties/Treaty SingleEA.htm [zuletzt eingesehen: 08.03.2008] 
Franziska Smolnik: Zwischen Anspruch und Wirklichkeit: Die EU-Konditionalität als Demokratisierungsinstrument. Eine Studie zur externen Demokratieförderung an den Beispielen Georgien und Mazedonien

SIPRI (2007): The SIPRI military expenditure data base.

http://first.sipri.org/non first/milex.php [zuletzt eingesehen 31.03.2008].

Southeast European Times (2007): Macedonia's political leaders agree on Judicial Council nominee. 14.12.2007.

http://www.balkantimes.com/cocoon/setimes/xhtml/en GB/newsbriefs/setimes/newsbriefs/2007 L12/14/nb-06 [zuletzt eingesehen: 09.03.2008].

Sumbadze, Nana (2006): Georgia Public Opinion Barometer 2006. Tbilisi.

Tabatadze, Rusudan et. al. (2007): Judiciary in Georgia. Is the Georgian Justice Independent and what is the Guarantee of its independence? Tbilisi.

The Reform of the Judicial System in the Republic of Macedonia (2005). Skopje. http://siteresources.worldbank.org/INTECA/Resources/Macedoniastrategija.pdf [zuletzt eingesehen: 09.03.2008].

Thessaloniki-Agenda für den westlichen Balkan (2003). Western Balkans - Council Conclusions. 16.06.200

http://ec.europa.eu/enlargement/enlargement process/accession process/how does a country joi $\mathrm{n}$ the eu/sap/thessaloniki agenda en.htm [zuletzt eingesehen: 09.03.2008].

Transparency International Georgia (2007): Political Parties in Georgia: Issues of party financing.

http://ti.itdc.ge/files/215 273464604 Political\%20Parties\%20in\%20Georgia, \%20Issue \%20of\%20P arty\%20Financing-E.pdf [zuletzt eingesehen: 09.03.2008].

UNECE (2007): Countries in figures. The Former Yugoslav Republic of Macedonia. http://www.unece.org/stats/profiles2007/tfyr macedonia.pdf [zuletzt eingesehen: 28.03.2008]

US Census Bureau (2008): Foreign Trade Statistics - U.S. Trade in Goods (Imports, Exports and Balance) by Country. http://www.census.gov/foreign-trade/balance/index.html [zuletzt eingesehen: 08.03.2008].

Usupaschwili, David (2004): Auf dem Weg zu einem georgischen Rechtsstaat, in: Kaufmann, Walter (Hg.), Diaspora, Öl und Rosen. Zur innenpolitischen Entwicklung in Armenien, Aserbaidschan und Georgien. Berlin, 94-104.

Vachudova, Milada Anna (2001): The Leverage of International Institutions on Democratizing States: Eastern Europe and the European Union. RSC Working Paper 33(2001).

Van de Walle, Nicolas (2007): Meet the new boss, same as the old boss? The evolution of political clientelism in Africa, in: Kitschelt, Herbert; Wilkinson, Steven I., Patrons, Clients and Policies. Patterns of Democratic Accountability and Political Competition. Camebridge, 50-67.

Van Evera, Stephen (1997): Guide to Methods for Students of Political Science. Ithaca/ New York. 
Franziska Smolnik: Zwischen Anspruch und Wirklichkeit: Die EU-Konditionalität als Demokratisierungsinstrument. Eine Studie zur externen Demokratieförderung an den Beispielen Georgien und Mazedonien

Varwick, Johannes (1998): Systemwechsel, Transformation, in: Woyke, Wichard (Hg.), Handwörterbuch Internationale Politik. Opladen, 369-378.

Vertrag zur Gründung der Europäischen Wirtschaftsgemeinschaft (1957). http://eurlex.europa.eu/de/treaties/dat/11957E/tif/TRAITES 1957 CEE 1 XM 0174 x111x.pdf [zuletzt eingesehen: 09.03.2008].

Vertrag über die Europäische Union (1992). Amtsblatt C 191. 29.06.1992. http://eurlex.europa.eu/de/treaties/dat/11992M/htm/11992M.html, [zuletzt eingesehen: 09.03.2008].

Vertrag von Nizza (2001). Amtsblatt C 80. 10.03. 2001. http://eur-

lex.europa.eu/de/treaties/dat/12001C/pdf/12001C DE.pdf [zuletzt eingesehen: 09.03.2008].

Whitehead, Laurence (1999): The International Dimensions of Democratization, in: ders. (Hg.), The International Dimension of Democratization. Europe and the Americas. New York, 3-25.

World Bank (2007) Country Classification. World Bank list of economies. http://www.worldbank.org [zuletzt eingesehen: 09.03.2008]. 


\section{ANNEX 1: Abbildungen}

Tabelle 1:

BIP-Vergleich: Mazedonien und die EU-15 bzw. EU-27

BIP pro Kopf (KKS) in $€$ :

\begin{tabular}{|l||r|r|r|r|r|r|r|r|}
\hline & 2000 & 2001 & 2002 & 2003 & 2004 & 2005 & 2006 & 2007 \\
\hline \hline Mazedonien & 5100 & 5000 & 5100 & 5300 & 5800 & 6200 & 6600 & 7000 \\
\hline EU-15 & 21900 & 22600 & 23300 & 23500 & 24400 & 25200 & 26200 & 27600 \\
\hline EU-27 & 19000 & 19700 & 20400 & 20600 & 21600 & 22400 & 23500 & 24700 \\
\hline
\end{tabular}

Quelle: Eurostat 2008a

Tabelle 2:

Arbeitslosigkeitsstatistik: Mazedonien und die EU-15 bzw. EU-27

Arbeitslosigkeit (in \%):

\begin{tabular}{|l||r|r|r|r|r|r|r|r|}
\hline & 2000 & 2001 & 2002 & 2003 & 2004 & 2005 & 2006 & 2007 \\
\hline \hline Mazedonien & 32,2 & 30,5 & 31,9 & 36,7 & 37,2 & 37,3 & 38 & 36,2 \\
\hline EU-15 & 7,7 & 7,2 & 7,6 & 7,9 & 8 & 8,1 & 7,7 & 6,9 \\
\hline EU-27 & 8,6 & 8,5 & 8,9 & 8,9 & 9 & 8,9 & 8,2 & 7 \\
\hline
\end{tabular}

Quellen: LABORSTA 2008; UNECE 2007; Eurostat 2008b

Tabelle 3:

Jährliche Militärausgaben Mazedoniens

\begin{tabular}{|l||r|r|r|r|r|r|r|r|}
\hline & 2000 & 2001 & 2002 & 2003 & 2004 & 2005 & 2006 & 2007 \\
\hline \hline in konstanten (2005) US\$ Mill. & 102 & 325 & 142 & 129 & 136 & 127 & 121 & \\
\hline als Prozent des BIP & 1,9 & 6,6 & 2,8 & 2,5 & 2,5 & 2,2 & & \\
\hline
\end{tabular}

Quelle: SIPRI 2007

Tabelle 4:

Außenhandel der EU bzw. den USA mit Mazedonien

\begin{tabular}{|c|c|c|c|c|c|c|c|c|}
\hline & 2000 & 2001 & 2002 & 2003 & 2004 & 2005 & 2006 & 2007 \\
\hline \multicolumn{9}{|l|}{ EU (in Mill EUR) } \\
\hline Importe & & & 591 & 677 & 778 & 947 & 1153 & 1595 \\
\hline Exporte & & & 1259 & 1152 & 1259 & 1244 & 1524 & 1881 \\
\hline \multicolumn{9}{|l|}{ USA (in Mill. \$US) } \\
\hline Importe & 152 & 112 & 73 & 61 & 78 & 48 & 42 & 73 \\
\hline Exporte & 69 & 33 & 19 & 26 & 21 & 32 & 22 & 34 \\
\hline
\end{tabular}

Quellen: Eurostat 2008; US Census Bureau 2008 
Tabelle 6:

BIP-Vergleich: Georgien und die EU-15 bzw. EU-27

BIP pro Kopf (KKS) in €:

\begin{tabular}{|l||r|r|r|r|r|r|r|r|}
\hline & 2000 & 2001 & 2002 & 2003 & 2004 & 2005 & 2006 & 2007 \\
\hline \hline Georgien & 1346 & 1697 & 1571 & 1794 & 1966 & 2221 & 2460 & 2821 \\
\hline EU-15 & 21900 & 22600 & 23300 & 23500 & 24400 & 25200 & 26200 & 27600 \\
\hline EU-27 & 19000 & 19700 & 20400 & 20600 & 21600 & 22400 & 23500 & 24700 \\
\hline
\end{tabular}

Quellen: Eurostat 2008a; IWF 2007

Tabelle 7:

Arbeitslosigkeitsstatistik: Georgien und die EU-15 bzw. EU-27

Arbeitslosigkeit in \%:

\begin{tabular}{|l||r|r|r|r|r|r|r|r|}
\hline & 2000 & 2001 & 2002 & 2003 & 2004 & 2005 & 2006 & 2007 \\
\hline \hline Georgien & 10,3 & 11,2 & 12,6 & 11,5 & 12,6 & 13,8 & 13,6 & 14,9 \\
\hline EU-15 & 7,7 & 7,2 & 7,6 & 7,9 & 8 & 8,1 & 7,7 & 6,9 \\
\hline EU-27 & 8,6 & 8,5 & 8,9 & 8,9 & 9 & 8,9 & 8,2 & 7 \\
\hline
\end{tabular}

Quellen: Eurostat 2008b; GEPLAC 2008

Tabelle 8:

\section{Jährliche Militärausgaben Georgiens}

\begin{tabular}{|l||r|r|r|r|r|r|r|r|}
\hline & 2000 & 2001 & 2002 & 2003 & 2004 & 2005 & 2006 & 2007 \\
\hline \hline in konstanten (2005) US\$ Mill. & 27 & 35 & 49 & 58 & 81 & 230 & 223 & \\
\hline als Prozent des BIP & 0,6 & 0,7 & 1 & 1,1 & 1,4 & 3,5 & & \\
\hline
\end{tabular}

Quelle: SIPRI 2007

Tabelle 9:

Außenhandel der EU, den USA bzw. Russlands mit Georgien

\begin{tabular}{|c|c|c|c|c|c|c|c|c|}
\hline & 2000 & 2001 & 2002 & 2003 & 2004 & 2005 & 2006 & 2007 \\
\hline \multicolumn{9}{|c|}{ EU (in Mill. \$US) } \\
\hline Importe & 76 & 62 & 63 & 82 & 128 & 217 & 225 & 269 \\
\hline Exporte & 188 & 241 & 232 & 431 & 657 & 740 & 1104 & 1539 \\
\hline \multicolumn{9}{|c|}{ USA (in Mill. \$US) } \\
\hline Importe & 32 & 31 & 17 & 54 & 78 & 194 & 105 & 189 \\
\hline Exporte & 110 & 106 & 99 & 131 & 227 & 214 & 264 & 364 \\
\hline \multicolumn{9}{|c|}{ Russland (in Mill. \$US) } \\
\hline Imports & 76,6 & 83,4 & 69 & 83,2 & 107 & 158 & 68,4 & \\
\hline Exports & 42,3 & 58,2 & 91,4 & 154 & 230 & 356 & 570 & \\
\hline
\end{tabular}

Quellen: GEPLAC 2008; US Census Bureau 2008;

Federal'naja služba gosudarstvennoj statistiki 2008 